Der Medizinischen Fakultät der Georg-August-Universität Göttingen

eingereicht von Prof. Dr. rer. nat. H. Jarry

\title{
Charakterisierung östrogener Effekte von Genistein im Modell der langzeitovarektomierten Maus
}

\author{
INAUGURAL-DISSERTATION \\ zur Erlangung des Doktorgrades \\ der Medizinischen Fakultät der \\ Georg-August-Universität zu Göttingen
}

vorgelegt von

Anne Niepelt, geb. Kuper

aus Bad Oldesloe

Göttingen 2014 
Die vorliegende Arbeit entstand in der Arbeitsgruppe Experimentelle Endokrinologie von Prof. Dr. med. W. Wuttke der Medizinischen Fakultät der Universität Göttingen. Die tierexperimentellen Untersuchungen wurden zwischen 2008 und 2010 durchgeführt.

Dekan:

Prof. Dr. rer. nat. H. K. Kroemer

1. Berichterstatter:

Prof. Dr. rer. nat. H. Jarry

2. Berichterstatter/in:

PD Dr. rer. nat. P. Thelen

Tag der mündlichen Prüfung:

21.10.2014 


\section{Inhaltsverzeichnis}

1.1 Perimenopausale Inzidenz von Herzerkrankungen 1

1.2 Perimenopausale Inzidenz von Osteoporose 1

1.3 Östrogene 2

1.3.1 Synthese, Funktion und Abbau $\quad 2$

1.3.2 Östrogene perimenopausal 3

1.3.3 Östrogenrezeptoren 3

1.4 Wirkung von Östrogen an ausgewählten Körperorganen 5

1.4.1 Wirkung von Östrogen auf das Herz-Kreislauf-System 5

1.4.2 Wirkung von Östrogen am Knochen $\quad 6$

1.4.3 Wirkung von Östrogen am Uterus $\quad 8$

1.4.4 Wirkung von Östrogen auf das Körpergewicht 9

1.5 Biologische Marker für die Östrogenwirkung 9

$\begin{array}{lll}1.5 .1 & \text { IGF-1 } & 10\end{array}$

$\begin{array}{lll}1.5 .2 & \mathrm{ER} \alpha & 10\end{array}$

$\begin{array}{ll}1.5 .3 \text { Myocardin } & 10\end{array}$

1.6 Klassische Hormonersatztherapie $\quad 11$

1.7 Phytoöstrogene 12

1.8 Genistein 14

1.9 Biologische Wirkung von Genistein 15

1.10 Wirkung von Genistein am Knochen 16

1.11 Kardiovaskuläre Wirkung von Genistein 17

1.12 Das Mausmodell 18

1.13 Ziel dieser Arbeit $\quad 19$

$\underline{2}$ Material und Methoden $\quad 20$

2.1 Material 20

2.1.1 Versuchstiere und Haltungsbedingungen 20

2.1.2 Ovarektomie und Implantation eines Identifikationsgeräts 20

$\begin{array}{lll}2.1 .3 & \text { Tierfutter } & 21\end{array}$

$\begin{array}{lll}2.1 .4 & \text { Versuchsablauf } & 21\end{array}$ 
2.1.5 Gewinnung des biologischen Probenmaterials 22

2.2 Methoden 23

2.2.1 Molekularbiologische Methoden 23

2.2.2 Gewebeaufbereitung und RNA-Isolierung 23

$\begin{array}{lll}2.2 .3 & \text { cDNA-Synthese } & 24\end{array}$

2.2.4 Real Time Quantitative PCR 25

2.2.5 Quantitative Computertomographie 28

2.3 Statistische Auswertung 32

$\underline{3}$ Ergebnisse $\quad 33$

3.1 Körpergewichte 33

3.1.1 Körpergewicht im Verlauf über drei Monate 35

3.2 Futterverbrauch 36

$\begin{array}{lll}3.3 & \text { Organentwicklung } & 39\end{array}$

3.4 Genexpression im Herzen $\quad 41$

$\begin{array}{lll}3.4 .1 & \text { IGF-1 } & 41\end{array}$

$\begin{array}{lll}3.4 .2 \mathrm{ER} \alpha & 42\end{array}$

$\begin{array}{lll}3.4 .3 \text { Myocardin } & 43\end{array}$

3.5 Knochenparameter $\quad 44$

3.5.1 Dichte der Spongiosa $\quad 44$

3.5.2 Anteil der Trabekel an der Spongiosaquerschnittsfläche 45

3.5.3 Polares Widerstandmoment 46

$\underline{4}$ Diskussion $\quad 48$

4.1 Entwicklung von Körpergewicht und Futterverbrauch 48

4.2 Organentwicklung 51

$\begin{array}{lll}4.2 .1 & \text { Uterus } & 51\end{array}$

4.2.2 Herz $\quad 53$

4.3 Knochenparameter $\quad 55$

4.3.1 Dichte der Spongiosa $\quad 57$

4.3.2 Prozentualer Anteil der Trabekel an der Spongiosaquerschnittsfläche 58

4.3.3 Polares Widerstandmoment 59

$\begin{array}{lll}4.4 & \text { Fazit } & 61\end{array}$

$\underline{5}$ Zusammenfassung $\quad 65$

$\underline{6}$ Literaturverzeichnis $\quad 68$ 


\section{Abkürzungsverzeichnis}

ACE Angiotensin-konvertierendes Enzym

AF-1 activating function-1

ANP atriales natriuretisches Peptid

cDNA komplementäre Desoxyribonukleinsäure

Ct threshold cycle, Schwellenwert-Zyklus

DNA Desoxyribonukleinsäure

E1 Estron

E2 Estradiol

E3 Estriol

EGF epidermal growth factor

ER $\alpha \quad$ Östrogenrezeptor- $\alpha$

ER $\beta \quad$ Östrogenrezeptor- $\beta$

FSH follikelstimulierendes Hormon

GEN Genistein

GH growth hormone, Wachstumshormon

HB-EGF heparin-binding epidermal growth factor

HDL high-density lipoprotein

HET Hormonersatztherapie

HRE hormone response element

IGF-1 Insulin-like growth factor 1

IL-1 Interleukin-1

Il-6 Interleukin-6

KG Körpergewicht

LDL low-density lipoprotein

LH luteinisierendes Hormon

L-Typ long-lasting type, langanhaltender Strom-Typ

M-CSF Monozytenkolonien-stimulierender Faktor

mg/kgKG Milligramm pro Kilogramm Körpergewicht

Myocd Myocardin

NF-кB nuclear factor 'kappa-light-chain-enhancer' of activated B-cells

NOS Stickstoffmonoxid-Synthetase

OECD Organization for Economic Co-operation and Development

OPG Osteoprotegerin 
ovx ovariectomized, ovarektomiert

PCR polymerase chain reaction, Polymerase-Kettenreaktion

PDGF platelet-derived growth factor

pQCT periphere quantitative Computertomographie

QCT quantitative Computertomographie

RANK receptor activator of $N F-\kappa B$

RANKL receptor activator of NF- $\kappa B$ ligand

RNA ribonucleic acid, Ribonukleinsäure

RT Reverse Transkriptase

SERM selective estrogen receptor modulator, selektive Östrogenrezeptormodulatoren

SHGB Sexualhormon-bindendes Globulin

SRC3 steroid receptor coaktivator 3

SRF serum response factor

SV-Scan scout view, Übersichtsscan

TGF- $\beta$ transforming growth factor- $\beta$

TNF- $\alpha \quad$ Tumornekrosefaktor- $\alpha$

UNG Uracil-N-Glycosylase

VEGF vascular endothelial growth factor

WHI Women's Health Initiative

ZNS zentrales Nervensystem

$\alpha$ ERKO Östrogenrezeptor- $\alpha$-Knock-out

$\beta E R K O \quad$ Östrogenrezeptor- $\beta$-Knock-out 


\section{Einleitung}

\subsection{Perimenopausale Inzidenz von Herzerkrankungen}

Kardiovaskuläre Erkrankungen und insbesondere die koronare Herzkrankheit sind die häufigste Todesursache in den Industrienationen (Yusuf et al. 2001, Lakatta 2002). Das Risiko für kardiovaskuläre Erkrankungen steigt mit zunehmendem Alter signifikant an. Epidemiologische Untersuchungen haben gezeigt, dass prämenopausale Frauen, verglichen mit Männern im gleichen Alter, ein deutlich niedrigeres Risiko für Herzkreislauferkrankungen haben. Postmenopausal steigt das Risiko für Frauen, an kardiovaskulären Erkrankungen wie Hypertonie, Hypercholesterinämie, Arteriosklerose und Myokardinfarkt zu erkranken, steil an. Diese deutliche Zunahme der Inzidenz wird unter anderem mit dem Abfall des weiblichen Östrogenspiegels in der Menopause erklärt (Colditz et al. 1987, Isles et al. 1992, Grodstein und Stampfer 1995). Ein Hormonersatz in der Menopause zur Vermeidung von kardiovaskulären Erkrankungen ist naheliegend, wird allerdings zurzeit nicht empfohlen (Deutsche Gesellschaft für Gynäkologie und Geburtshilfe 2010).

\subsection{Perimenopausale Inzidenz von Osteoporose}

Osteoporose ist die häufigste Knochenerkrankung im höheren Lebensalter. 80\% aller Osteoporoseerkrankungen betreffen Frauen nach der Menopause (Herold u.a. 2010). Statistisch wird jede zweite Frau, aber nur jeder vierzigste Mann, während des Lebens eine durch Osteoporose bedingte Fraktur erleiden (Hillard und Stevenson 1991). Das Auftreten von Frakturen, was eine der Hauptfolgen von Osteoporose ist, betrifft vor allem Frauen ab dem siebten Lebensjahrzehnt. Diese starke Zunahme der Inzidenz von Osteoporose durchschnittlich zehn bis 20 Jahre nach der Menopause deutet daraufhin, dass das Hormon Östrogen eine zentrale Rolle in der Aufrechterhaltung des Skelettsystems und bei der Entwicklung einer Osteoporose spielt (Pacifici 1998). Der Verlust von körpereigenem Östrogen führt zu einem Ungleichgewicht im Knochenstoffwechsel und dadurch zu einer Abnahme der Knochendichte und dem Abbau von Knochenstruktur, woraus eine erhöhte Frakturanfälligkeit resultiert (HorstSikorska und Wawrzyniak 2011). Die zunehmende Lebenserwartung lässt Osteoporose und osteoporosebedingte Frakturen $\mathrm{zu}$ einem weiter an Bedeutung gewinnenden Gesundheitsproblem werden. Neben der subjektiven Belastung der Patienten durch frakturbedingte Schmerzen und Immobilisation entstehen, bedingt durch die Therapie und die häufig lange Immobilisation nach einer osteoporotischen Fraktur, wirtschaftlich betrachtet erhebliche 
finanzielle Belastungen für das öffentliche Gesundheitssystem (Sandhu und Hampson 2011). Dies ist eine starke Motivation für die Forschung an Östrogen und östrogenhaltigen Substanzen.

\section{3 Östrogene}

\subsubsection{Synthese, Funktion und Abbau}

Östrogene sind die wichtigsten weiblichen Sexualhormone. Sie gehören zur Gruppe der Steroidhormone. Das wichtigste Östrogen ist Estradiol (E2). Daneben gibt es noch Estron (E1) und Estriol (E3), die eine deutlich geringere biologische Aktivität zeigen. Neben den natürlich vorkommenden Östrogenen gibt es auch synthetische, welche eine leichte Veränderung in der Molekularstruktur zeigen und auch bei oraler Gabe wirksam sind.

Bei der Frau werden Östrogene in den Granulosazellen des Ovars und während einer Schwangerschaft in der Plazenta produziert. Geringe Mengen entstehen in der Nebenniere, in Muskel- Fett- und Nervengewebe (Gruber et al. 2002). Die Synthese von Östrogen erfolgt ausgehend vom Cholesterin über verschiedene Zwischenstufen zu Testosteron; dieses wird dann über das Enzym Aromatase in Östrogen umgewandelt. Die ovarielle Hormonproduktion wird über das Hypothalamus-Hypophysen-System mit Hilfe von Gonadotropinen und über Rückkopplung gesteuert. Der Abbau von Östrogen erfolgt über Kopplung an Sulfat oder Glucuronsäure in der Leber und anschließende Ausscheidung über Galle oder Niere.

Östrogen fördert die Entwicklung und das Wachstum von Vagina, Uterus und Ovar sowie die Ausbildung von sekundären Geschlechtsmerkmalen wie weiblicher Brust und Fettverteilung (Huppelsberg und Walter 2005). Auch spielt Östrogen eine zentrale Rolle in der Steuerung des Menstruationszyklus. Östrogen sorgt unter anderem für eine Proliferation des Endometriums in der Follikelphase, eine Förderung der Follikelreifung, die Spinnbarkeit des Cervixschleims und eine gesteigerte Tubenmotilität (Huppelsberg und Walter 2005). Die höchsten Serumöstrogenkonzentrationen werden präovulatorisch, die niedrigsten prämenstruell erreicht.

Östrogene haben zusätzlich zu der Wirkung auf die weiblichen Geschlechtsorgane auch wichtige Funktionen für den Gesamtorganismus. Die Wasser- und Salzausscheidung wird durch Östrogen erniedrigt. Auch wird die Gerinnungsneigung des Blutes durch Östrogen verstärkt, wodurch sich die Thrombosegefahr erhöht (Silbernagl und Despopoulos 2001). Östrogene beeinflussen im zentralen Nervensystem (ZNS) Lernen, Gedächtnis, Bewusstsein, Feinmotorik, Temperatur-regulation, Stimmungslage und reproduktive Funktionen (Nilsson und Gustafsson 
2002). Weiter werden Knochen, kardiovaskuläre Organe, Leber, Magen-Darm-Trakt, Haut und auch das Immunsystem durch Östrogene beeinflusst (Gruber et al. 2002). Die für diese Arbeit relevanten östrogenen Effekte der untersuchten Organe werden in Abschnitt 1.4 ausführlicher dargestellt.

\subsection{2 Östrogene perimenopausal}

Mit Nachlassen der endokrinen Funktion des Ovars durch Verringerung der Anzahl der ovariellen Follikel sinkt der Östrogenspiegel dauerhaft ab. Folgen sind das permanente Ausbleiben der Menstruation und der Verlust der Fruchtbarkeit. Die letzte vom Ovar gesteuerte Regelblutung wird als Menopause definiert (Edwards und Li 2013). Die Phase des hormonellen Übergangs vor und nach der Menopause wird als Klimakterium bezeichnet. Die Menopause kann spontan (natürliche Menopause) mit durchschnittlich 52 Jahren oder iatrogen (induzierte Menopause) nach Entfernung der Ovarien, Strahlen-, Chemo-, oder antiöstrogener Hormontherapie eintreten (Pfleiderer et al. 1999). Durch Versiegen der Hormonsekretion aus dem Ovar kommt es zum Wegfall der negativen Rückkopplung von Östrogen auf Hypothalamus und Hypophyse mit folglich hohen Plasmaspiegeln von FSH (follikelstimulierendes Hormon) und LH (luteinisierendes Hormon).

Das Östrogendefizit im Klimakterium kann zu verschiedenen Beschwerden führen, die unterschiedlich stark ausgeprägt sein können und auch unter dem Begriff des klimakterischen Syndroms zusammengefasst werden. Dazu gehören unter anderem vegetative Symptome wie Hitzewallungen, Schlafstörungen, psychische Beeinträchtigungen wie depressive Verstimmung und Reizbarkeit. Auch treten somatische Veränderungen auf, die nicht nur die klassischen Zielorgane von Östrogen wie Ovarien, Uterus, Vagina und Brustdrüsen betreffen, sondern auch andere Gewebe, die über Steroidrezeptoren verfügen wie kardiovaskuläre Organe und Knochen (Huppelsberg und Walter 2005, Edwards und Li 2013).

\subsection{3 Östrogenrezeptoren}

Östrogenrezeptoren gehören zur Gruppe der nukleären Steroidrezeptoren, die als ligandenaktivierte Transkriptionsfaktoren fungieren (Matthews und Gustafsson 2003). Bisher sind zwei Östogenrezeptorsubtypen bekannt, ER $\alpha$ (Green et al. 1986) und ER $\beta$ (Kuiper et al. 1996). Beide verfügen über sechs funktionelle Domänen, die mit den Buchstaben A-F bezeichnet werden. Im klassischen Weg bindet der Ligand an den Rezeptor und es kommt zu einer Konformationsänderung im Rezeptormolekül und zur Dimerisierung von zwei Rezeptoren, 
die jeweils Östrogen gebunden haben. Anschließend erfolgt die Translokation des homo- oder heterodimeren Rezeptorkomplexes in den Zellkern. Im Kern lagert sich der Komplex an spezifische DNA-Sequenzen an, sogenannte hormon reponsive elements (HRE), was zur Aktivierung der Transkription führt. Hierbei spielen Koaktivatoren zur Modulation der Genexpression eine wichtige Rolle (Nilsson et al. 2001).

Neben der klassischen Aktivierung der Östrogenrezeptoren durch natürliche oder synthetische Hormone sind auch alternative Wege ohne Ligandenbindung beschrieben. Hierbei sind Wachstumsfaktoren wie EGF (epidermal growth factor) und IGF-1 (insulin-like growth factor 1) wichtig, die durch Phosphorylierung den Rezeptor aktivieren und so die Transkription modulieren (Gruber et al. 2002). Auch ein schneller Aktivierungsweg mit Invagination des Östrogenrezeptors an der Zellmembran und Aktivierung der Mitogen-aktivierten Proteinkinase ist beschrieben (Gruber et al. 2002).

ER $\alpha$ und ER $\beta$ zeigen bei Vergleich der Aminosäuresequenz eine hohe Übereinstimmung von 97\% in der DNA-Bindungsdomäne, jedoch nur 56\% in der Ligandenbindungsdomäne. Kaum Übereinstimmung mit 24\% zeigt der N-terminale Abschnitt der A/B-Domäne. Hier ist der Transaktivierungsbereich AF-1 (activating function-1) lokalisiert, der als ligandenunabhängiger Transkriptionsaktivator fungiert (Dahlman-Wright et al. 2006). Eine Folge davon sind Unterschiede in der Bindungsaffinität der Rezeptorsubtypen für verschiedene Liganden, im Aktivierungspotential der Rezeptoren und in der Transkriptionsaktivität (McInerney et al. 1998).

Die beiden Östrogenrezeptoren sind in den einzelnen Geweben unterschiedlich verteilt. In einigen Organen sind beide Rezeptor-Subtypen auf ähnlichem Niveau exprimiert, während in anderen Organen einer der beiden Subtypen überwiegt (Dahlman-Wright et al. 2006). ER $\alpha$ wird in Gebärmutter, Prostata, Eierstock, Hoden, Nebenhoden, Knochen, Brust, verschiedenen Regionen des Gehirns, der Leber und weißem Fettgewebe exprimiert. ER $\beta$ ist in Darm, Prostata, Hoden, Eierstock, Knochenmark, Speicheldrüse, Gefäßendothel und einigen Hirnarealen zu finden (Kuiper et al. 1997, Dahlman-Wright et al. 2006).

Beiden Rezeptoren werden sowohl individuelle als auch überlappende Funktionen zugeordnet (Matthews und Gustafsson 2003). Sie stehen in einem engen Verhältnis zueinander, das mit einer Art Yin-Yang-Beziehung beschrieben werden kann (Lindberg 2002). Werden ER $\alpha$ und ER $\beta$ koexprimiert, kann ER $\beta$ als Gegenspieler von ER $\alpha$ auftreten, indem es der durch ER $\alpha$ vermittelten Genexpression entgegenwirkt. (Matthews und Gustafsson 2003). Für die Rezeptorsubtypen sind zahlreiche Splicevarianten bekannt. Diese können miteinander viele 
unterschiedliche Homo-dimere oder Heterodimere bilden, die jeweils die Transkriptionswirkung verschieden stark beeinflussen (Petersen et al. 1998).

Die beschriebenen Unterschiede der Östrogenrezeptoren in der Gewebeverteilung und Ligandenbindungsaffinität tragen zur selektiven Wirkung der Liganden als Rezeptoragonisten und -antagonisten in verschiedenen Geweben bei und bilden die Grundlage für das Verständnis von SERM (selective estrogen receptor modulator) (Kuiper et al. 1997). Das sind Arzneistoffe, die ihre Wirkung über Östrogenrezeptoren vermitteln, chemisch betrachtet jedoch nicht über die für Östrogene typische Steroid-Struktur verfügen. SERM wirken organselektiv als Östrogenagonisten oder -antagonisten (Dutertre und Smith 2000).

\subsection{Wirkung von Östrogen an ausgewählten Körperorganen}

In diesem Abschnitt wird näher auf die Wirkung von Östrogen auf die Zielorgane, die in dieser Arbeit untersucht wurden, eingegangen.

\subsubsection{Wirkung von Östrogen auf das Herz-Kreislauf-System}

Epidemiologische Studien deuten darauf hin, dass Östrogene protektive Funktionen im HerzKreislauf-System übernehmen (Walsh et al. 1991, Kuhl 1996). Diese schützende Wirkung scheint durch viele verschiedene Mechanismen der Östrogenwirkung zu entstehen, auf die im Folgenden näher eingegangen wird. Östrogene erhöhen im Serum die HDL-Konzentration (high-density lipoprotein) und senken die LDL-Konzentration (low-density lipoprotein), wodurch sie einen positiven Einfluss auf den Lipidstoffwechsel ausüben und indirekt das Risiko für die Entwicklung einer Arteriosklerose senken. Möglicherweise hemmt Östrogen auch die Oxidation von LDL-Cholesterin. Oxidiertes Cholesterin soll besonders stark zur Plaquebildung beitragen (Finking et al. 2000).

Bei den direkten Effekten auf das Gefäßsystem unterscheidet man genomische, das heißt rezeptorvermittelte, von nichtgenomischen, die wesentlich schneller eintreten (Karck et al. 1998). Östrogene wirken protektiv auf die Gefäßwand. So hemmen Östrogene die Proliferation von glatten Gefäßmuskelzellen und die Migration von Myozyten und Fibroblasten. Sie reduzieren Plasminogen- und Fibrinogen-Konzentrationen (Mendelsohn und Karas 1999, Tostes et al. 2003). In vivo ist ein günstiger Einfluss auf die Regenerierung des Endothels nach vaskulären Verletzungen beschrieben (Bian et al. 2001). Östrogen induziert eine schnelle, direkte Abnahme des Gefäßtonus über eine Aktivierung der NOS (StickstoffmonoxidSynthetase) in den Endothelzellen und durch Öffnung bestimmter Kalzium-aktivierter Kalium- 
Ionenkanäle in der Zellmembran der glatten Gefäßmuskelzellen (White et al. 1995, Khan und Malhotra 2003). Auch beeinflussen Östrogene das Renin-Angiotensin-Aldosteron-System durch herabgesetzte Transkription von ACE (angiotensin-converting enzyme) sowie eine verminderte Expression des Angiotensin-1-Rezeptors (Kamakshi et al. 1999, Gallagher et al. 1999).

Neben der positiven Wirkung von Östrogen auf das Gefäßsystem hat sich das Interesse jüngst stärker auf die Östrogenwirkung am Herzen gerichtet (Ling et al. 2006, Arias-Loza et al. 2008, Kararigas et al. 2010). Die molekulare Grundlage hierfür bildet der Nachweis von ER $\alpha$ und ER $\beta$ in Herzmuskelzellen (Grohé et al. 1997, Nordmeyer et al. 2004, Nguyen et al. 2012b). In vorangegangenen Untersuchungen der Arbeitsgruppe konnten in vivo an gesunden, ovarektomierten Tieren nach E2-Gabe eine signifikante Erhöhung des relativen Herzgewichts sowie eine Zunahme der Zellgröße der Kardiomyozyten und eine gesteigerte Genexpression gemessen werden (Nguyen et al. 2012b). Diese Ergebnisse bestätigen die direkte Wirkung von Östrogen am Herzen.

Im Myokard stimuliert Östrogen die Expression der endothelialen und induzierbaren NOS (Nuedling et al. 1999). Es konnte gezeigt werden, dass die Anzahl der L-Typ-(long-lastingtype)-Kalzium-Kanäle durch den Östrogenrezeptor reguliert wird. Östrogenmangel kann zu einer vermehrten Anzahl von L-Typ-Kalzium-Kanälen im Herzen führen und zu einem erhöhtem intrazellulären Kalziumspiegel, woraus Störungen in der Erregbarkeit des Herzmuskels, Herzrhythmusstörungen und Hypertrophien des Herzmuskels resultieren können (Johnson et al. 1997; Jovanović et al. 2000). Bei Tieren mit hypertropher Druckbelastung am Herzen ließ sich unter Östrogen eine erhöhte Expression von ANP (atriales natriuretisches Peptid) nachweisen (Eickels et al. 2001). ANP hat eine schützende Wirkung bei ventrikulärer Hypertrophie (Masciotra et al. 1999). Möglicherweise beeinflusst Östrogen auch die Transkription von Genen, die mit einer Hypertrophie am Herzen assoziiert werden, wie Isoformen der schweren Myosinkette und strukturellen Matrixproteinen (Douglas et al. 1998).

\subsubsection{Wirkung von Östrogen am Knochen}

Östrogen übernimmt eine Schlüsselposition in der Regulation des Kochenstoffwechsels. Die osteoprotektive Wirkung von Östrogen wurde vielfach am Tiermodell und am Menschen, insbesondere bei postmenopausalen Frauen, nachgewiesen (Rodan und Martin 2000, Delmas 2002, Raisz 2005, Chien und Karsenty 2005, Nakamura et al. 2007, Marini et al. 2012). Die Kenntnisse über die exakten Wirkmechanismen von Östrogen am Knochen sind noch unvollständig und lediglich wenige sind gut verstanden. 
Im Knochen werden sowohl ER $\alpha$ als auch ER $\beta$ exprimiert. Immunhistologische Untersuchungen am neonatalen menschlichen Knochen haben gezeigt, dass ER $\alpha$ überwiegend in der Kortikalis und ER $\beta$ in der Spongiosa exprimiert wird (Bord et al. 2001). Dennoch werden beide Östrogenrezeptorsubtypen in fast allen Zelltypen im Knochen exprimiert (Sims et al. 2002).

Studien an Knockout-Mäusen konnten zeigen, dass die Östrogenrezeptorsubtypen im Knochen bei Männchen und Weibchen unterschiedliche Wirkungen vermitteln, die auch abhängig von der Östrogen- und Androgenkonzentration sein können (Sims et al. 2002). Mäuse, denen das ER $\alpha$-Gen fehlt ( $\alpha$ ERKO), wiesen Skelettanomalien mit Einschränkungen des Längswachstums der Knochen und einen leichten Rückgang der Knochendichte auf (Dahlman-Wright et al. 2006). Östrogen bewirkt einen Epiphysenschluss (Cutler 1997). Studien an weiblichen ER $\beta$-Knock-out-Mäusen ( $\beta E R K O)$ zeigen, dass ER $\beta$ verantwortlich ist für die Unterdrückung der wachstumsfördernden Wirkung von Östrogen auf den Knochen, die über ER $\alpha$ vermittelt wird (Dahlman-Wright et al. 2006). Bei weiblichen Mäusen konnte gezeigt werden, dass ER $\beta$ in Abwesenheit von ER $\alpha$ möglicherweise in der Lage ist, den Verlust von ER $\alpha$ zumindest teilweise zu kompensieren (Sims et al. 2003).

Interleukin-1 (IL-1), Interleukin-6 (Il-6), Tumornekrosefaktor- $\alpha$ (TNF- $\alpha$ ), Monozytenkolonienstimulierender Faktor (M-CSF) und Prostaglandin $\mathrm{E}_{2}\left(\mathrm{PGE}_{2}\right)$ sind proinflammatorische Zytokine, die den Knochenabbau beschleunigen. Dies geschieht vor allem durch Erhöhung der Pool-größe von Pre-Osteoklasten im Knochenmark (Pacifici 1998, Manolagas 2000). Diese Zytokine werden durch Östrogen herunterreguliert. TGF- $\beta$ (transforming growth factor- $\beta$ ) wird durch Östrogen hochreguliert. TGF- $\beta$ hemmt die Knochenresorption, indem es direkt an den Osteoklasten wirkt, deren Aktivität hemmt und die Apoptose von Osteoklasten fördert (Manolagas 2000).

Ein wichtiger Mechanismus für das Gleichgewicht im Knochenstoffwechsel ist das RANK/RANKL-System (receptor activator of $N F-\kappa B$ /receptor activator of $N F-\kappa B$ ligand). Hier agiert Östrogen als Suppressor von RANKL-induzierter Osteoklastendifferenzierung (Shevde et al. 2000). Darüber hinaus steigert Östrogen die Expression von Osteoprotegerin (OPG), das der Osteoklastendifferenzierung über den RANKL-Weg entgegenwirkt (Hofbauer et al. 2000). Somit hemmen Östrogene durch viele verschiedene Mechanismen den Knochenabbau. Ein Mangel an Östrogen führt zu einer Erhöhung des Knochenstoffwechsels mit 
Ungleichgewicht zwischen Knochenbildung und Resorption und folglich fortschreitendem Verlust von trabekulärer Knochenmasse und schließlich Osteoporose.

\subsubsection{Wirkung von Östrogen am Uterus}

Der Uterus ist, wie bereits in 1.3.1 beschrieben, ein Hauptzielorgan von Östrogen. Dieses ist neben Progesteron entscheidend für den weiblichen Menstruationszyklus. Im Verlauf des weiblichen Zyklus unterliegt die Östrogenkonzentration großen Schwankungen. Im Klimakterium kommt es durch Mangel von Östrogen zu einer Atrophie des Uterus. Im Uterus sind die Rezeptoren ER $\alpha$ und ER $\beta$ vorhanden. Bei dem geschlechtsreifen Uterus ist ER $\alpha$ der dominante Rezeptor, ER $\beta$ wird durch die höhere Östrogenkonzentration herunterreguliert (Weihua et al. 2000).

Östrogen wirkt am Uterus am Endo- sowie Myometrium proliferierend. Schon innerhalb der ersten 4 h nach Östrogenverabreichung sind bei Ratten eine Zunahme des Uterusgewichts, ein gesteigerter Glukose-Metabolismus, Histaminabbau und eine erhöhte RNA-PolymeraseAktivität messbar (Murphy und Ghahary 1990). Wichtig sind nach Murphy und Ghahary in dieser frühen Phase die Aktivierung von Protoonkogenen und die erhöhte Expression von Wachstumsfaktoren und deren Rezeptoren und Proteinkinasen. Wichtige Wachstumsfaktoren sind hier unter anderem IGF-1, HB-EGF (heparin-binding epidermal growth factor) und VEGF (vascular endothelial growth factor) (Murphy und Ghahary 1990, Cullinan-Bove und Koos 1993, Zhang et al. 1998). Vier Stunden bis zwei Tage nach Östrogensubstitution sind Steigerungen der Protein-und RNA-Synthese und eine Erhöhung des Gebärmuttertrockengewichts und des DNA-Gehalts quantifizierbar (Murphy und Ghahary 1990). Cullinan-Bove et al. beschreiben die frühe Phase nach Östrogengabe mit einer Hyperämie und einer erhöhten Gefäßpermeabilität verbunden mit Ödemen. Es folgt eine spätere Phase mit Hypertrophie und Hyperplasie von Endo- und Myometrium.

Die stark proliferierende Wirkung von Östrogen ist nach der Menopause unerwünscht, da sie ein erhöhtes Risiko für ein Endometriumkarzinom bedeuten kann (Pike et al. 1997, Weiderpass et al. 1999). Im Rahmen einer Hormonersatztherapie zur Behandlung postmenopausaler Beschwerden kann man dem Risiko eines Endometriumkarzinoms durch kombinierte Gabe von Östrogenen mit Gestagenen entgegen wirken. 


\subsubsection{Wirkung von Östrogen auf das Körpergewicht}

Östrogen spielt auch im Energiestoffwechsel und bei der Kontrolle des Körpergewichts eine bedeutende Rolle (He et al. 2012). In den Adipozyten werden beide Östrogenrezeptoren exprimiert (Mayes und Watson 2004). Es wird jedoch angenommen, dass ER $\alpha$ die dominantere Rolle bei der Regulation des Körpergewichts einnimmt (Wegorzewska et al. 2008).

Bei Nagetieren sowie beim Menschen wurde eine Korrelation zwischen Östrogen und Fettgewebsmasse beobachtet (Dahlman-Wright et al. 2006). Östrogen reduziert die Nahrungsaufnahme und verringert die Fettgewebsmasse durch gesteigerte Lipolyse. Der Wegfall von Östrogen in der Menopause kann eine Gewichtszunahme begünstigen. Bei postmenopausalen Frauen oder ovarektomierten Nagern ist Östrogenmangel mit einem erhöhten Risiko für Übergewicht und Diabetes mellitus Typ 2 assoziiert (He et al. 2012). Östrogensubstitution bei ovarektomierten Tieren unterdrückt die Entwicklung von Fettleibigkeit durch eine Verringerung der Nahrungsaufnahme und durch einen gesteigerten Energieaufwand.

Östrogensubstitution erhöht den Schutz gegen Insulinresistenz und Diabetes mellitus Typ 2 (Dahlman-Wright et al. 2006). Frauen, die in der WHI- (Women's Health Initiative) Studie eine Hormonersatztherapie erhielten, waren schlanker, empfindlicher für Insulin und hatten ein geringeres Risiko, einen Diabetes mellitus Typ 2 zu entwickeln als Frauen die ein Placebo erhielten (D’Eon et al. 2005). Zusätzlich wurde beobachtet, dass Östrogen ähnliche Auswirkungen auf Nahrungsaufnahme und Körpergewicht hat wie das Hormon Leptin; beide bewirken eine vorübergehende Verringerung der Nahrungsaufnahme und eine moderate Reduktion des Körpergewichts bei ovarektomierten weiblichen Mäusen (Fungfuang et al. 2013). Östrogen und Leptin haben teilweise sich überlappende Funktionen und eng miteinander verflochtene Signalwege (He et al. 2012). Östrogen scheint zudem die Signalwege von Leptin bei Aktivierung von hypothalamischen Melanocortinzellen imitieren zu können (Gao und Horvath 2008).

\subsection{Biologische Marker für die Östrogenwirkung}

Die Wirkung von Östrogen auf den Körper kann man untersuchen, indem man Gene analysiert, die in ihrer Transkription direkt oder indirekt durch Östrogen beeinflusst werden. Im folgenden Kapitel wird näher auf die Genexpression von IGF-1, ER $\alpha$ und Myocardin eingegangen, die im Rahmen dieser Arbeit untersucht wurden. 


\subsubsection{IGF-1}

IGF-1 ist ein Wachstumsfaktor, der strukturelle und funktionelle Ähnlichkeiten zu Insulin aufweist. IGF-1 ist bedeutsam für Wachstum und Organentwicklung. Er wird überwiegend von der Leber nach Stimulation mit GH (growth hormone) sezerniert. IGF-1 wird jedoch auch in nahezu allen anderen Geweben exprimiert und wirkt über einen membranständigen Rezeptor (Yakar et al. 2005). IGF-1, IGF-1-Bindungsproteine und der IGF-Rezeptor werden neben der wachstumstimmulierenden Wirkung auch mit einer starken anti-apoptotischen Wirkung und Krebsentstehung in Verbindung gebracht (LeRoith und Roberts 2003, Renehan et al. 2004). Am Herzen hat IGF-1 günstige Auswirkungen auf die Funktion und das Überleben von Kardiomyozyten (Chao et al. 2003; Fujio et al. 2000; Li et al. 1997).

Neben GH wird die Expression von IGF-1 auch durch Östrogen stimuliert. An östrogensensitiven Organen wie dem Uterus und dem Knochen konnte eine direkte Stimulierung von IGF-1 durch Östrogen nachgewiesen werden. (Ernst et al. 1989, Murphy und Ghahary 1990). Hieraus resultiert, dass IGF-1 als Marker zur Beurteilung der Östrogenwirkung am Gewebe dienen kann.

\subsubsection{ERa}

Wie bereits unter 1.3.3. beschrieben, werden Östrogenrezeptoren in vielen verschieden Organen exprimiert. Die Expression von ER $\alpha$ und ER $\beta$ variiert in Abhängigkeit von Individuum, Alter und Hormonstatus. Am Herzen konnte gezeigt werden, dass prämenopausale Frauen mit hohen Expressionsraten von Östrogenrezeptoren in glatten Muskelzellen von Koronararterien weniger Arteriosklerose aufwiesen. Möglicherweise sind die Östrogenrezeptoren, insbesondere ER $\alpha$, wichtig für den Schutz vor Arteriosklerose (Losordo et al. 1994). Mit einer Messung der ER $\alpha-$ Expression kann man Hinweise auf die östrogene Wirkung im Herzen erhalten.

\subsubsection{Myocardin}

Myocardin ist Transkriptionskoaktivator von serum response factor (SRF). Myocardin wird in Herzmuskel- und glatten Muskelzellen exprimiert und ist für die Regulation der Transkription von glatten Gefäßmuskelzellen und die Differenzierung von glatten Muskelzellen bedeutsam (Wang et al. 2001, Wang et al. 2003). Für Myocardin konnte gezeigt werden, dass es vom Steroidhormonrezeptor reguliert wird. Der Grund hierfür ist, dass der Östrogenrezeptorkoaktivator steroid receptor coaktivator 3 (SRC3) auch ein Koaktivator von Myocardin ist (Li 
et al. 2007, Nguyen et al. 2012a). Mit der Messung von Myocardin sind somit Rückschlüsse auf die östrogene Wirkung am Herzen möglich.

\subsection{Klassische Hormonersatztherapie}

Die Hormonersatztherapie (HET) wird eingesetzt, um die durch einen Hormonmangel in der menopausebedingten Beschwerden zu lindern. Da es sich um eine elektive Maßnahme handelt, ist eine gründliche Abwägung von Nutzen und Risiko notwendig.

Zur Auswahl stehen eine Monotherapie mit Östrogen oder eine sequentielle Kombinationstherapie von Östrogen und Gestagen. Eine Therapie mit reinen Östrogenen erhöht das Risiko für ein Endometriumkarzinom und darf deshalb nur bei hysterektomierten Frauen durchgeführt werden. Bei einer kombinierten Östrogen-Gestagen-Therapie ist das Risiko für ein Endometriumkarzinom nicht erhöht (Rossouw et al. 2002). Als Darreichungsform gibt es Tabletten zur oralen Anwendung, aber auch Pflaster, Cremes oder Gele zur transdermalen Applikation. Bei Wahl des jeweiligen Medikaments und der Darreichungsform spielen verschiedene, individuelle Faktoren eine Rolle. Grundsätzlich sollte die geringstmögliche Dosis an Hormonen gewählt werden, mit der sich die klimakterischen Beschwerden beheben lassen.

Die klassische HET hat positive Effekte auf Wechseljahrsbeschwerden wie Hitzewallungen, Atrophien und Entzündungen im Urogenitalbereich und kann klimakterisch bedingte Depressionen lindern (Zweifel und O’Brien 1997, Greendale et al. 1998). Zudem können eine postmenopausale Osteoporose vermindert und das mit einer Osteoporose verbundene Frakturrisiko durch eine HET gesenkt werden. Allerdings sollte diese bei Osteoporose nur bei einer Unverträglichkeit oder Kontraindikation gegenüber anderen zur Osteoporosetherapie primär empfohlenen Arzneimitteln angewendet werden (Deutsche Gesellschaft für Gynäkologie und Geburtshilfe 2010, Rossouw et al. 2002).

Wie bereits in Abschnitt 1.1 beschrieben, steigt die Inzidenz von Herzerkrankungen bei Frauen in der Menopause deutlich an. Dieser Anstieg der Erkrankungsrate wird unter anderem mit dem zunehmenden Östrogendefizit in der Menopause erklärt. In epidemiologischen Untersuchungen zur HET bei menopausalen Beschwerden wurde eine protektive Wirkung auf kardiovaskuläre Erkrankungen beobachtet. In danach folgenden großen prospektiven, randomisierten Interventionstudien wurde zunächst eine signifikante Risikoerhöhung vor allem im ersten Jahr gemessen, gefolgt von einem Trend mit signifikanter Risikominderung in Bezug auf kardiovaskuläre Ereignisse. Zusammenfassend hat eine HET perimenopausal zur Primär- oder 
Sekundärprophylaxe von kardiovaskulären Erkrankungen in klinischen Studien keinen signifikanten Nutzen geliefert und wird derzeit nicht empfohlen (Grodstein und Stampfer 1995, Rees et al. 2008, Deutsche Gesellschaft für Gynäkologie und Geburtshilfe 2010, Hulley et al. 2013).

Neben den oben genannten Vorteilen für die klassische HET sind durch große internationale Langzeitstudien auch viele Nachteile bekannt geworden, die den Einsatz dieser Medikamente stark in Frage stellen. Der Abbruch eines Teils der WHI-Studie wegen lebensbedrohlicher Nebenwirkungen im Jahre 2002 sorgte öffentlich für Aufregung. Unter anderem auch durch die One-Million-Women-Studie wurde bestätigt, dass das Risiko für Mamma- und Ovarialkarzinom durch eine Hormonersatztherapie in der Menopause signifikant erhöht ist (Schairer et al. 2000, Beral und Collaborators 2003, Beral et al. 2007). Auch die Wahrscheinlichkeit für thrombembolische Ereignisse ist gesteigert (Nelson et al. 2002). Hinzu kommen ein vergrößertes Risiko an einer Gallenblasenentzündung zu erkranken und eine erhöhte Progredienz bei bestehendem kolorektalen Karzinom ((Grodstein et al. 1994, Chlebowski et al. 2004)). Mit einer kombinierten Östrogen-Gestagen-Therapie ist das Risiko an Darmkrebs zu erkranken erwiesenermaßen geringer (Chlebowski et al. 2004). Lange Zeit wurde angenommen, dass eine Hormonersatztherapie kognitive Störungen oder eine Demenz positiv beeinflusst. Diese Vermutung konnte in jüngeren Untersuchungen nicht bestätigt werden (Sano et al. 2008, Hogervorst et al. 2009).

Vor dem Hintergrund schwerwiegender Nebenwirkungen der konventionellen HET wird deutlich, wie wichtig die Erforschung von Therapiealternativen bei Wechseljahrsbeschwerden und Osteoporose ist. Die Aufmerksamkeit richtete sich in den vergangenen Jahren zunehmend auf Phytoöstrogene als eine potentielle Alternative zur klassischen pharmakologischen Hormonersatztherapie (Holmes et al. 2004).

\subsection{Phytoöstrogene}

Phytoöstrogene sind eine heterogene Gruppe von sekundären Pflanzeninhaltsstoffen, die östrogenartige Effekte ähnlich dem menschlichen 17ß-Estradiol in östrogenabhängigen Geweben zeigen. Sie binden direkt an ER $\alpha$ und ER $\beta$ und entfalten eine östrogene oder antiöstrogene Wirkung. Phytoöstrogene sollen in der Lage sein, Wechseljahrsbeschwerden und Herz-kreislauferkrankungen positiv zu beeinflussen, eine Erhöhung der Knochendichte postmeno-pausal zu bewirken und die Inzidenz von hormonabhängigen Krebserkrankungen 
senken (Anderson und Garner 1998, Chiechi et al. 1999, Ramsey et al. 1999, Chiechi 1999, Goldwyn et al. 2000).

Epidemiologische Studien haben gezeigt, dass asiatische Frauen eine geringere Inzidenz von Wechseljahrsbeschwerden, Gebärmutter- und Brustkrebs und Herzkreislauferkrankungen und Übergewicht im Vergleich zur westlichen Bevölkerung haben (Adlercreutz und Mazur 1997, Bagchi et al. 2001, Yamori 2004). Auch die Rate an Schenkelhalsfrakturen ist bei Asiatinnen niedriger. Zudem ist bekannt, dass der Östrogenspiegel im Blut bei asiatischen Frauen signifikant niedriger ist (Shimizu et al. 1990, Wu et al. 2000) und der Menstruationszyklus im Durchschnitt zwei bis drei Tage länger dauert (Cassidy et al. 1994, Kurzer 2002, Hooper et al. 2009). Migrationsstudien zeigen, dass genetische Ursachen zwischen asiatischen und westlichen Frauen als mögliche Erklärung für den Effekt ausgeschlossen werden können. Asiatinnen, die in westliche Länder emigrieren und die westlichen Ernährungsgewohnheiten übernehmen, zeigen ein ebenso hohes Erkrankungsrisiko wie die westliche Bevölkerung bei den oben aufgeführten Erkrankungen. Deshalb wird angenommen, dass neben dem unterschiedlichen Lebensstil und kulturellen Faktoren vor allem die unterschiedlichen Ernährungsgewohnheiten eine Rolle spielen. Die asiatische Ernährung enthält traditionell viel Soja und sojahaltige Produkte und ist damit reich an Phytoöstrogenen (Adlercreutz 1998).

Epidemiologische Untersuchungen und klinische Studien an postmenopausalen Frauen sehen auch einen Zusammenhang zwischen phytoöstrogenreicher Ernährung und einer reduzierten Körperfettmasse, die positive Auswirkungen auf die Entwicklung von chronischen Erkrankungen haben kann (Goodman-Gruen und Kritz-Silverstein 2003). Besonders in den USA wird deshalb die Zufuhr von Soja für Frauen in der Menopause beworben. Viele Studien deuten zudem darauf hin, dass vor allem der Konsum von Soja und sojahaltigen Produkten vor der Pubertät das Risiko für Brustkrebs im Tiermodell und beim Menschen senkt. Bei Zufuhr von Phytoöstrogenen ausschließlich im Erwachsenenalter konnte hingegen keine Reduzierung des Brustkrebsrisikos festgestellt werden (Cabanes et al. 2004).

Phytoöstrogene sind chemisch betrachtet Phenole. Anhand ihrer chemischen Struktur werden sie in 5 Hauptgruppen eingeteilt: Isoflavone, Flavone, Stilbene, Coumestane und Ligane (Wocławek-Potocka et al. 2013). Die jeweiligen Gruppen und ihre Wirkstoffe zeigen ein unterschiedliches Bindungsverhalten an den Östrogenrezeptoren und beeinflussen Regelkreise in unterschiedlicher Weise. Die meisten Phytoöstrogene binden bevorzugt an den ER $\beta$. Diese Eigenschaft von Phytoöstrogenen erklärt, weshalb sie zu den natürlichen SERM zählen (Kuiper 
et al. 1998, Simons et al. 2012). Ein idealer SERM sollte eine positiv östrogenähnliche Wirkung im Gehirn, einschließlich des Hypothalamus, im Skelett- und Kardiovaskulärem System sowie im Uro-genitaltrakt entfalten. In Brustdrüse und Uterus ist jedoch eine antiöstrogene, proliferations-hemmende Eigenschaft wünschenswert (Wuttke et al. 2002). Inwieweit Phytoöstrogene diese Kriterien in der klinischen Praxis erfüllen und wie die Risiken und Nebenwirkungen bei langfristigem Einsatz zu bewerten sind, ist aktuell nicht sicher $\mathrm{zu}$ beurteilen und Gegenstand der Forschung.

In dieser Arbeit wurden die Wirkungen des Isoflavons Genistein untersucht, auf das im folgenden Abschnitt näher eingegangen wird.

\subsection{Genistein}

Genistein ist ein Phytohormon aus der Gruppe der Isoflavone. Es lässt sich unter anderem aus der Sojabohne und dem Rotklee gewinnen (Mazur 1998, Liggins et al. 2000). Der weit verbreitete menschliche Verzehr von Soja sowie die gute Verfügbarkeit und das Wirkprofil von Genistein wecken großes Interesse an diesem Phytohormon in der Forschung. Genistein weist wie andere Phytohormone auch eine strukturelle Ähnlichkeit zu Östrogen auf (siehe Abbildung 1). Auch hat Genistein mit 270,24 g/mol ein ähnliches Molekulargewicht wie Estradiol mit $272,38 \mathrm{~g} / \mathrm{mol}$.
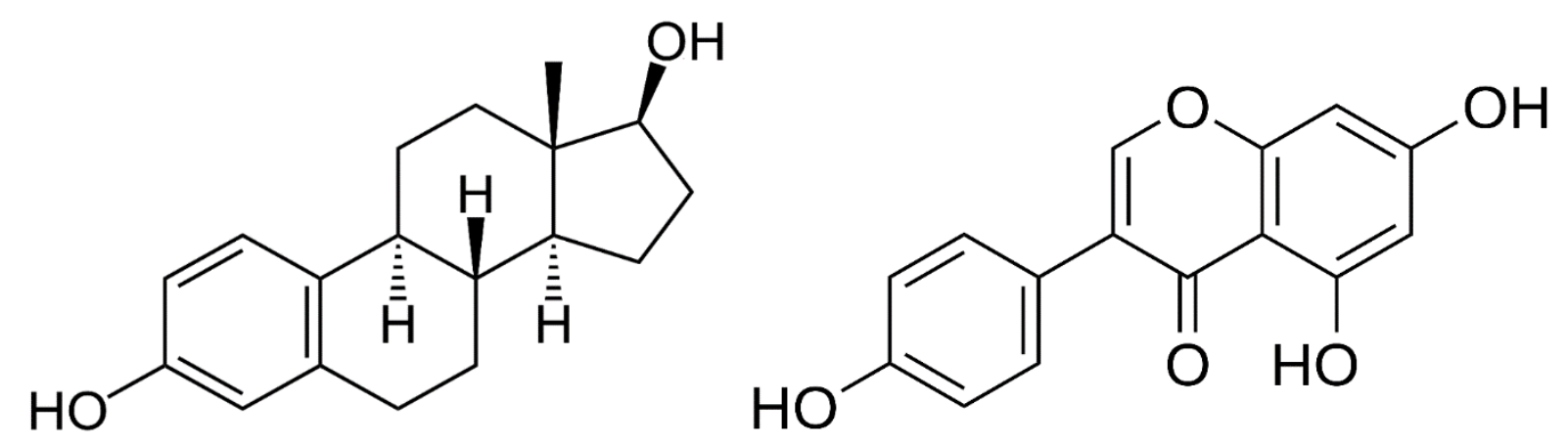

Abbildung 1: Strukturformeln von Genistein (rechts) und Estradiol (links). Die Summenformel von Genistein ist $\mathrm{C}_{15} \mathrm{H}_{10} \mathrm{O}_{5}$, die von Estradiol $\mathrm{C}_{18} \mathrm{H}_{24} \mathrm{O}_{2}$. (nach Wikipedia.org)

Genistein bindet an Östrogenrezeptoren in verschiedenen Organen und löst östrogene Aktivitäten aus (Davis et al. 1999, Whitten und Patisaul 2001). Dies kann durch die beschriebene Ähnlichkeit zum Estradiol und durch damit verbundene ähnliche Transkriptionseigenschaften erklärt werden (Mueller et al. 2004, Rimoldi et al. 2007, Vitale et 
al. 2012). Das Bindungspotential von Genistein ist insgesamt 100- bis 1000-fach niedriger als das von Estradiol (McClain et al. 2006). Eine vergleichsweise hohe Dosierung von Genistein führt aber dennoch zu messbaren Reaktionen sowohl bei Tieren als auch bei Menschen (Vitale et al. 2012). Verglichen mit Östrogen zeigt Genistein eine stärkere Affinität zu ER $\beta$ als zum ER $\alpha$ (Kuiper et al. 1998). Diese Eigenschaft lässt Genistein als SERM in Erscheinung treten (Setchell 2001).

\subsection{Biologische Wirkung von Genistein}

In Tierversuchen sowie in klinischen Studien konnte gezeigt werden, dass Genistein das Uteruswachstum stimulieren kann. (Kanno et al. 2003, Diel et al. 2004, Unfer et al. 2004). Auch im Brustgewebe ließ sich eine Proliferationssteigerung durch Genistein nachweisen, was ein Risikofaktor für die Entwicklung von Krebs sein kann (Gadducci et al. 2005, Rimoldi et al. 2007). In einer Vielzahl von Studien an Tiermodellen wurde eine proliferationsfördernde und -hemmende Auswirkung von Genistein auf Brustkrebszellen beschrieben und kontrovers diskutiert (Rimoldi et al. 2007). Möglicherweise spielen der Zeitpunkt und die Dauer der Exposition von Genistein eine ausschlaggebende Rolle. In Entwicklungsstudien konnte im Tiermodell sowie am Menschen demonstriert werden, dass die frühe, prepubertäre Exposition von Soja oder Genistein eine präventive Wirkung auf die Entwicklung von Brustkrebs im Erwachsenenalter haben kann (Lamartiniere 2002, Cabanes et al. 2004, Rimoldi et al. 2007).

Genistein kann die Synthese von SHGB (Sexualhormon-bindendes Globulin) stimulieren (Mousavi und Adlercreutz 1993) und einige Schlüsselenzyme in der Östrogen- und AndrogenSynthese wie $5 \alpha$ Reduktase (Evans et al. 1995), 17ß-Hydroxysteroid-Oxidoreduktase (Mäkelä et al. 1998) und Aromatase (Adlercreutz et al. 1993) hemmen.

Genistein ist in vitro und in vivo ein Inhibitor der Tyrosinkinase (Akiyama et al. 1987, Gao et al. 2004). Tyrosinkinasen sind Enzyme, die eine entscheidende Rolle bei der Kontrolle von Zellwachstum und -differenzierung spielen (Geer et al. 1994). Für Genistein ist zudem bekannt, dass es die DNA-Topoisomerase hemmt und die Angiogenese inhibiert (Markovits et al. 1989, Fotsis et al. 1998, Zhou et al. 1999). Auch antioxidative Wirkungen sind für Genistein beschrieben worden (Wei et al. 1996, Kapiotis et al. 1997). Diese Eigenschaften machen Genistein sehr interessant für die Krebsprävention und -therapie. Publikationen verdeutlichen, dass Genistein in Zellkulturen oder im Tiermodell eine hemmende Wirkung auf Tumore in Prostata (Hwang et al. 2009), Ovar (Gercel-Taylor et al. 2004), Gebärmutterhals (Kim et al. 2009), Brust (de Lemos 2001, Sakamoto et al. 2010), Colon (Pereira et al. 1994, Nakamura et al. 
2009) und Pankreas (Büchler et al. 2003) haben kann (Messina et al. 1994, Barnes 1995). Diese antikanzerogene Wirkung von Genistein konnte in klinischen Studien bei Prostatakrebs bisher nicht belegt werden (Strom et al. 2000, deVere White et al. 2010, Posadzki et al. 2013). Auch eine sechsmonatige Interventionsstudie mit Isoflavonen bei gesunden, westlichen Hochrisikopatientinnen für Brustkrebs konnte die Wirksamkeit in der Prävention von Brustkrebs nicht sicher bestätigen (Khan et al. 2013). Weitere klinische Untersuchungen bleiben abzuwarten, um eingehender beurteilen zu können, ob sich die Ergebnisse von Genistein in Zellkulturen und Tierexperimenten in Bezug auf die Krebsprävention und -therapie auf die Klinik transferieren lassen und wie sicher der Einsatz von Genistein ist (Taylor et al. 2009).

Die von vielen Frauen in der Menopause beklagten klimakterisch bedingten Hitzewallungen lassen sich durch Isoflavone reduzieren (Taku et al. 2012). Verschiedene Publikation deuten darauf hin, dass durch Genistein Körpergewicht und -fett reduziert werden können (GoodmanGruen und Kritz-Silverstein 2003, Naaz et al. 2003, Yamori 2004, Kim et al. 2006).

Untersuchungen von Genistein im Hinblick auf klinisch relevante Wirkungen auf die Schilddrüsenfunktion haben in der Vergangenheit zu unterschiedlichen Ergebnissen geführt. Bei euthyreoter Stoffwechsellage und ausreichender Jodversorgung scheint Genistein keine Auswirkung auf die Schilddrüsenfunktion zu haben. Weitere Untersuchungen insbesondere bei Frauen und Kindern sind notwendig, um die Sicherheit von Genistein auf die Schilddrüsenfunktion bewerten zu können (Marini et al. 2012).

In den folgenden beiden Abschnitten soll nun ausführlicher auf die Wirkung von Genistein an Knochen und Herz eingegangen werden.

\subsection{Wirkung von Genistein am Knochen}

Es gibt zahlreiche Untersuchungen, die vielversprechende Ergebnisse von Phytoöstrogenen wie Genistein im Hinblick auf einen Einsatz in der Osteoporoseprävention und -therapie liefern (Fanti et al. 1998, Heim et al. 2004). In Zellkulturen hemmt Genistein das Wachstum von Osteoklasten und stimuliert das Wachstum von Osteoblasten (Yamagishi et al. 2001, Rickard et al. 2003, Hertrampf et al. 2006). In randomisierten klinischen Studien konnte durch ein- oder zweijährige Gabe von täglich 54 mg Genistein eine Abnahme des Knochenverlustes und eine Zunahme der Knochenneubildung bei postmenopausalen Frauen gemessen werden (Morabito et al. 2002, Marini et al. 2007). Genistein war in der Effektivität, verglichen mit einer 
konventionellen Hormonersatztherapie, gleichwertig, ohne eine östrogene Wirkung an Gebärmutter oder Brustdrüse zu erzeugen (Morabito et al. 2002).

Im Gegensatz dazu konnte in anderen, ebenfalls randomisierten klinischen Studien mit postmenopausalen Frauen bei Einnahme von Isoflavonen, die auch Genistein einschlossen, kein positiver Effekt auf die Knochendichte gemessen werden. (Alekel et al. 2010; Levis et al. 2013; W. W. Wong et al. 2009). Gründe für die Diskrepanz der Ergebnisse können Unterschiede in der Zusammensetzung der Soja-Supplementierung, der Dosierung, der Art der Intervention und der Dauer sein. Die aktuelle Studienlage motiviert die weitere Erforschung von Genistein in der Osteoporosetherapie.

\subsection{Kardiovaskuläre Wirkung von Genistein}

Neben den klassischen hormonabhängigen Zielorganen von Phytoöstrogenen wie Brustdrüse, Gebärmutter und Knochen ist auch das Herz ein bedeutendes Zielorgan von Genistein. In vielen Publikationen ließ sich eine Auswirkungen von Genistein auf kardiovaskuläre Erkrankungen nachweisen (Lissin und Cooke 2000, Carlson et al. 2008, Gencel et al. 2013). Es konnte gezeigt werden, dass Genistein unabhängig vom Östrogenrezeptor die myokardiale Kontraktilität stimuliert ( $\mathrm{Li}$ et al. 2008). Genistein wirkt an verschiedenen Stellen des intrazellulären Kalziumstoffwechsels im Herzmuskel. Es hemmt die L-Typ-Kalzium-Stromspitze und wirkt sich auf die kontraktile Funktion von ventrikulären Myozyten aus (Liew et al. 2003). Genistein moduliert Tyrosinkinase-gesteuert die spannungsabhängigen Kaliumkanäle in ventrikulären Myozyten von Ratten (Gao et al. 2004). Darüber hinaus kann Genistein die durch Glukosetoxizität verursachte kardiale Dysfunktion am Herzen reduzieren und besitzt somit therapeutisches Potential gegen Diabetes-assoziierte Herzerkrankungen (Hintz und Ren 2004). Zudem konnte in vorangegangenen Untersuchungen der Arbeitsgruppe gezeigt werden, dass Genistein bei gesunden, ovarektomierten Tieren die Zellgröße der Kardiomyozyten und die kardiale Genexpression beeinflussen kann (Nguyen et al. 2012b). Diese direkte Wirkung am Herzen wird vermutlich ähnlich wie bei E2 über Östrogenrezeptoren vermittelt.

Neben der Wirkung am Herzen sind auch Wirkungen von Genistein auf das Gefäßsystem beschrieben. Es ist sehr gut untersucht, dass Isoflavone wie Genistein die LDL-Cholesterinkonzentration um bis zu 10 \% senken (bei Personen mit hohen LDL-Ausgangswerten sogar noch stärker) und ein leichter Anstieg der HDL-Cholesterinkonzentration erreicht wird (Clarkson 2002). Für Genistein ist zudem bekannt, dass es einen Schlüsselmechanismus der Plaquebildung, die Blutgerinnung, hemmt. Dieser Effekt ist möglicherweise mit der Hemmung 
von Wachstumsfaktoren wie PDGF (platelet-derived growth factor) verbunden und daraus folgenden Auswirkungen auf die Thrombinbildung (Sargeant et al. 1993, Wilcox und Blumenthali 1995). Im Rahmen klinischer Studien am Gefäßsystem bei Frauen und Männern konnte gezeigt werden, dass Genistein NO-abhängig und Endothel-abhängig eine Vasodilatation in ähnlicher Weise wie Estradiol erzeugt. Diese Ergebnisse könnten die Basis für neue Ansätze in der Bluthochdrucktherapie und der primären und sekundären Prävention von Arteriosklerose sein (Walker et al. 2001, Squadrito et al. 2003).

\subsection{Das Mausmodell}

Für die durchgeführten Experimente wurde das Modell der langzeitovarektomierten Maus gewählt (Nguyen et al. 2012b). Zur Charakterisierung östrogener Effekte von einer Testsubstanz auf den Körper ist bei In-Vitro-Versuchen keine ausreichende Aussage über Aufnahme, Verteilung, Metabolisierung und Ausscheidung möglich. Das Modell des immaturen oder ovarektomierten Tieres hat sich daher für diese Anwendung etabliert.

Ein vielfach verwendetes und von der Organisation für wirtschaftliche Zusammenarbeit und Entwicklung (OECD) validiertes Verfahren zur Erforschung östrogener Wirkungen ist das Protokoll des uterotrophen Assays (Kanno et al. 2003). Hierbei erhalten die immaturen oder ovarektomierten Tiere, meist Ratten, die applizierte Testsubstanz für drei Tage. Zu berücksichtigen ist hier, dass die Zykluslänge der weiblichen Ratte durchschnittlich vier Tage beträgt. Eine Östrogenersatztherapie bei postmenopausalen Frauen sollte in der Regel über einen erheblich längeren Zeitraum als eine Zykluslänge eingenommen werden. Die Ergebnisse aus Kurzzeitversuchen nach dem OECD-Protokoll sind daher besonders in Bezug auf Langzeitwirkungen und -nebenwirkungen, insbesondere auch auf andere Organe als die Gebärmutter, von begrenzter Aussagefähigkeit (Owens und Ashby 2002, Nguyen et al. 2012a).

In den vergangenen Jahren hat die Arbeit mit Knock-out-Tieren enorm an Bedeutung gewonnen.

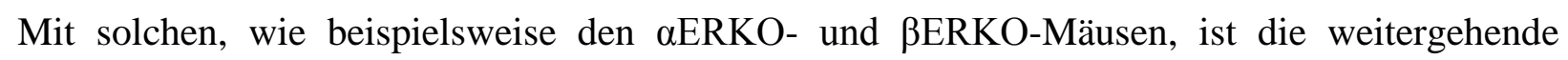
Erforschung östrogener Effekte von Testsubstanzen möglich geworden. Da die Herstellung von Knock-out-Ratten schwierig ist, werden meist Mäuse verwendet. Ergebnisse aus früheren Untersuchungen am Modell der Ratte sind nicht direkt mit dem der Knock-out-Maus komparabel. Zur besseren Vergleichbarkeit mit Knock-out-Mäusen ist es folglich wichtig, auch Untersuchungen an Mäusen ohne genetische Manipulation wie in dieser Arbeit durchzuführen. In einer vorherigen Studie der Arbeitsgruppe konnte das Modell der ovarektomierten Maus über drei Monate erstmals etabliert werden. Es konnte gezeigt werden, dass das Mausmodell dem 
Modell der ovarektomierten Ratte nach dem Protokoll der OECD zur Erforschung von Hormonersatztherapien bei postmenopausalen Frauen gleichwertig ist (Nguyen et al. 2012b).

Unter Berücksichtigung der oben genannten Anmerkungen wurden die in dieser Arbeit verwendeten Testsubstanzen über einen Zeitraum von drei Monaten verabreicht. Hiermit sollte die Verwendung am Menschen im Hinblick auf östrogene Langzeiteffekte simuliert werden.

\subsection{Ziel dieser Arbeit}

Bisher sind nur wenige Daten über den langfristigen Einsatz und eine sichere und wirksame Dosis von Genistein am Menschen vorhanden. In vorherigen Untersuchungen der Arbeitsgruppe am Modell der langzeitovarektomierten Maus konnte gezeigt werden, dass Genistein in einer Dosis von $1 \mathrm{~g} / \mathrm{kg}$ als Futterzusatz einen osteoprotektiven Effekt am Knochen hat. Darüber hinaus konnte in dieser Dosierung eine direkte Wirkung von Genistein am Herzen gemessen werden, die jedoch nicht signifikant ausfiel und nicht vergleichbar war mit einer in derselben Studie beobachteten direkten In-Vivo-Wirkung von Östrogen am Herzen (Nguyen et al. 2012b). Basierend auf diesen Vorgängerexperimenten soll daher im Rahmen der vorliegenden Arbeit die Wirkung von Genistein am Modell der langzeitovarektomierten Maus auf ausgewählte östrogenselektive Organe genauer untersucht werden. Insbesondere soll die Wirkung auf Körpergewicht, Knochenparameter und Organentwicklung des Uterus genauer als bisher untersucht werden und geprüft werden, ob eine Dosisabhängigkeit besteht. Darüber hinaus sollen auch die Wirkung von Genistein am nicht zu den klassischen Östrogenzielorganen gehörenden Herzen und die Genexpression am Herzen betrachtet werden.

Die Untersuchung soll, analog zu einer HET am Menschen, im Mausmodell über einen langfristigen Zeitraum von drei Monaten erfolgen. Es wurden Mäuse anstatt Ratten als Versuchstiere verwendet, um im Hinblick auf mögliche nachfolgende Untersuchungen an Knockout-Mäusen eine bessere Vergleichbarkeit zu gewährleisten. Der Dosisbereich wird anhand von Vorgängerexperimenten, bei denen eine Wirkung von Genistein beobachtet wurde, ausgewählt und in beide Richtungen erweitert, um eine große Spannbreite abzudecken. Zur Bestimmung der Dosisabhängigkeit werden die Versuchstiere in Gruppen eingeteilt, die mit unterschiedlich hohen Genisteinkonzentrationen versetztes Futter erhalten. Eine weitere Gruppe erhält Futter mit Estradiolzusatz. Durch den Vergleich mit dieser Gruppe sowie einer nicht ovarektomierten Kontrollgruppe und einer ovarektomierten Kontrollgruppe, die jeweils sojafreies Futter erhalten, können eine mögliche östrogene Wirkung von Genistein sowie ein Potential für den Einsatz von Genistein in der HET bestimmt werden. 


\section{Material und Methoden}

\subsection{Material}

\subsubsection{Versuchstiere und Haltungsbedingungen}

Als Versuchstiere wurden 80 weibliche Wildtyp-Mäuse (C57 BL/6J) verwendet, die von der Firma Winkelmann GmbH, Borchen bezogen wurden.

$\mathrm{Zu}$ Beginn des Experiments waren die Tiere zwei Monate alt und wogen im Durchschnitt 17,2 g. Sie wurden unter standardisierten Bedingungen gehalten: Gruppen von je fünf Mäusen lebten in einem Käfig (Makrolon® ${ }^{\circledR}$ Typ IV) bei einer durchschnittlichen Raumtemperatur von $23 \pm 1^{\circ} \mathrm{C}$ und einer durchschnittlichen Luftfeuchtigkeit von 50-55\%. Der Haltungsraum wurde täglich von 06:00 bis 18:00 Uhr (12 h Tag-Nacht-Zyklus) mit maximal 500 Lux beleuchtet. Den Tieren standen ohne Einschränkungen Leitungswasser und Futter zur freien Verfügung. Bis zu Beginn des Versuchs erhielten die Tiere sojafreies Pelletfutter der Firma Ssniff, Soest.

Für die Tierexperimente lag eine Genehmigung der Bezirksregierung Braunschweig mit dem Aktenzeichen 33.9.42502-04-071/09 vor.

\subsubsection{Ovarektomie und Implantation eines Identifikationsgeräts}

Vor Beginn des Versuchs wurden 70 der 80 Tiere beidseitig ovarektomiert. Die Eingriff erfolgte in Narkose durch kurze $\mathrm{CO}_{2}$-Inhalation und anschließende intraperitoneale Injektion von Ketamin (Hostaket ${ }^{\circledR}$, Hoechst, Dosierung: 62,5 mg/kgKG) und Xylazin (Rompun ${ }^{\circledR}$, Bayer, Dosierung: 7,5 mg/kgKG).

Der Bereich kaudal des Rippenbogens wurde rasiert und desinfiziert. Mit einem etwa $1 \mathrm{~cm}$ großen Schnitt im Bereich des vorbereiteten Operationsgebietes erfolgte die Eröffnung der Bauchhöhle und Freilegung der Ovarien mittels Pinzette. Nach Ligation zwischen Uterushorn und Ovidukt mit resorbierbarem Nahtmaterial (3 -0Vicryl ${ }^{\circledR}$, Ethicon Norderstedt, Germany) wurden das Ovar mittels Skalpell entfernt und die vorgelagerten Uterusanteile wieder in die Bauchhöhle reponiert. Es folgte der einschichtige Verschluss der Muskulatur mittels eines einfachen Knopfheftes unter Verwendung des oben genannten Catguts. Die Subcutis und Cutis wurden mit Einzelheften eines nicht-resorbierbaren Nahtmaterials (Supramid®, Braun) 
verschlossen. Dieselbe Prozedur wurde auf der gegenüberliegenden Körperseite zur Entfernung des zweiten Ovars durchgeführt.

Anschließend erfolgte bei jedem Tier die Implantation eines Transponder-Systems unter die Nackenhaut zur eindeutigen Identifizierung. Mit einem tragbaren Transponder-Lesegerät (Gesreader II, ISO kompatibler Taschenleser) konnte der jeweilige Zahlencode des Transponders abgelesen werden und jedes Tier eindeutig identifiziert werden.

Postoperativ erhielten die Tiere zur Vermeidung einer Dehydration je $1 \mathrm{ml}$ isotone Kochsalzlösung (Braun) subkutan. Als Schmerzprophylaxe wurde postoperativ einmalig Rimadyl (Dosierung: 5 mg/kg) subkutan appliziert. Die Tiere wurden bis zum vollständigen Erwachen beaufsichtigt.

\subsubsection{Tierfutter}

Mit Beginn des Versuchs wurde dem zuvor sojafreien Pelletfutter das untersuchte Phytohormon Genistein in verschiedenen Dosierungen hinzugefügt. Die Tiere der Positivkontrolle erhielten sojafreies Futter mit Estradiol, die Negativkontrollgruppe sojafreies Futter ohne Zusätze. Eine weitere nicht ovarektomierte, intakte Kontrollgruppe erhielt ebenfalls sojafreies Futter ohne Zusätze. Bei dem verwendeten Tierfutter handelt es sich um eine spezielle Anfertigung der Firma Ssniff, Soest.

\subsubsection{Versuchsablauf}

Für das Experiment wurden die 70 ovarektomierten Tiere in sieben Gruppen mit je zehn Tieren aufgeteilt. Fünf der sieben Gruppen erhielten genisteinhaltiges Futter in verschiedenen Konzentrationen, die anderen beiden Gruppen erhielten Estradiol als Zusatz oder sojafreie Diät. Die zehn nicht ovarektomierten Tiere bildeten die intakte Kontrollgruppe, die ebenfalls sojafreies Futter erhielt.

Die nachfolgende Tabelle gibt einen Überblick über die jeweiligen Behandlungsgruppen und die Konzentrationen der verabreichten Testsubstanzen. Die Abkürzungen der jeweiligen Gruppennamen werden im weiteren Verlauf dieser Arbeit Verwendung finden. 
Tabelle 1: Übersicht der Behandlungsgruppen mit Konzentration der verabreichten Testsubstanzen und den jeweils verwendeten Abkürzungen

\begin{tabular}{|c|l|l|}
\hline Gruppe & Beschreibung & Abkürzung \\
\hline 1 & Ovarektomiert, sojafreies Futter & Kontrolle \\
\hline 2 & Intakt, sojafreies Futter & Intakt \\
\hline 3 & Ovarektomiert, estradiolhaltiges Futter $(4,32 \mathrm{mg} / \mathrm{kg})$ & E2 \\
\hline 4 & Ovarektomiert, genisteinhaltiges Futter $(10 \mathrm{~g} / \mathrm{kg})$ & Gen $10 \mathrm{~g}$ \\
\hline 5 & Ovarektomiert, genisteinhaltiges Futter $(3 \mathrm{~g} / \mathrm{kg})$ & Gen $3 \mathrm{~g}$ \\
\hline 6 & Ovarektomiert, genisteinhaltiges Futter $(1 \mathrm{~g} / \mathrm{kg})$ & Gen $1 \mathrm{~g}$ \\
\hline 7 & Ovarektomiert, genisteinhaltiges Futter $(0,3 \mathrm{~g} / \mathrm{kg})$ & Gen $0,3 \mathrm{~g}$ \\
\hline 8 & Ovarektomiert, genisteinhaltiges Futter $(0,1 \mathrm{~g} / \mathrm{kg})$ & Gen $0,1 \mathrm{~g}$ \\
\hline
\end{tabular}

Die Dosierung der verabreichten Testsubstanzen orientiert sich an Erfahrungen aus einer vorherigen Studie, im Rahmen derer ovarektomierte Mäuse für drei Monate sojafreies Futter versetzt mit Genistein in der Dosierung $1 \mathrm{~g} / \mathrm{kg}$ erhielten und östrogene Effekte nachgewiesen werden konnten (Sehmisch et al. 2010, Nguyen et al. 2012b). Die hier gewählten Dosierungen zwischen 0,01 und $10 \mathrm{~g} / \mathrm{kg}$ streuen somit um die Dosierung im Vorgängerexperiment.

Während des gesamten Behandlungszeitsraums wurden die Tiere täglich auf gesundheitliche Schäden untersucht. Keines der Tiere zeigte zu irgendeinem Zeitpunkt Symptome von Toxizität oder Anzeichen für andere körperliche Missstände. Es wurde von einer durchschnittlichen Futteraufnahme von $3 \mathrm{~g}$ pro Tier und Tag ausgegangen. Wöchentlich wurde der Futterverbrauch pro Gruppe ermittelt. 14-tägig erfolgte die Messung des Körpergewichts für jedes einzelne Tier. Die Verabreichung der Testsubstanzen erfolgte für drei Monate. Nach Ende des Versuchs wurden die Tiere unter tiefer $\mathrm{CO}_{2}$-Narkose durch Dekapitation mit einer Guillotine getötet.

\subsubsection{Gewinnung des biologischen Probenmaterials}

Unter tiefer $\mathrm{CO}_{2}$-Narkose wurde von jeder Maus durch retroorbitale Punktion Blut in 1,5 mlRöhrchen gesammelt. Anschließend erfolgten die Entnahme von Uterus und Leber sowie am Herzen die separate Entnahme von linkem und rechtem Ventrikel und Atrium. Die gewonnenen Organe wurden feucht gewogen. Des Weiteren wurde die linke Tibia entnommen und von Muskel- und Sehnenresten befreit. Die entnommenen Organe wurden in 
Eppendorf-Cups in flüssigem Stickstoff tiefgefroren und bis zur weiteren Verarbeitung bei $70{ }^{\circ} \mathrm{C}$ gelagert.

\subsection{Methoden}

\subsubsection{Molekularbiologische Methoden}

Zur Untersuchung der Genexpression von IGF-1, ER $\alpha$ und Myocardin im linken Ventrikel fanden molekularbiologische Methoden Anwendung. Zunächst wurde die Gesamt-RNA des linken Ventrikels unter Verwendung eines RNeasy Total RNA Kit (Qiagen, Hilden) isoliert. Anschließend wurde sie durch M-MLV Reverse Transkriptase (PROMEGA, Mannheim) in cDNA umgeschrieben. Die Genexpression wurde mit quantitativer Echtzeit-PCR gemessen.

\subsubsection{Gewebeaufbereitung und RNA-Isolierung}

Zur Extraktion der Gesamt-RNA wurde das tiefgekühlte Gewebe der linken Ventrikel in $600 \mu \mathrm{l}$ RT-Lysis-Puffer (aus dem RNeasy Kit, Qiagen, Hilden) mit einem Ultra Turrax (TP18/10, Janke \& Kunkel, Staufen) eine halbe Minute zerkleinert. Im Anschluss daran wurde die Suspension in einem Ultraschallbad (Bransonic 32 Sonicator Bath, Branson Instruments, Danbury, CT, USA) für 15 Sekunden homogenisiert. Danach wurde die Suspension in QIAshredder-Säulen (Qiagen, Hilden) pipettiert und für zwei Minuten bei 12.000 rpm zentrifugiert. Das entstandene Filtrat wurde anschließend mit $600 \mu 1$ 70\%-igem Ethanol versetzt und in RNeasy Mini Spin Columns (Qiagen, Hilden) nochmals für 15 Sekunden bei 10.000 rpm zentrifugiert. Die zu extrahierende RNA befand sich danach in der Säulenmembran und der abzentrifugierte Flüssigkeitsrest konnte verworfen werden. Es folgte ein Waschschritt, indem $700 \mu$ RW1-Puffer aus dem RNeasy Mini Kit auf das Säulengefäß gegeben wird und nachfolgend für 15 Sekunden bei 10.000 rpm zentrifugiert wurde.

Die Säule wurde in ein neues Auffangröhrchen (Collection Tubes aus dem RNeasy Mini Kit) überführt, und es wurden bei den beiden sich anschließenden Waschzyklen jeweils $500 \mu 1$ RPE-Puffer aus dem RNeasy Mini Kit auf die Säule pipettiert. Dann wurde zunächst 15 Sekunden bei 10.000 rpm und nachfolgend zwei Minuten bei 12.000 rpm zentrifugiert. Die abgefangene Flüssigkeit wurde jeweils verworfen.

Um die extrahierte RNA aus der Membran der Säule zu eluieren, wurden die Säulen in 1,5 ml Eppendorf-Cups (Sarstedt, Nümbrecht) überführt und mit $50 \mu 1$ RNase-freiem Wasser 
(RNeasy Mini Kit Bestandteil) befüllt und eine Minute lang bei 10.000 rpm zentrifugiert. Um die RNAse-Aktivität möglichst gering zu halten, wurden sämtliche oben beschriebene Arbeitsschritte zügig und auf Eis durchgeführt. Die RNA-Proben wurden mit einem RNase-freie DNase I-Set (Qiagen, Hilden) behandelt, um die Anwesenheit von genomischer DNA zu vermeiden. Die Gesamt-RNA-Konzentration wurde durch Absorptionsmessungen bei $260 \mathrm{~nm}$ und $280 \mathrm{~nm}$ unter Verwendung eines UV-Spektrophotometers (BioPhotometer, Hamburg, Deutschland) bestimmt. Die RNA-Lösung wurde durch Zugabe von VelcorinWasser auf eine Konzentration von $20 \mathrm{ng} / \mu \mathrm{l}$ verdünnt und bis zur weiteren Bearbeitung bei $-70{ }^{\circ} \mathrm{C}$ aufbewahrt.

\subsection{3 cDNA- Synthese}

Die gewonnene RNA wurde mit der Hilfe der RNA-abhängigen DNA-Polymerease Reverse Transkriptase (M-MLV Reverse transcriptase (RT) RNAse H Minus, Point Mutant (Set), Promega, Mannheim) in cDNA umgeschrieben. Zur Anlagerung der Random-Primer an die RNA wurde zunächst folgender Ansatz hergestellt:

$10 \mu \mathrm{l}$ RNA-Lösung (Konzentration: $20 \mathrm{ng} / \mu \mathrm{l})$

$3 \mu \mathrm{l} \quad$ Velcorin-Wasser

$1 \mu \mathrm{l} \quad$ Random Primer (Invitrogen, Karlsruhe; 1:30).

Dieser Ansatz wurde im Thermocycler (Biometra, Göttingen) bei $70{ }^{\circ} \mathrm{C}$ für 10 Minuten inkubiert, um Sekundärstrukturen zu lösen. Danach wurden dem Reaktionsansatz folgende Substanzen zugesetzt:

$4 \mu \mathrm{l} \quad$ M-MLV RT $5 \times$ Reaktionspuffer (Setbestandteil)

$1 \mu \mathrm{l} 10 \mathrm{mM}$ dNTP Mix (Invitrogen, Karlsruhe)

$1 \mu \mathrm{l}$ M-MLV RT

0,1 $\mu$ RNasin (RNasin Ribonucleaseinhibitor, Progema, Mannheim). 
Im Thermocycler wurden folgende Reaktionsschritte durchlaufen:

10 min bei $22{ }^{\circ} \mathrm{C} \quad$ Anlagerung der Primer

50 min bei $42{ }^{\circ} \mathrm{C} \quad$ Synthese der cDNA

10 min bei $95^{\circ} \mathrm{C} \quad$ Inaktivierung von Enzymen und Denaturierung von RNA-cDNAHybriden

Nach kurzem Abkühlen wurden die Proben zentrifugiert und bei $-20^{\circ} \mathrm{C}$ bis zur weiteren Verarbeitung aufbewahrt.

\subsubsection{Real Time Quantitative PCR}

Die Bestimmung von IGF-1 wurde im TaqMan® ${ }^{\circledR}$-PCR Assay (Applied Biosysytem, Darmstadt) durchgeführt. Hier wird der Fluoreszenz-Resonanzenergietransfer (fluorescence resonance energy transfer, FRET) mit Hilfe von Sonden ausgenutzt. Ein Donor-Fluorchrom (Reporter), das durch eine Lichtquelle angeregt wird, gibt ein Teil seiner Energie während einer bestimmten Phase der PCR an einen in der Nähe befindlichem Akzeptor Fluorchrom (dark quencher) ab. Diese Methode ist sehr sensitiv.

Die Analysen von ER $\alpha$ und Myocardin wurden mit dem iCycler ${ }^{\circledR}$ (BioRad iCycler, Hercules, CA, USA) vorgenommen. Dies ist eine einfache Methode zur Quantifizierung von PCRProdukten, bei der DNA-Farbstoff (SYBR Green) mit der DNA interkaliert und zur Fluoreszenz angeregt wird. Die Zunahme der DNA korreliert direkt mit der Zunahme der Fluoreszenz.

Die bei beiden Methoden jeweils verwendeten Materialen und Arbeitsabläufe sollen hier kurz erläutert werden. 


\subsubsection{TaqMan ${ }^{\circledR}-$ PCR}

Vorab wurde ein zweifach-TaqMan ${ }^{\circledR P C R}$ Pastermix angesetzt. Dieser bestand aus folgenden Inhaltsstoffen der Firma Eurogentec, Köln:

$2,5 \mu \mathrm{l} \quad 10 \times$ Reaktionspuffer

$1,75 \mu \mathrm{l} \quad 50 \mathrm{nM} \mathrm{MgCl} 2$

$1 \mu \mathrm{l} \quad$ 5,0 mM dNTP-Mix

$0,125 \mu \mathrm{l} \quad$ PCR-Enzym

0,25 $\mu 1 \quad$ UNG (Uracil DNA N-Glykosylase)

6,875 $\mu \mathrm{l} \quad$ Ampuwa $\mathrm{H}_{2} \mathrm{O}$ (Aqua ad iniectabilia, Braun, Melsungen).

Alle Reagenzien wurden in eine Mikrotiterplatte mit 96 Vertiefungen (MicroAmp ${ }^{\circledR}$ Optical 96-Well Reaction Plate, PE Applied Biosystems, Weiterstadt) pipettiert und jede Vertiefung mit optischen Deckeln (MicroAmp Optical Caps, PE Applied Biosystems, Weiterstadt) verschlossen. Jeder Ansatz beinhaltete eine Standardkurve mit einer cDNA aus sechs bis acht Punkten in Doppelbestimmung sowie Negativkontrollen ohne cDNA, um eventuelle Kontaminationen zu erkennen. Die Erstellung der Standardkurve erfolgte mit 1:10 Verdünnungsschritten.

Der Reaktionsansatz pro Vertiefung enthielt $25 \mu 1$ mit folgender Zusammensetzung:

$2 \mu \mathrm{l} \quad \mathrm{cDNA}$

12,5 $\mu \mathrm{l} \quad 2 \times$ Taqman-PCR-Mastermix

$0,5 \mu 1 \quad$ Sonde (entsprechend $225 \mu \mathrm{M}$ )

$0,75 \mu \mathrm{l} \quad$ Sense Primer $(300 \mu \mathrm{M})$

$0,75 \mu 1 \quad$ Antisense Primer $(300 \mu \mathrm{M})$

8,5 $\quad$ Ampuwa $\mathrm{H}_{2} \mathrm{O}$.

Die real-time PCR fand im ABI PRISM 7700 Sequence Detection System (PE Applied Biosystems GmbH, Darmstadt) statt und wurde durch den eingebauten Thermocycler gestartet. Hierzu durchliefen die Proben zunächst die Temperaturzyklen 1 und 2 und anschließend 40 Mal die Temperaturzyklen 3 und 4: 
Zyklus 1: 2 min bei $50{ }^{\circ} \mathrm{C}$

Zyklus 2: 10 min bei $95{ }^{\circ} \mathrm{C}$

Zyklus 3: 15 s bei $95{ }^{\circ} \mathrm{C}$

Zyklus 4: $1 \mathrm{~min}$ bei $60^{\circ} \mathrm{C}$
Schutz vor Carryover-Kontaminationen durch UNG Inaktivierung von UNG, Aktivierung des PCR-Enzyms. Denaturierung von Doppelstrang-DNA in Einzelstränge Hybridisierung mit Primern, Extension (Entstehung des Reporter-Signals).

Mit Hilfe eines Argon-Lasers (488 nm), dessen Lichtstrahl über ein optisches System in die Vertiefung der Mikrotiterplatte weitergeleitet wurde, erfolgte die Fluoreszenzanregung. Die entstandene Fluoreszenzemission $(518 \mathrm{~nm})$ wurde mit einem Spektrographen und einer Kamera aufgezeichnet. Die Steuerung erfolgte computergesteuert.

Mit einer Standardkurve können den Emissionen der untersuchten Proben Werte zugewiesen werden. Diese wurde durch Auftragen der bekannten cDNA-Konzentrationen gegen den dazugehörigen Zyklus ermittelt, ab welchem ein signifikantes Signal messbar war (threshold cycle, Ct).

\subsubsection{2 iCycler ${ }^{\circledR P C R}$}

Zu Beginn wurde ein PCR-Mastermix aus $2 \times$ Supermix (IQ BioRad SYBR Green Supermix, Hercules, CA, USA), den Primern und Ampuwa hergestellt. Jeweils $22 \mu$ dieser Reaktionslösung wurden in eine Vertiefung der Mikrotiterplatte mit 96 Vertiefungen (96 Multiply PCR plate, Sarstedt, Nümbrecht) pipettiert. Anschließend erfolgte der Verschluss mit einer optischen Klebefolie (Adhäsiv Folie, Sarstedt, Nümbrecht). Der Reaktionsansatz hatte folgende Bestandteile:

$2 \mu \mathrm{l} \quad$ cDNA der Probe

$10 \mu 1$ BioRad IQ SYBR Green Supermix $(2 \times)$

$1 \mu \mathrm{l} \quad$ Primer sense

$1 \mu \mathrm{l}$ Primer antisense

$8 \mu \mathrm{l} \quad$ Ampuwa

Die Untersuchung der Proben erfolgte im iCycler IQ Real-Time Detection System (BioRad, Hercules, CA, USA). Die Echtzeit-PCR wurde gestartet, wobei folgende Temperaturzyklen durchlaufen wurden: 


$\begin{array}{ll}10 \text { min bei } 95{ }^{\circ} \mathrm{C} & (1 \text { Zyklus }) \\ 30 \text { s bei } 95^{\circ} \mathrm{C} & (60 \text { Zyklen }) \\ 1 \text { min bei } 60{ }^{\circ} \mathrm{C} & (1 \text { Zyklus }) \\ 15 \text { s bei } 55^{\circ} \mathrm{C} & (80 \text { Zyklen })\end{array}$

Es wurde eine Analyse der Schmelzkurve durchgeführt, um die Spezifität der PCR (Stettner et al. 2007) zu belegen. Eine Verdünnungsreihe aus einem cDNA-Pool der Proben wurde als Standardkurve verwendet. Zusätzlich erhielt jeder Probenansatz eine Negativkontrolle ohne cDNA. Die Auswertung der Ergebnisse erfolgte über die iCycler Optical System Software (BioRad, Hercules, CA, USA).

\subsubsection{Primer und Sonden}

Für die jeweiligen Gene wurden folgende Primer und Sonden verwendet:

IGF-1: Eurogentec (Seraing, Belgium)

Sense Primer: 5'-CTTCAACAAGCCCACAGGCTA-3'

Antisense Primer: 5'-GCTCCGGAAGCAACACTCAT-3'

Sonde: 5’-CTCCAGCATTCGGAGGGCACCTC-3’

$\mathrm{ER} \alpha:$

Primer: Mm_Esr1_2_SG, QuantiTect Primer Assay (Qiagen, Hilden)

Sonde: SYBR Green (Applied Biosystems, Foster City)

Myocardin:

Primer: Mm_Myocd_1_SG, QuantiTect Primer Assay (Qiagen, Hilden)

Sonde: SYBR Green (Applied Biosystems, Foster City)

\subsubsection{Quantitative Computertomographie}

Die Knochenparameter wurden mit Hilfe eines quantitativen peripheren Computertomographen (qPCT), dem XCT Research Bone Scanner (Stratec Medizintechnik GmbH, Pforzheim), erhoben. Das Gerät ist in Abbildung 2 zu sehen. Es ist speziell für Messungen bei Kleintieren entwickelt worden (Helterbrand et al. 1997). qCT ist eine sensitive, reproduzierbare und nicht-invasive Methode zur Überwachung von Veränderungen der Knochenmasse, Knochendichte und anderer geometrischen Knochenparameter (Gasser 1995). Die Messung wurde an den bei der Sektion der Versuchstiere entnommenen und 
präparierten Tibiae (siehe Abbildung 3) durchgeführt. Um Artefakte während des Messvorgangs zu vermeiden, wurden die Tibiae in einer eigens hierfür vorgesehenen Kunststoffhalterung fixiert. Das Messprinzip soll hier kurz erläutert werden, eine ausführliche Beschreibung findet sich im Handbuch des XCT Research Bone Scanners.

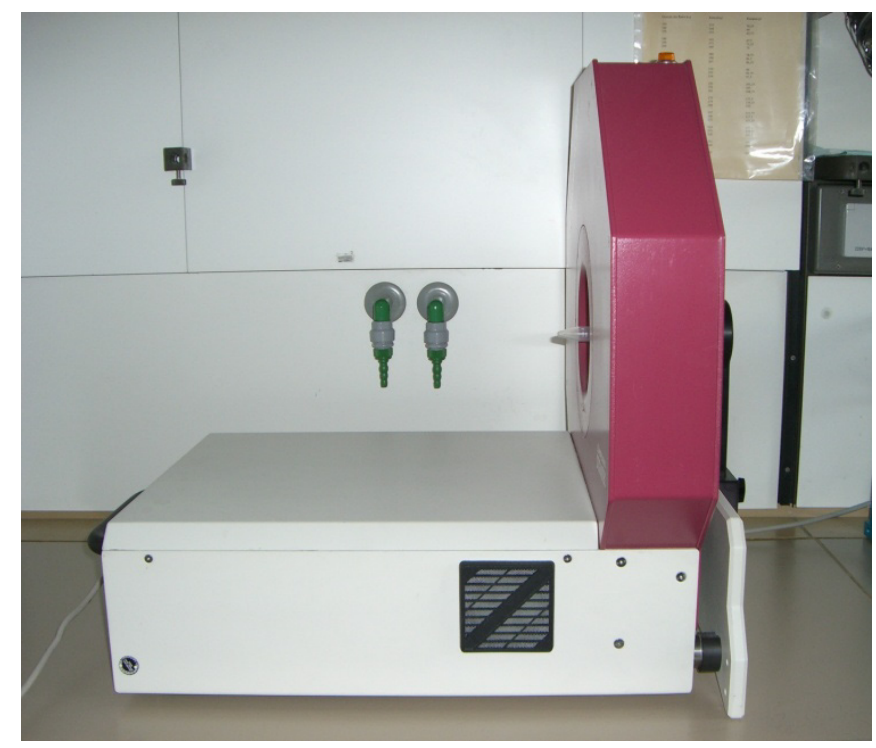

Abbildung 2: XCT Research Bone Scanner

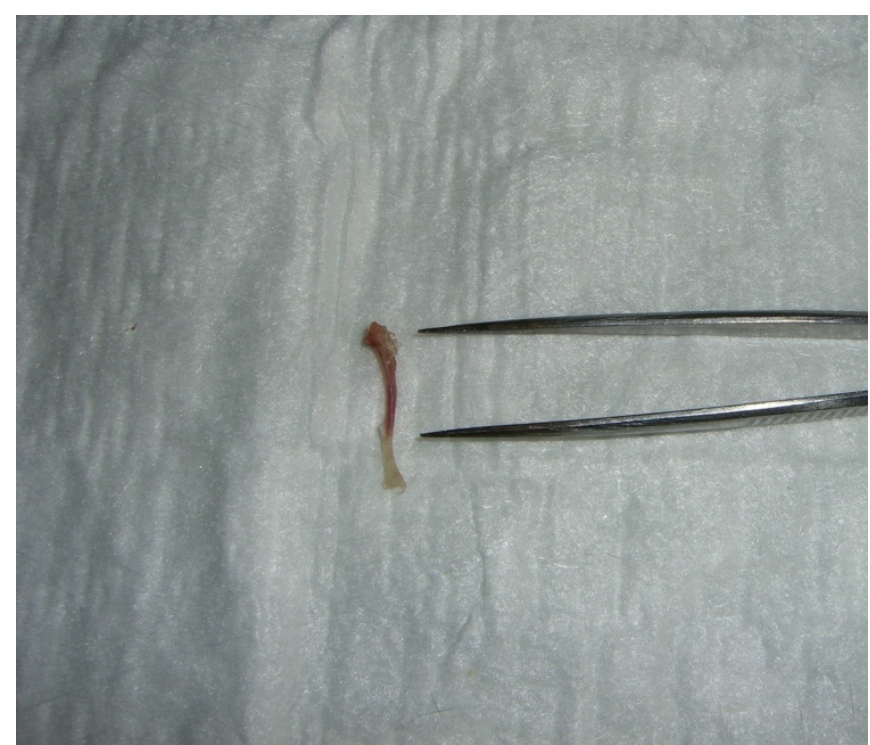

Abbildung 3: präparierte Tibia

Die Messung beruht auf der Absorption von Photonen durch das zu messende Objekt. Durch mathematische Verknüpfung möglichst vieler Absorptionsprofile aus verschiedenen Winkeln wird ein Querschnittsbild berechnet. Zunächst fertigt das Gerät auf Höhe der Metaphyse einen 
Übersichtsscan (SV-Scan) an, der den Messbereich grob festlegt. Der Messbereich wird durch die Position einer Referenzlinie genauer definiert. Die Positionierung der Referenzlinie in der proximalen Tibiametaphyse erfolgt auf Vorschlag der Software, kann jedoch gegebenenfalls manuell verändert werden. In Abbildung 4 ist ein Ausschnitt aus dem Übersichtsscan exemplarisch dargestellt.

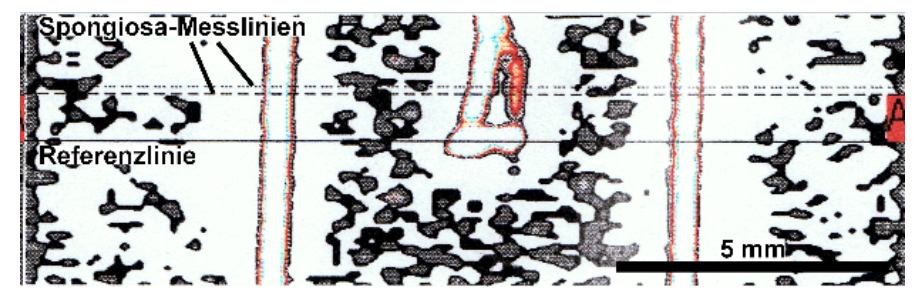

Abbildung 4: Ausschnitt aus einem Übersichtsscan mit eingezeichneten Spongiosa-Messlinien

Nachfolgend wurden zwei Messungen in der Spongiosa (siehe Abbildung 5 und Abbildung 6) mit 1,75 mm und 2 mm Abstand von der Referenzlinie und eine Messung in der diaphysären Kortikalis (siehe Abbildung 7) mit 7,5 mm Abstand von der Referenzlinie durchgeführt. Zur weiteren Auswertung der Daten wurden die Messungen auf einem Computer gespeichert und die Querschnittsbilder durch ein vollautomatisiertes Programm berechnet.

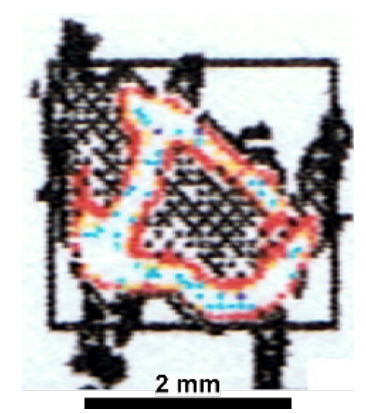

Abbildung 5: Querschnittsbild 1, erste Messlinie auf Höhe Spongiosa 


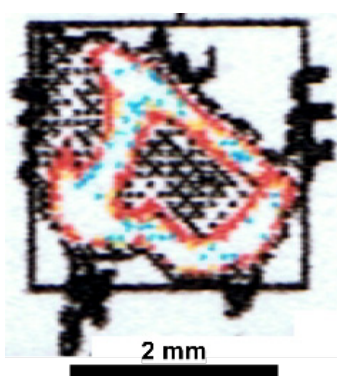

Abbildung 6: Querschnittsbild 2, zweite Messlinie auf Höhe Spongiosa

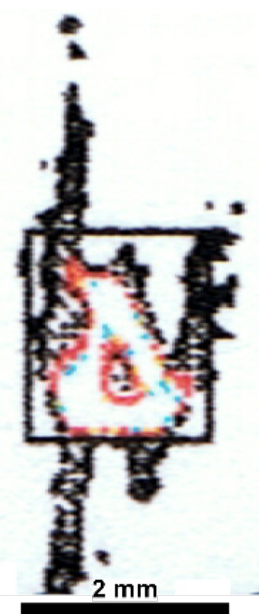

Abbildung 7: Querschnittsbild 3, Messlinie auf Höhe Kortikalis

Es entsteht ein farblich codiertes Rasterbild, das in einem ersten Schritt zwischen hellen Knochenanteilen und dunkel dargestellten Weichteilen differenziert, wobei als Grenzwert eine Knochendichte von $280 \mathrm{mg} / \mathrm{cm}^{3}$ festgelegt ist. In einem zweiten Schritt wird der Knochen in Spongiosa und Kortikalis unterteilt, der Grenzwert beträgt hier $400 \mathrm{mg} / \mathrm{cm}^{3}$. Zusätzlich lassen sich durch die ermittelten Daten weitere Parameter von Knochen und umliegendem Gewebe berechnen. 


\subsection{Statistische Auswertung}

Die statistische Auswertung wurde mit Hilfe des Softwareprogramms GraphPad Prism 5® (San Diego, CA, USA) durchgeführt. Anwendung fand die einfache Varianzanalyse für wiederholte Messungen eines Faktors (ANOVA) mit anschließendem multiplem T-Test nach Dunett. Als Vergleichsgruppe wurde die ovarektomierte Kontrollgruppe gewählt und in Relation zu den Ergebnissen der anderen Behandlungsgruppen gesetzt. Das Signifikanzniveau wurde in dieser Arbeit auf $\mathrm{p}<0,05$ festgelegt.

Für jede Gruppe wurden der Mittelwert und Standardfehler des Mittelwertes (SEM) ermittelt und graphisch in Form von Säulendiagrammen dargestellt. Signifikante Ergebnisse sind in den Graphen mit den Symbolen * oder über der entsprechenden Säule gekennzeichnet. 


\section{Ergebnisse}

In diesem Kapitel sind die Ergebnisse von Körpergewicht, Futterverbrauch, Organentwicklung, Genexpression und Knochen dargestellt. Zur besseren Übersicht werden für die einzelnen Gruppen die Abkürzungen aus Kapitel 2 verwendet. Bei den Abbildungen wurde für jede Gruppe jeweils eine bestimmte Farbe verwendet.

\subsection{Körpergewichte}

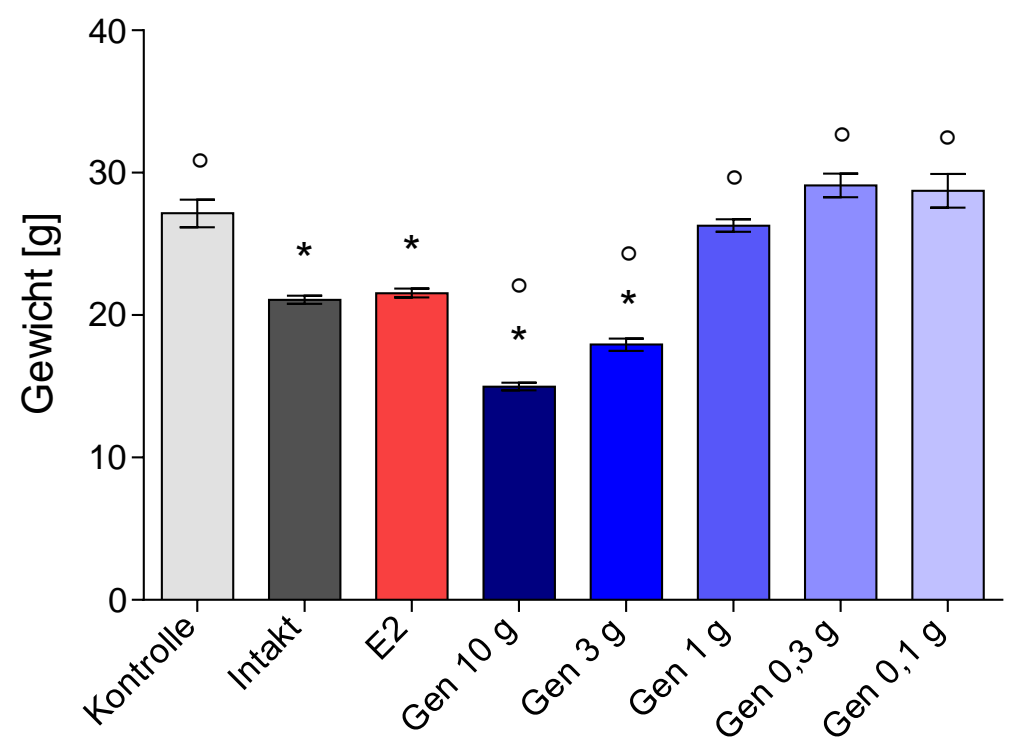

Abbildung 8: Körpergewicht der verschiedenen Behandlungsgruppen bei Obduktion, Mittelwerte +/- SEM, * $\mathrm{p}<0,05$ versus Kontrolle, ${ }^{\circ} \mathrm{p}<0,05$ versus E2, $\mathrm{n}=10$ pro Gruppe

In Abbildung 8 ist das Körpergewicht der verschieden Behandlungsgruppen bei Obduktion dargestellt. Die Mäuse der Kontrollgruppe wogen bei Obduktion im Durchschnitt 27,15 g. Die Tiere der Gruppen Gen 0,1 $\mathrm{g}$ und Gen 0,3 $\mathrm{g}$ wogen durchschnittlich 28,74 $\mathrm{g}$ und 29,12 g.

Die nicht ovarektomierten Mäuse der Gruppe Intakt wogen im Mittel 21,07 g. Ein ähnliches Endgewicht erreichte die mit Estradiol-haltigem Futter ernährte Gruppe mit durchschnittlich 21,55 g. Beide Gruppen haben ein signifikant geringeres Endgewicht als die Kontrolle.

Auch die Mäuse der Gruppe Gen $3 g$ und Gen $10 \mathrm{~g}$ wogen bei Versuchsende signifikant weniger als die Tiere der Kontrollgruppe. Mit Endgewichten von 17,92 g und 14,98 g wogen sie auch signifikant weniger als die Tiere der Gruppe E2. 
Die Veränderung des Körpergewichts errechnet sich aus dem Gewicht zu Versuchsbeginn, subtrahiert von dem Obduktionsgewicht. Sie verdeutlicht die mittlere Gewichtszunahme über den Versuchszeitraum.

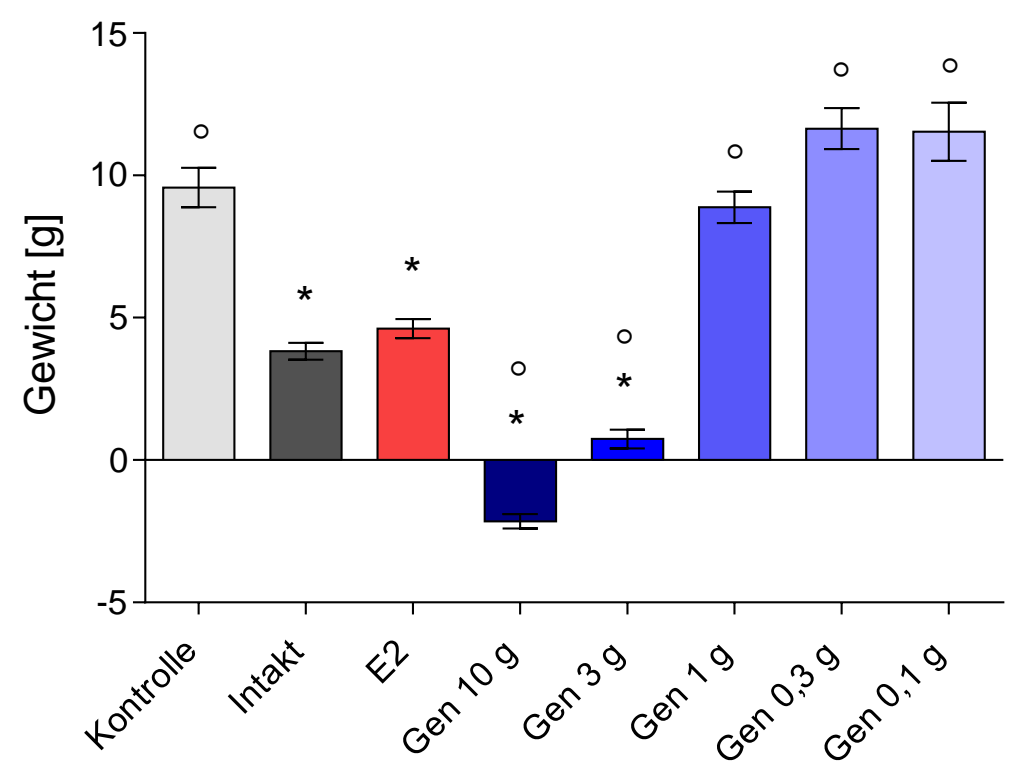

Abbildung 9: Die Körpergewichtsänderung der verschiedenen Behandlungsgruppen über den Versuchszeitraum Mittelwerte $+/$ SEM, $* \mathrm{p}<0,05$ versus Kontrolle, ${ }^{\circ} \mathrm{p}<0,05$ versus E2, $\mathrm{n}=10$ pro Gruppe

Abbildung 9 zeigt, dass die mittlere Gewichtszunahme über den Versuchszeitraum bei den Gruppen Intakt, E2, Gen $10 \mathrm{~g}$ und Gen $3 \mathrm{~g}$ signifikant geringer war als bei der Kontrollgruppe. Zusätzlich ist zu sehen, dass die Gruppe Gen $10 \mathrm{~g}$ bei Versuchsende weniger wog als zu Versuchsbeginn. Die Gruppen Gen $1 \mathrm{~g}$, $0,3 \mathrm{~g}$ und $0,1 \mathrm{~g}$ zeigten keinen signifikanten Unterschied zur Kontrollgruppe. Die Gruppen Gen $10 \mathrm{~g}$ und Gen $3 \mathrm{~g}$ haben über den dreimonatigen Versuchszeitraum eine signifikant niedrigere Körpergewichtsänderung aufgewiesen als die Gruppe E2. Die restlichen Genisteingruppen zeigten eine signifikant höhere Körpergewichts-änderung als die Mäuse der Gruppe E2. 


\subsubsection{Körpergewicht im Verlauf über drei Monate}

In Abbildung 10 ist die Entwicklung des Körpergewichts im Verlauf über drei Monate bei verschiedenen Dosierungen von Genistein im Vergleich zur Kontrollgruppe dargestellt. Die Tiere der Kontrollgruppe sowie Gruppen mit einer Dosierung von bis zu 1 g/kg Genistein im Futter nahmen während des gesamten Versuchszeitraums stetig an Gewicht zu. Tiere, die mit Estradiol-versetztem Futter ernährt wurden, nahmen ähnlich der intakten, nicht ovarektomierten Gruppe langsamer, aber stetig an Gewicht zu. Mäuse der Gruppen Gen $3 g$ und Gen $10 \mathrm{~g}$ nahmen besonders in den ersten beiden Versuchswochen deutlich an Gewicht ab. Im weiteren Versuchsverlauf nahmen sie wieder langsam zu. Die weiter oben beschriebene Gewichtsabnahme der Gruppe Gen $10 \mathrm{~g}$ fand also nicht stetig über den gesamten Versuchszeitraum statt; vielmehr nahmen alle Tiere ab der zweiten Versuchswoche langsam an Gewicht zu. Die Tiere mit einer dem Futter versetzten Dosierung von $3 \mathrm{~g} / \mathrm{kg}$ Genistein erreichten wieder ihr Ausgangsgewicht. Die Tiere der Gruppe Gen $10 \mathrm{~g}$ wogen bei Versuchsende durchschnittlich 2,15 g weniger als zu Versuchsbeginn.

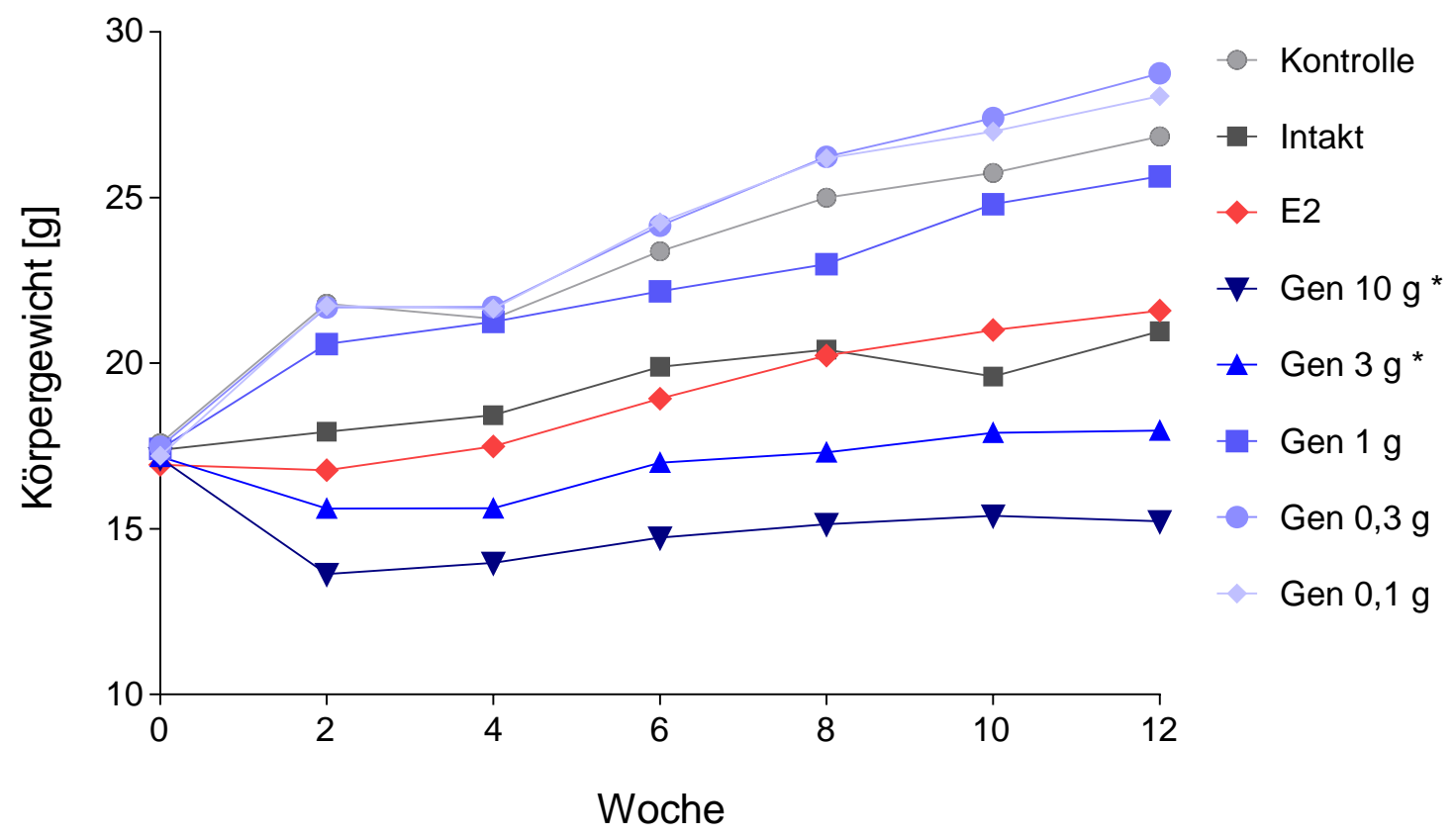

Abbildung 10: Zeitlicher Verlauf des durchschnittlichen Körpergewichts der verschieden Behandlungsgruppen über drei Monate. Mittelwerte, $\mathrm{n}=10$ pro Gruppe, ${ }^{*} \mathrm{p}<0,05$ versus Kontrolle, aus Gründen der Übersichtlichkeit keine Abbildung der SEM 


\subsection{Futterverbrauch}

Abbildung 11 zeigt für die einzelnen Gruppen den Verlauf der Futteraufnahme über den gesamten Versuchszeitraum. Die durchschnittliche Futteraufnahme variierte nach 2 Wochen je nach Gruppe zwischen 2,59 $\mathrm{g}$ und 3,55 g und bei Versuchsende zwischen 1,89 $\mathrm{g}$ und 3,19 g. Die Graphik impliziert bei allen Tiergruppen eine Abnahme der Futteraufnahme über den Versuchszeitraum. Keine Gruppe zeigte ein abweichendes Verhalten.

Im Vergleich zur Kontrollgruppe haben Mäuse, die estradiolhaltiges Futter erhielten, über den gesamten Versuchszeitraum signifikant mehr Nahrung aufgenommen. Tiere der Gruppen Gen $3 \mathrm{~g}$ und Gen $10 \mathrm{~g}$ haben signifikant weniger Futter zu sich genommen als die Kontrollgruppe. Verglichen mit der Gruppe E2 haben alle anderen Tiergruppen signifikant weniger Futter im Verlauf über drei Monate aufgenommen.

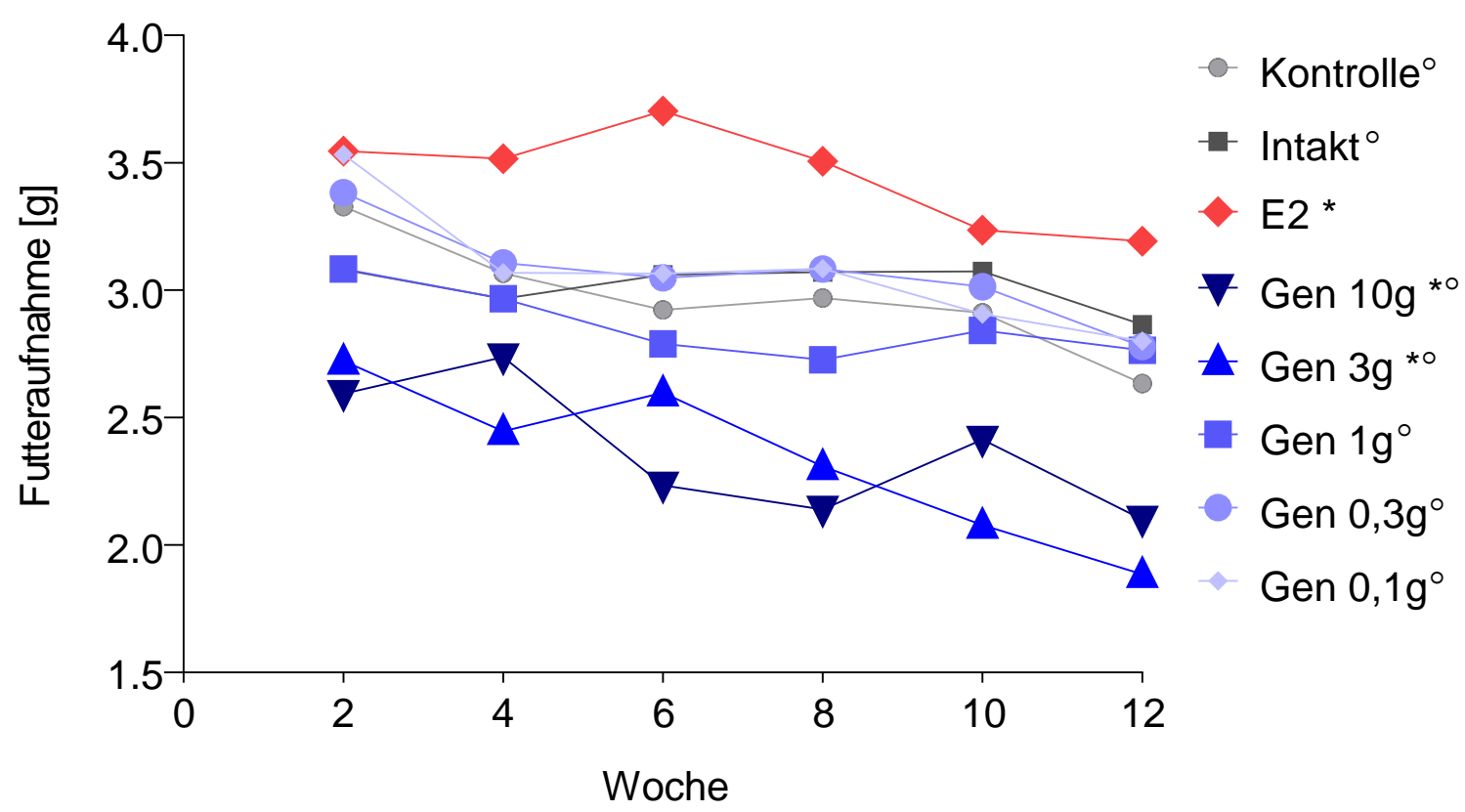

Abbildung 11: Futteraufnahme im Verlauf über drei Monate. Mittelwerte, $\mathrm{n}=10$ /Gruppe, $* \mathrm{p}<0,05$ versus Kontrolle, ${ }^{\circ} \mathrm{p}<0,05$ versus E2, aus Gründen der Übersichtlichkeit keine Abbildung der SEM 
In Tabelle 2 sind die Unterschiede der durchschnittlichen täglichen Futteraufnahme über den gesamten Versuchszeitraum und die hieraus errechnete quantitative Aufnahme von Genistein pro Tier und Tag dargestellt. Tiere, die mit Estradiol-haltiger Nahrung gefüttert wurden, haben mit durchschnittlich 3,45 g pro Tag am meisten Futter aufgenommen. Eine mittlere Nahrungsaufnahme von etwa $3 \mathrm{~g}$ pro Tag lag bei den Gruppen Intakt, Kontrolle, Gen 0,1 g und Gen 0,3 $\mathrm{g}$ vor. Weiter zeigt Tabelle 2, dass die Gruppen Gen $3 \mathrm{~g}$ und Gen $10 \mathrm{~g}$ mit durchschnittlich 2,34 g und 2,37 g pro Tag mit Abstand am wenigsten Futter zu sich genommen haben.

Im Abschnitt 3.1 wurde gezeigt, dass die Gruppen Gen $3 \mathrm{~g}$ und Gen $10 \mathrm{~g}$ über den gesamten Versuchszeitraum das geringste Körpergewicht aufwiesen. Es bleibt zu klären, ob das geringe Körpergewicht nur durch die geringe Futteraufnahme dieser beiden Gruppen verursacht wurde oder ob auch noch andere Mechanismen eine Rolle spielen. Mit der Darstellung von Körpergewichtänderung zu Gesamtfutteraufnahme in Tabelle 2 rechte Spalte und in Abbildung 12 (siehe Seite 38) wird ersichtlich, inwieweit die aufgenommene Futtermenge in eine Gewichtszunahme umgesetzt wurde.

Tabelle 2: Tägliche Futter- und quantitative Genisteinaufnahme pro Tier und Verhältnis von Änderung des Körpergewichts zu Gesamtfutteraufnahme pro Tier

\begin{tabular}{|c|c|c|c|c|}
\hline Gruppe & $\begin{array}{c}\text { Tägliche } \\
\text { Futteraufnahme } \\
\text { pro Tier [g] }\end{array}$ & $\begin{array}{c}\text { Tägliche } \\
\text { Genisteinaufnahme } \\
\text { pro Tier [mg] }\end{array}$ & $\begin{array}{c}\text { Delta } \\
\text { Körpergewicht } \\
\text { [g] }\end{array}$ & $\begin{array}{c}\text { Verhältnis von Delta- } \\
\text { Körpergewicht zu } \\
\text { Gesamtfutteraufnahme } \\
\text { pro Tier [\%] }\end{array}$ \\
\hline Kontrolle & 2,97 & - & 9,57 & 3,52 \\
\hline Intakt & 3,02 & - & 3,82 & 1,38 \\
\hline E2 & 3,45 & - & 4,62 & 1,48 \\
\hline Gen $10 \mathrm{~g}$ & 2,37 & 23,7 & $-2,15$ & $-0,99$ \\
\hline Gen $3 \mathrm{~g}$ & 2,34 & 7,02 & 0,74 & 0,35 \\
\hline Gen $1 \mathrm{~g}$ & 2,86 & 2,86 & 8,88 & 3,36 \\
\hline Gen $0,3 \mathrm{~g}$ & 3,07 & 0,92 & 11,64 & 4,14 \\
\hline Gen $0,1 \mathrm{~g}$ & 3,08 & 0,31 & 11,53 & 4,09 \\
\hline
\end{tabular}




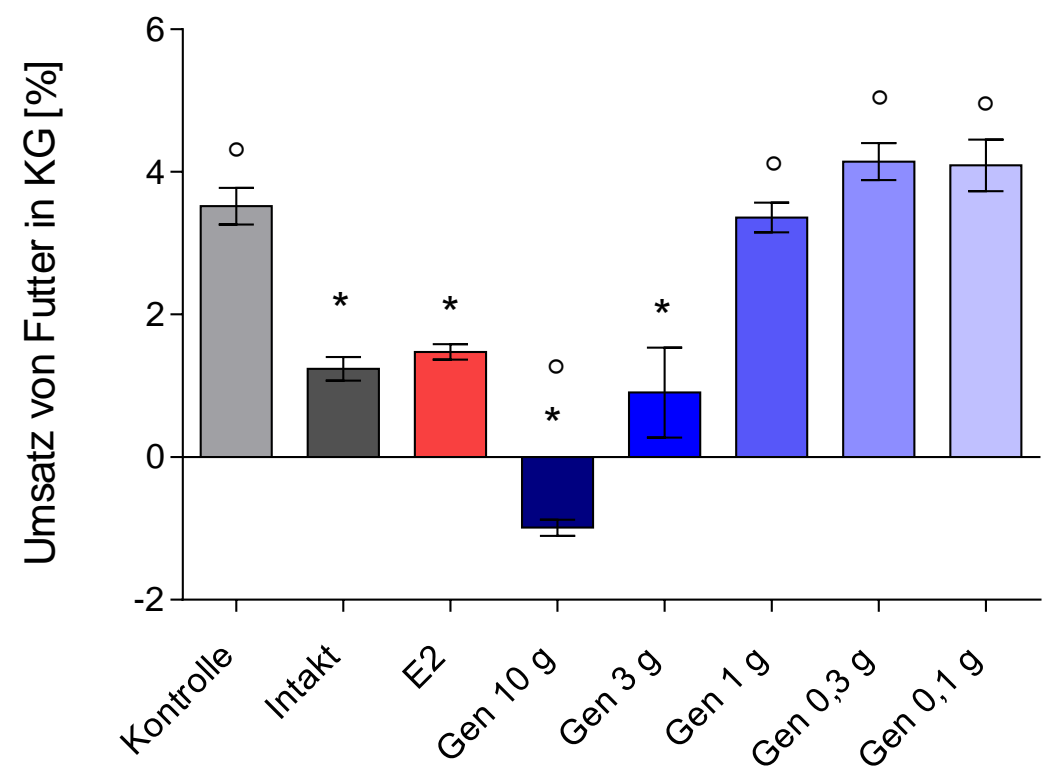

Abbildung 12: Verhältnis von Körpergewichtsänderung zu Gesamtfutteraufnahme Mittelwerte +/- SEM; * $\mathrm{p}<0,05$ versus Kontrolle, ${ }^{\circ} \mathrm{p}<0,05$ versus E2, $\mathrm{n}=10$ pro Gruppe

Die Gruppen Intakt und E2 haben signifikant weniger Futter in Körpergewicht umgesetzt als die ovarektomierte Kontrollgruppe sowie die Gruppen, die eine geringe Genisteindosis erhielten. Die Gruppen mit dem höheren Genisteingehalt von $3 \mathrm{~g} / \mathrm{kg}$ und $10 \mathrm{~g} / \mathrm{kg}$ im Futter zeigten ebenfalls eine im Vergleich zur Kontrollgruppe signifikant verringerte Umsetzung der Futtermenge in Körpergewicht. Bei der Gruppe Gen $10 \mathrm{~g}$ ist der Wert sogar negativ, weil diese Gruppe über den Gesamtzeitraum abgenommen hat. Die Gruppen Gen 1 g, 0,3 $g$ und $0,1 \mathrm{~g}$ zeigten keinen signifikanten Unterschied bei dem Verhältnis von Körpergewichtsänderung zu Gesamtfutteraufnahme verglichen mit der Kontrolle. Tiere der Gruppe Gen $10 \mathrm{~g}$ haben die aufgenommene Futtermenge signifikant schlechter in Körpergewicht umgesetzt als die Gruppe E2. Die Kontrollgruppe und die Gruppen Gen $1 \mathrm{~g}$, $0,3 \mathrm{~g}$ und $0,1 \mathrm{~g}$ zeigten eine signifikant gesteigerte Umsetzung der Futtermenge in Körpergewicht verglichen mit der Gruppe E2. 


\subsection{Organentwicklung}

Abbildung 13 zeigt das relative Uterusgewicht der Versuchstiere bei Obduktion, das heißt das Gewicht des Uterus in Bezug auf das Körpergewicht. Die Tiere der ovarektomierten Kontrollgruppe verfügten im Mittel über ein relatives Uterusgewicht von 0,058 \% bei Obduktion. Bei der Gruppe Intakt war dieser Wert mit 0,514 \% signifikant höher. Die Tiere der Gruppe E2 wiesen ein ähnliches relatives Uterusgewicht auf wie die intakten Tiere. Bei den mit Genistein gefütterten Tieren zeigte sich eine Dosisabhängigkeit: während die Gruppen Gen 0,1 g, 0,3 $\mathrm{g}$ und $1 \mathrm{~g}$ keine signifikante Änderung zur Kontrollgruppe aufwiesen, zeigte sich bei den Gruppen Gen $3 \mathrm{~g}$ und Gen $10 \mathrm{~g}$ eine signifikante Zunahme des relativen Uterusgewichts. Das relative Gewicht der Gebärmutter einer Maus, die Futter mit einem Genisteingehalt von $10 \mathrm{~g} / \mathrm{kg}$ zu sich nahm, ist mit 0,875\% sogar deutlich höher als bei Estradiolgabe, wo das relative Uterusgewicht 0,614 \% beträgt. Verglichen mit der Gruppe E2 war das relative Uterusgewicht bei den Gruppen Gen $3 \mathrm{~g}, 1 \mathrm{~g}, 0,3 \mathrm{~g}, 0,1 \mathrm{~g}$ und der Kontrollgruppe signifikant reduziert.

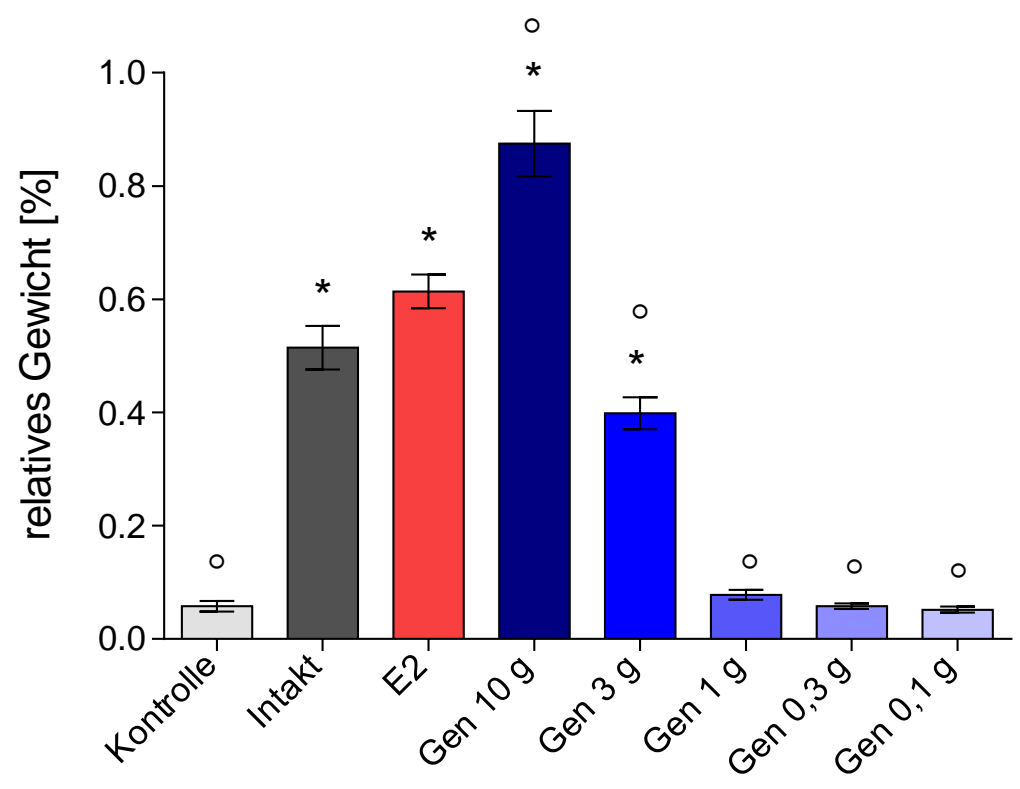

Abbildung 13: Relatives Uterusgewicht, Mittelwerte $+/-\mathrm{SEM}, * \mathrm{p}<0,05$ versus Kontrolle, ${ }^{\circ} \mathrm{p}<0,05$ versus E2, $\mathrm{n}=10$ pro Gruppe 


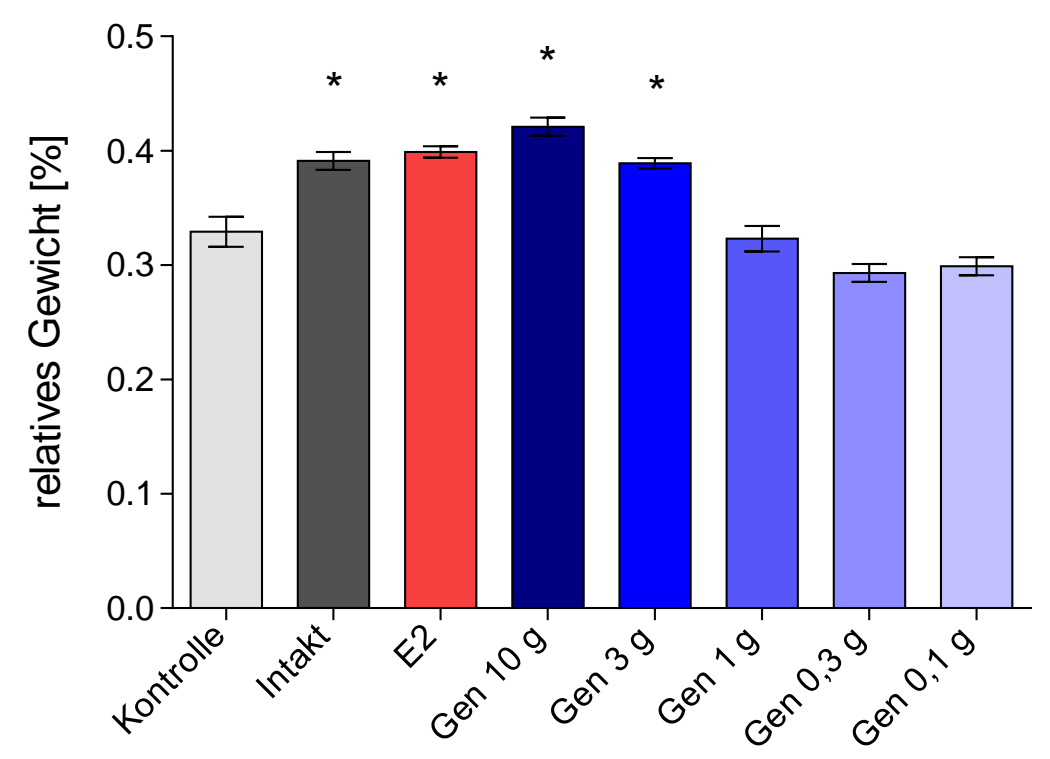

Abbildung 14: Relatives Gewicht linker Ventrikel, Mittelwerte +/- SEM, * $\mathrm{p}<0,05$ versus Kontrolle, $\mathrm{n}=10$ pro Gruppe

In Abbildung 14 wird das Gewicht des linken Ventrikels in Relation auf das Körpergewicht bei Obduktion dargestellt. Bei den Gruppen Gen $10 \mathrm{~g}$ und Gen $3 \mathrm{~g}$ ließ sich im Vergleich zur Kontrollgruppe eine signifikante Erhöhung des Gewichts des linken Ventrikel bezogen auf das Körpergewicht messen. Die gleiche, ebenfalls signifikante Entwicklung des relativen Gewichts des linken Ventrikels war bei den Mäusen der Gruppen Intakt und E2 zu verzeichnen. Bei Genisteindosen von $1 \mathrm{~g}$ oder weniger lag das relative Gewicht des linken Ventrikels im Bereich der Kontrollgruppe. 


\subsection{Genexpression im Herzen}

\subsubsection{IGF-1}

Der Einfluss von Genistein auf die IGF-1 Expression im linken Ventrikel ist in Abbildung 15 veranschaulicht. Die Genexpression von IGF-1 wurde am stärksten und signifikant durch die Gabe von E2 stimuliert. Eine ebenso starke und signifikante Transkriptionssteigerung war bei dem Futterzusatz Genistein $3 \mathrm{~g} / \mathrm{kg}$ auszumachen. Die Expression ließ sich auch mit Genisteindosierungen von $10 \mathrm{~g} / \mathrm{kg}$ und $1 \mathrm{~g} / \mathrm{kg}$ steigern, jedoch ohne Signifikanz. Keine erhöhte IGF-1 Expression zeigten die Gruppen Intakt, Gen 0,3 $\mathrm{g}$ und Gen 0,1 g.

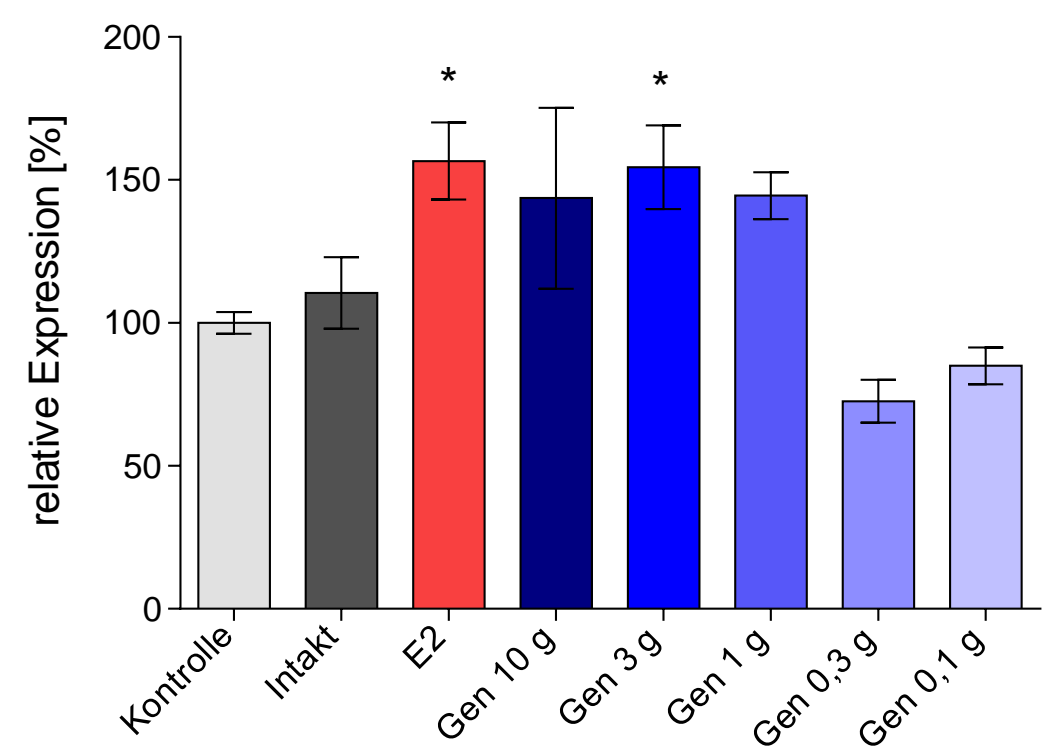

Abbildung 15: Expression von IGF-1 im linken Ventrikel, Mittelwerte +/- SEM, * $\mathrm{p}<0,05$ versus Kontrolle, $\mathrm{n}=10$ pro Gruppe 


\subsubsection{ERa}

Abbildung 16 zeigt die gemessene Genexpression von ER $\alpha$ im linken Ventrikel unter Einfluss unterschiedlicher Genisteindosierungen. Es war eine leichte, nicht signifikante Zunahme der Transkription von ER $\alpha$ bei einer Genisteinkonzentration von $10 \mathrm{~g} / \mathrm{kg}$ im Futter zu messen. Bei allen anderen Gruppen war kein Effekt auf die Expressionsrate im Vergleich zur Kontrollgruppe nachweisbar.

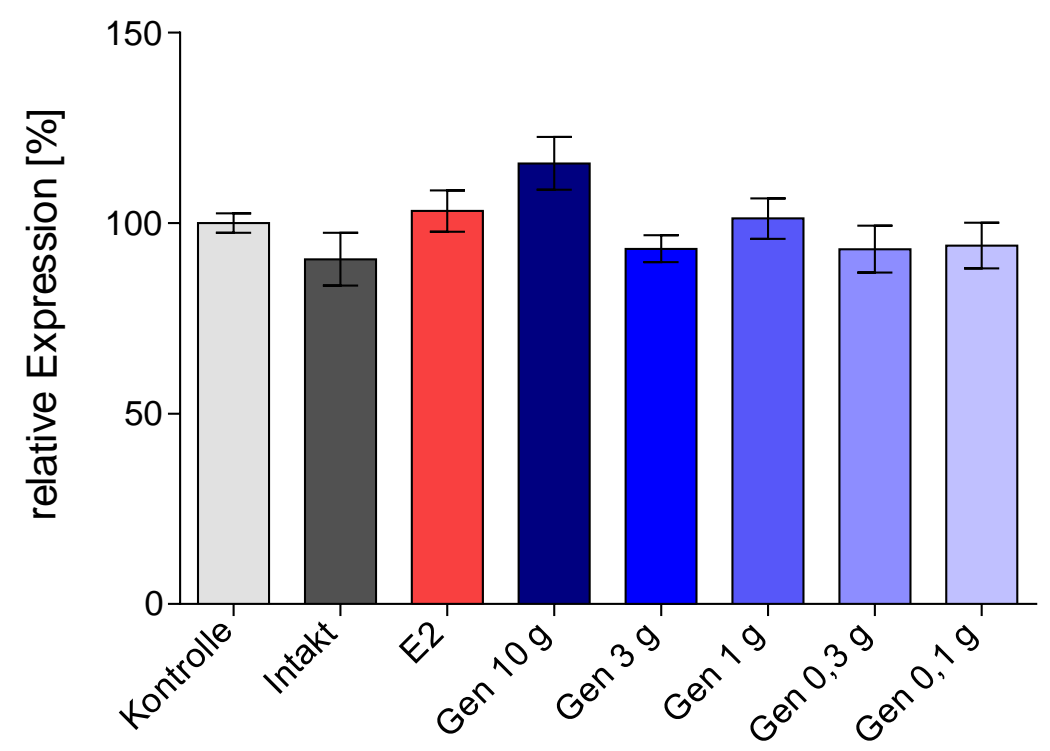

Abbildung 16: Expression von ER $\alpha$ im linken Ventrikel, Mittelwerte +/- SEM, * $\mathrm{p}<0,05$ versus Kontrolle, $\mathrm{n}=10$ pro Gruppe 


\subsubsection{Myocardin}

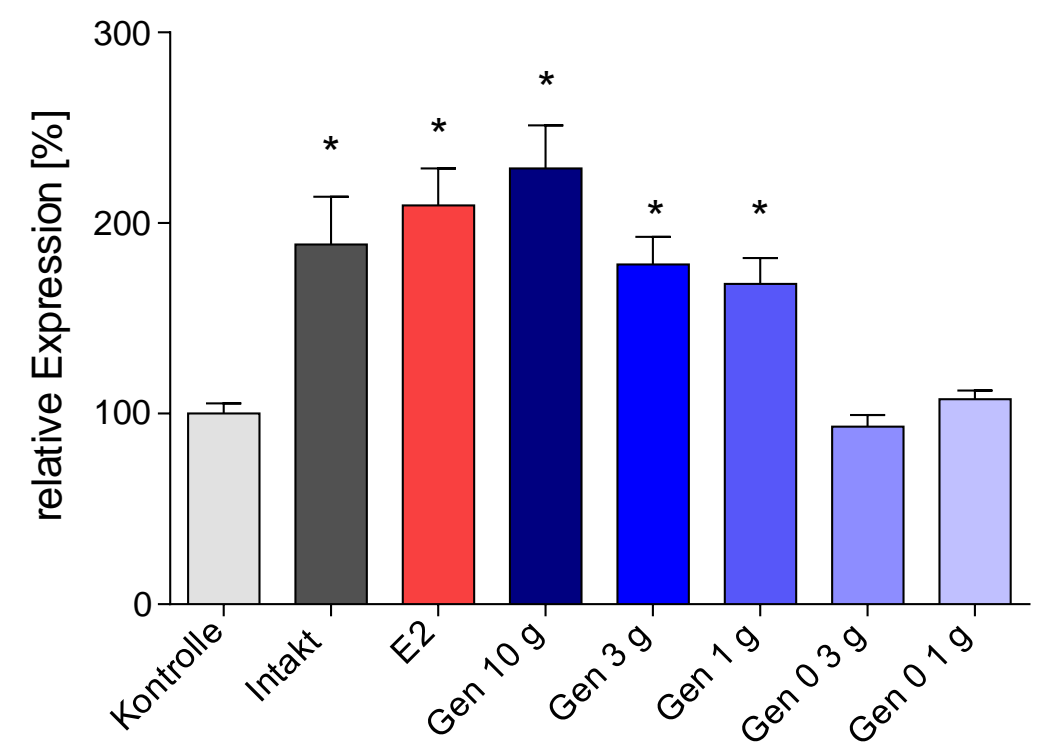

Abbildung 17: Expression von Myocardin im linken Ventrikel, Mittelwerte +/- SEM, * $\mathrm{p}<0,05$ versus Kontrolle, $\mathrm{n}=10$ pro Gruppe

Abbildung 17 veranschaulicht die prozentrelativierte Amplifikation von Myocardin im linken Ventrikel. Die Gruppen Intakt und E2 zeigten eine erhöhte, signifikante Expression von Myocardin gegenüber der Kontrollgruppe. Der Graphik ist weiter zu entnehmen, dass es bei Genisteinkonzentrationen von $1 \mathrm{~g} / \mathrm{kg}$ und höher $\mathrm{zu}$ einer signifikanten Erhöhung der Myocardinexpression im linken Ventrikel kam. Bei Genisteinkonzentrationen von unter $1 \mathrm{~g} / \mathrm{kg}$ im Futter waren im Vergleich zur Kontrollgruppe keine Änderungen der Transkriptionsmenge von Myocardin in der linken Herzkammer zu messen. 


\subsection{Knochenparameter}

\subsubsection{Dichte der Spongiosa}

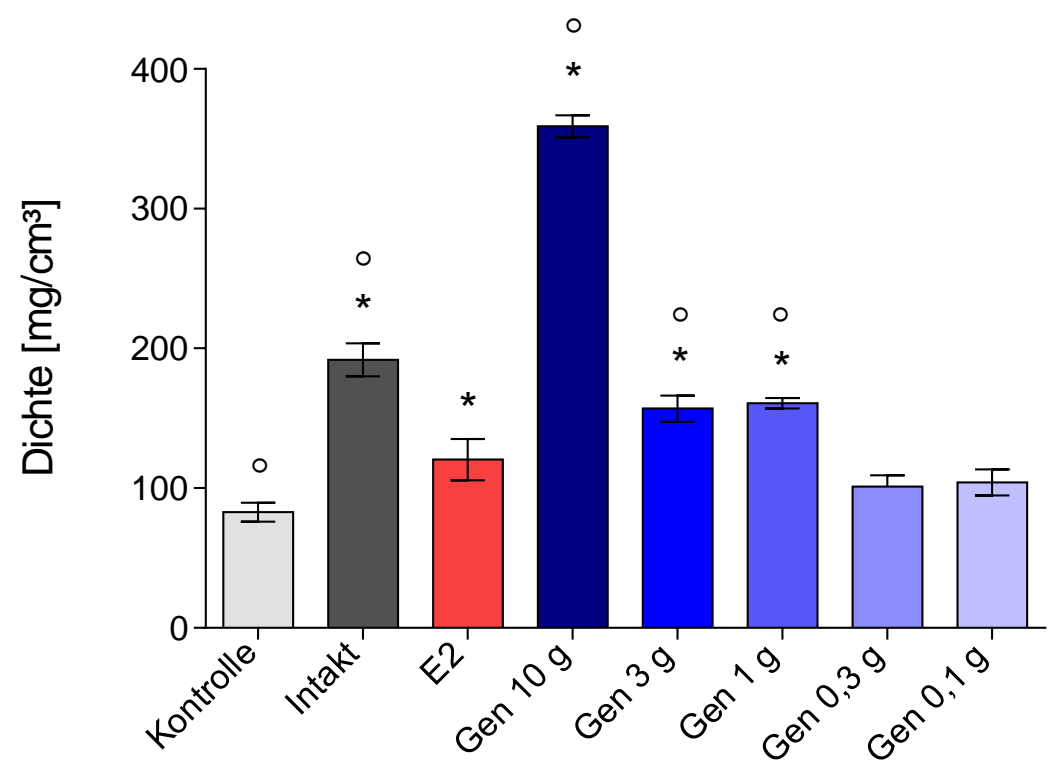

Abbildung 18: Dichte der Spongiosa, Mittelwerte +/- SEM, * $\mathrm{p}<0,05$ versus Kontrolle, ${ }^{\circ} \mathrm{p}<0,05$ versus E2, $\mathrm{n}=10$ pro Gruppe

In Abbildung 18 sind die Einflüsse von unterschiedlichen Genisteindosierungen auf die in der Kleintiercomputertomographie gemessene Spongiosadichte der Tibia- Metaphyse dargestellt.

Die Spongiosadichte der intakten Tiere lag im Durchschnitt bei 191,76 mg/cm³ und war damit signifikant höher als die Spongiosadichte der Kontrollgruppe, die durchschnittlich 82,83 $\mathrm{mg} / \mathrm{cm}^{3}$ betrug. Auch die Spongiosadichte der Gruppe E2 war mit durchschnittlich $120,39 \mathrm{mg} / \mathrm{cm}^{3}$ signifikant erhöht in Relation zur Kontrollgruppe.

Bei den Tiergruppen, die einen Genisteinzusatz von $1 \mathrm{~g} / \mathrm{kg}$ und mehr im Futter hatten, war der Dichteanstieg der Spongiosa relativ zur Kontrollgruppe signifikant. Mit 358,93 mg/cm³ war die durchschnittliche Spongiosadichte der Gruppe Gen $10 \mathrm{~g}$ deutlich gesteigert verglichen mit allen anderen Versuchsgruppen. Verglichen mit der Gruppe E2 war die Spongiosadichte bei den Gruppen Gen $10 \mathrm{~g}$, $3 \mathrm{~g}$ und $1 \mathrm{~g}$ sowie bei den intakten Tieren signifikant gesteigert. 


\subsubsection{Anteil der Trabekel an der Spongiosaquerschnittsfläche}

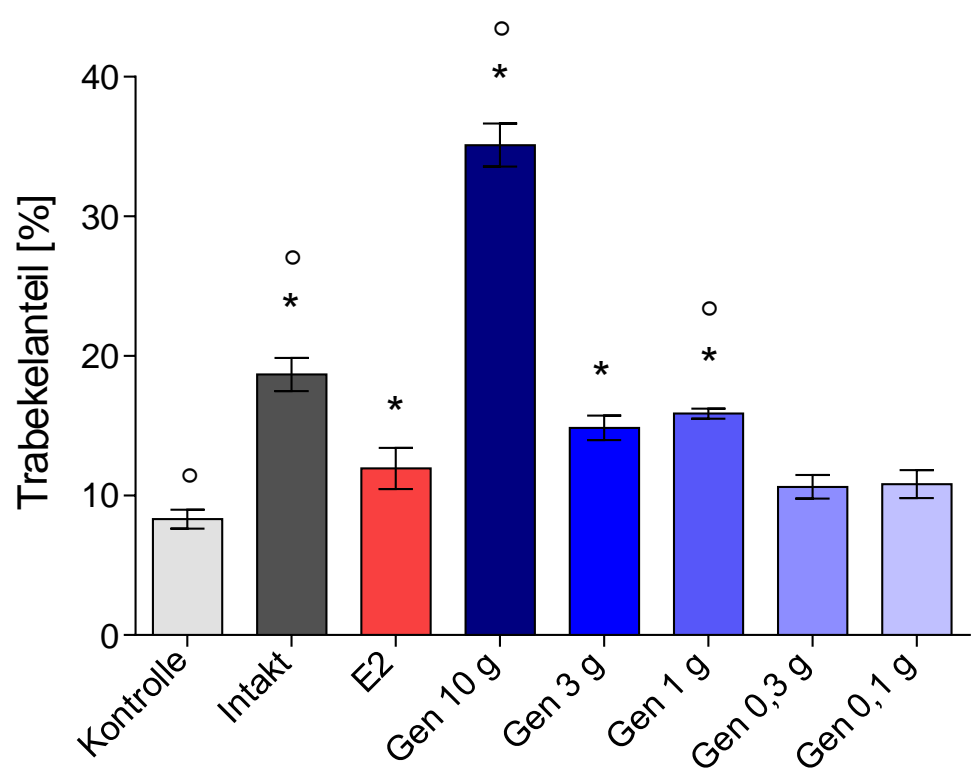

Abbildung 19: Anteil der Trabekel an der Spongiosaquerschnittsfläche, Mittelwerte +/- SEM, * $\mathrm{p}<0,05$ versus Kontrolle, ${ }^{\circ} \mathrm{p}<0,05$ versus $E 2, \mathrm{n}=2 \times 10$ pro Gruppe

In Abbildung 19 ist der prozentuale Anteil der Trabekel an der Spongiosaquerschnittsfläche zu sehen. Aus den computertomographisch gewonnenen Messergebnissen für die Spongiosaund Kortikalisdichte lässt sich der prozentuale Anteil der Trabekel an der Spongiosaquerschnittsfläche berechnen:

$$
\frac{\text { Spongiosadichte Slice } 1}{\text { Kortikalisdichte Slice } 3} \cdot 100=\text { Trabekelanteil an der Spongiosaquerschnittsfläche in \% }
$$

und

$\frac{\text { Spongiosadichte Slice } 2}{\text { Kortikalisdichte Slice } 3} \cdot 100=$ Trabekelanteil an der Spongiosaquerschnittsfläche in \%.

Auf diese Weise erhält man für eine Gruppe von zehn Tieren 20 Messwerte, wenn alle Bilder auswertbar sind. Bei allen Tiergruppen war der prozentuale Anteil der Trabekel an der Spongiosaquerschnittsfläche höher als bei der Kontrollgruppe. Bei den Gruppen Intakt und E2 war der Anteil der Trabekel an der Spongiosaquerschnittsfläche mit jeweils 18,67 \% und 11,94 \% signifikant erhöht verglichen mit der Kontrollgruppe. 
Bei den Tiergruppen, die einen Genisteinzusatz im Futter hatten, waren die Werte ab einer Dosierung $1 \mathrm{~g} / \mathrm{kg}$ signifikant höher als bei der Kontrollgruppe. Die Tiergruppe Gen $10 \mathrm{~g}$ hatte mit 35,11 \% den höchsten prozentualen Trabekelanteil an der Spongiosaquerschnittsfläche.

Verglichen mit der Gruppe E2 war der Anteil der Trabekel an der Spongiosaquerschnittsfläche bei den Gruppen Gen $10 \mathrm{~g}$, Gen $1 \mathrm{~g}$ und Intakt signifikant gesteigert, bei der Kontrollgruppe signifikant reduziert.

\subsubsection{Polares Widerstandmoment}

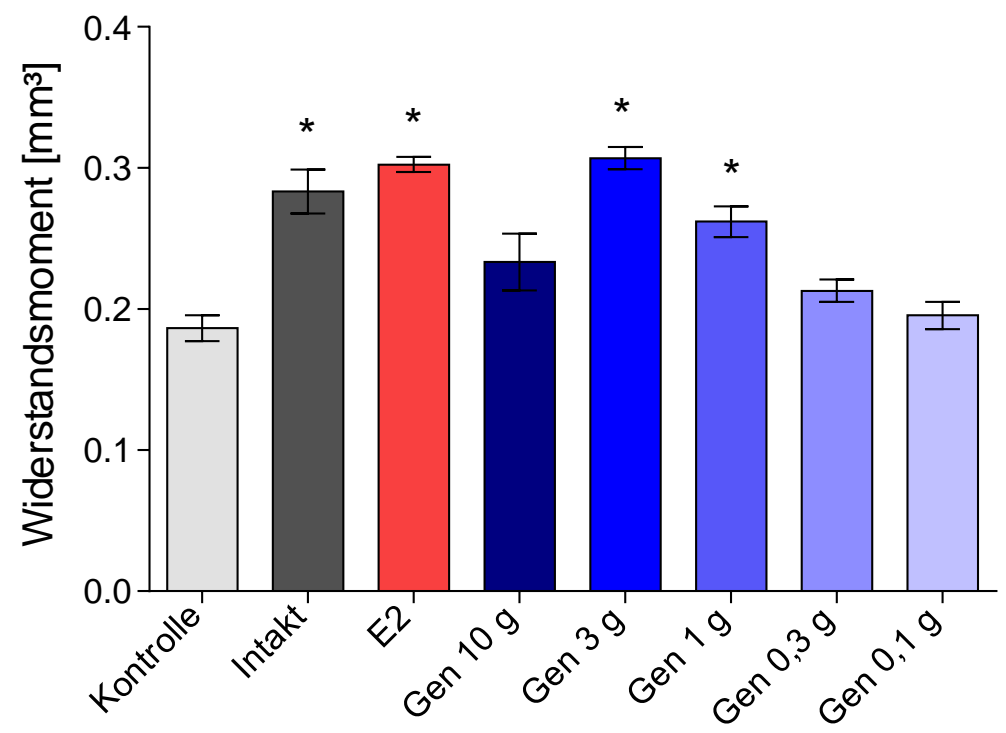

Abbildung 20: Polares Widerstandmoment, Mittelwerte +/- SEM, * $\mathrm{p}<0,05$ versus Kontrolle, $\mathrm{n}=10$ pro Gruppe

In Abbildung 20 ist zu sehen, welchen Einfluss die unterschiedlichen Genisteindosierungen auf das polare Widerstandmoment, gemessen in der Tibiametaphyse der Versuchstiere, hatten. Das polare Widerstandsmoment gibt Auskunft über den Widerstand, den die Tibia mit gegebenem Querschnitt einer bestimmten Belastung entgegensetzt.

Bei allen Versuchsgruppen war das gemessene polare Widerstandsmoment höher als bei der ovarektomierten Kontrollgruppe. Bei Tieren, die einen Genisteinzusatz von 3 g/kg hatten, war das polare Widerstandsmoment mit $0,307 \mathrm{~mm}^{3}$ am höchsten. Auch bei Tieren, die $1 \mathrm{~g} / \mathrm{kg}$ 
Genistein als Futterbestandteil hatten, ließ sich eine Abnahme des polaren Widerstandsmoments signifikant verhindern. Ebenso sind die Ergebnisse signifikant unter Einfluss von Estradiol und bei der nicht ovarektomierten Tiergruppe. Bei der Versuchsgruppe mit Estradiolzusatz blieb das polare Widerstandsmoment mit $0,3025 \mathrm{~mm}^{3}$ auf einem vergleichbar hohen Niveau wie bei der Gruppe Gen $3 \mathrm{~g}$. Der Wert betrug hier 0,307 mm³. 


\section{Diskussion}

Im Rahmen dieser Arbeit wurde die dosisabhängige Wirkung von Genistein an krankheitsund stressfreien Mäusen untersucht. Insbesondere die Auswirkung von Genistein auf Körpergewicht, Organgewichte, Genexpression und Knochenparameter war Gegenstand näherer Betrachtungen.

\subsection{Entwicklung von Körpergewicht und Futterverbrauch}

In diesem Abschnitt wird die dosisabhängige Wirkung von Genistein auf das Körpergewicht diskutiert. Zunächst wird die Körpergewichtsentwicklung der verschiedenen Gruppen näher erörtert, anschließend wird auf den Futterverbrauch und die Umsetzung der aufgenommenen Futtermenge in Körpergewicht eingegangen.

Wie in Kapitel 3.1 veranschaulicht, hatten die ovarektomierten Tiere, die weder Genistein noch E2 erhielten, über den gesamten Versuchszeitraum ein höheres Körpergewicht als die Tiere der Gruppe Intakt. Ovarektomierte Tiere, die 4,32 mg E2 erhielten, hatten über den ganzen Versuchszeitraum eine ähnliche Körpergewichtsentwicklung wie die intakten Tiere, die E2- und sojafreies Futter erhielten. Durch Östrogensubstitution kann also bei den Mäusen eine durch Ovarektomie bedingte Zunahme des Körpergewichts erfolgreich abgeschwächt werden. Diese Ergebnisse stehen im Einklang mit der Literatur. Eine Ovarektomie bewirkt eine Gewichtszunahme, die durch zusätzliche Gabe von E2 wieder ausgeglichen werden kann (Yoneda et al. 1998).

Im Fall von Genistein zeigte sich eine Dosisabhängigkeit. Mit einem Futterzusatz von $3 \mathrm{~g} / \mathrm{kg}$ oder $10 \mathrm{~g} / \mathrm{kg}$ Genistein ließ sich die durch eine Ovarektomie bedingte Gewichtszunahme verhindern. Die Wirkung war bei den beiden höchsten Genisteindosierungen sogar stärker ausgeprägt als bei E2, da diese Tiere mit durchschnittlich 17,48 g und 14,98 g signifikant weniger wogen als Tiere der Gruppe E2 mit einem durchschnittlichen Gewicht von 21,55 g bei Obduktion. Bei geringeren Genisteindosierungen im Futter ließ sich kein signifikanter Effekt auf die Gewichtsentwicklung nachweisen. In der Literatur finden sich Angaben, dass nach dreiwöchiger oraler Gabe von 1,5 g/kg Genistein bei ovarektomierten Mäusen eine Gewichtsreduktion bei vermehrter Apoptose von Adipozyten erzielt werden konnte (Kim et al. 2006). Das Körpergewicht der Tiergruppe Gen $1 \mathrm{~g}$ lag zwar nach drei Wochen sowie während des gesamten Versuchszeitraums minimal unter dem der Kontrollgruppe, jedoch noch ohne Signifikanz. Auch epidemiologische Studien und Ernährungsinterventionsstudien 
haben vielfach bewiesen, dass ein hoher Sojakonsum mit vermindertem BMI und verringerter Körperfettmasse assoziiert ist (Kim et al. 2006, Maskarinec et al. 2008). Genistein wurde deshalb in der Literatur zur Prävention oder Therapie von verstärkter Gewichtszunahme nach Menopause vorgeschlagen (Naaz et al. 2003, Kim et al. 2006). Die Ergebnisse in dieser Arbeit deuten auf eine kritische Dosis zwischen $1 \mathrm{~g} / \mathrm{kg}$ und $3 \mathrm{~g} / \mathrm{kg}$ Genistein als Futterzusatz zur Reduzierung des Körpergewichts bei ovarektomierten Mäusen hin.

Neben der Entwicklung des Körpergewichts wurde auch der Futterverbrauch über den gesamten Versuchszeitraum regelmäßig gemessen (siehe Abschnitt 3.2). Bei Tieren, die einen Estradiolzusatz im Futter erhielten, ließ sich über den gesamten Versuchszeitraum die höchste Nahrungsaufnahme aller Gruppen messen. Der Futterverbrauch der Gruppe E2 war signifikant erhöht, das Körpergewicht jedoch signifikant niedriger als bei der ovarektomierten Kontrollgruppe. Es gibt Studien zu ovarektomierten Ratten, wo ebenfalls ein verringertes Körpergewicht nach Östrogensubstituion gemessen wurde, allerdings in Verbindung mit weniger Futteraufnahme (Wade 1975, Butera 2010). In der Literatur ist beschrieben, dass Östrogen über zentrale neurobiologische Mechanismen die Nahrungsaufnahme steuert. Im paraventrikulären Kern des Hypothalamus (PVN), einer bestimmten Region im Gehirn, die eine Rolle bei der Kontrolle der Nahrungsaufnahme spielt, befinden sich östrogensensitive Neurone. Östrogen beeinflusst Nahrungsaufnahme und Appetit durch Interaktion mit dem Hormon Leptin und Peptiden wie Cholecystokinin (CCK), Neuropeptid Y (NPY) und Ghrelin (Asarian und Geary 2006, Butera 2010, Fungfuang et al. 2013). Weiter ist bekannt, dass Östrogen zahlreiche lipolytische Wirkungen an Fettzellen hat (Wade und Heller 1993, Seidlová-Wuttke et al. 2006). Darüber hinaus wurde bei ovarektomierten Nagern unter Östrogensubstitution auch eine erhöhte körperliche Aktivität beobachtet, die ebenfalls zu einer Gewichtsreduzierung beiträgt (Wade und Heller 1993, Xu et al. 2011). Da in dieser Arbeit keine verringerte Futteraufnahme der Gruppe E2 beobachtet wurde, liegt es nahe, dass bei der verwendeten E2-Dosis womöglich nicht alle genannten Wirkmechanismen aufgetreten sind.

Die oben beschriebene Gewichtsabnahme bei hohen Genisteindosierungen ist zum Teil auch durch eine Änderung der Futteraufnahme erklärbar. Die durchschnittliche Nahrungsausnahme pro Maus war in den Gruppen Gen $3 \mathrm{~g}$ und $10 \mathrm{~g}$ signifikant reduziert. Auch die Änderung im Futterverbrauch ist somit dosisabhängig. Möglicherweise wirkt Genistein in hohen Dosierungen in ähnlicher Weise wie Östrogen direkt an bestimmten Regionen im Gehirn und übt Einfluss auf die Kontrolle der Nahrungsaufnahme aus. Hier könnten die lange Form des 
Leptinrezeptors und die Proteintyrosinphosphatase SHP2 in ähnlicher Weise, wie es für Östrogen beschrieben ist, von Bedeutung sein (He et al. 2012, Nguyen et al. 2012a, Fungfuang et al. 2013).

Um beurteilen zu können, ob es bei den untersuchten Mäusen neben der reduzierten Nahrungsaufnahme noch weitere Gründe für eine Gewichtsabnahme gibt, wurde geprüft, inwieweit die aufgenommene Futtermenge in Körpergewicht umgesetzt wurde. Hierbei wurde für die Gruppen Gen $3 \mathrm{~g}$ und $10 \mathrm{~g}$ eine signifikant verringerte Umsetzung der aufgenommenen Futtermenge in Körpergewicht festgestellt. Die Gruppen mit den beiden höchsten Genisteindosierungen haben also weniger Futter gefressen und darüber hinaus auch die aufgenommene Futtermenge in geringerem Maße in eine Gewichtszunahme umgewandelt. Auch die Tiere, die estradiolhaltiges Futter erhielten, haben signifikant weniger Futter in Körpergewicht umgesetzt als die ovarektomierte Kontrolle. Es liegt nahe, dass hier bei Genistein und E2 ein ähnlicher Wirkmechanismus auftritt, eventuell verknüpft mit der oben beschriebenen lipolytischen Wirkung oder mit gesteigerter körperlicher Aktivität.

Zusammenfassend lässt sich für Genistein eine dosisabhängige Wirkung auf das Körpergewicht nachweisen. Zwei Mechanismen scheinen hierbei eine Rolle zu spielen. Zum einen die verringerte Nahrungsaufnahme und zum anderen die geringere Umsetzung der aufgenommenen Futtermenge in eine Gewichtszunahme. Für beide Mechanismen liegt die kritische Dosis gleich hoch bei $1-3 \mathrm{~g} / \mathrm{kg}$ Genistein im Futter. Genistein ist daher möglicherweise ein vielversprechender Kandidat für den Einsatz in der Therapie von Gewichtszunahme nach der Menopause. 


\subsection{Organentwicklung}

\subsubsection{Uterus}

In diesem Abschnitt wird die Wirkung von Genistein auf das Uterusgewicht in Relation zum Körpergewicht der verschiedenen Behandlungsgruppen betrachtet. Die Messung des primären Uterusfeuchtgewichts liefert erste Aussagen über eine mögliche dosisabhängige proliferative Wirkung der untersuchten Testsubstanzen auf den Uterus (Hodge 1966).

Die Ergebnisse der Messung des relativen Uterusgewichts (siehe Abschnitt 3.3) zeigen wie erwartet, dass die ovarektomierten Tiere der Kontrolle ein signifikant geringeres relatives Uterusgewicht als die nicht ovarektomierten Tiere der Gruppe Intakt hatten. Dieses Ergebnis bestätigt, dass Östrogenmangel beispielsweise durch eine Ovarektomie zu einer Atrophie und folglich einer Abnahme des Uterusgewichts führt (Rimoldi et al. 2007). Die Gabe von E2 hatte hingegen eine erhaltende Wirkung auf den Uterus.

Für Genistein konnte in der vorliegenden Arbeit eine Dosisabhängigkeit in Bezug auf das relative Uterusgewicht nachgewiesen werden. Bei Genisteindosierungen von 1 g oder weniger war keine signifikante Änderung des relativen Uterusgewichts gegenüber der ovarektomierten Kontrollgruppe messbar. Diese Beobachtung deckt sich mit einer anderen Untersuchung, wo sich bei ovarektomierten Mäusen, die über drei Monate $1 \mathrm{~g} / \mathrm{kg}$ Genistein als Futterzusatz erhielten, auch keine Veränderung des Uterusgewichts nachweisen ließ (Sehmisch et al. 2010, Nguyen et al. 2012a). In der vorliegenden Arbeit konnte ab einer Dosierung von $3 \mathrm{~g} / \mathrm{kg}$ Genistein im Futter eine signifikante Zunahme des relativen Uterusgewichts, verglichen mit der Kontrolle, gemessen werden. Demnach liegt auch in Bezug auf das relative Uterusgewicht die kritische Dosis für eine Proliferationsinduktion mit Zunahme des Uterusgewichts zwischen 1 und $3 \mathrm{~g} / \mathrm{kg}$ als Futterzusatz. In einer anderen Publikation mit ovarektomierten Mäusen konnten Forscher ebenfalls zeigen, dass sich bei einer subkutanen Genisteinapplikation von 5 mg/Tag eine Erhöhung des Uterusgewichts induzieren ließ, jedoch nicht bei 0,7 mg/Tag (Ishimi et al. 2000).

Die gefundene Erhöhung des relativen Uterusgewichts bei hohen Genisteindosen und Langzeitverabreichung deutet auf eine agonistische Wirkung am Uterusgewebe hin. Dieser Effekt wird vermutlich durch Bindung von Genistein an ER $\alpha$ und eine dadurch gesteigerte Expression bestimmter Gene vermittelt, die eine Zunahme des Uterusgewichts bewirken (Santell et al. 1997, Erlandsson et al. 2005). 
Bei der Gruppe Gen $10 \mathrm{~g}$ lag das relative Uterusgewicht sogar signifikant über dem der Gruppe E2. Dies bestätigt, dass Genistein in hohen Konzentrationen, ähnlich wie es in der Literatur für E2 beschrieben ist, eine dosisabhängige proliferierende Wirkung hat, die unter anderem in Form einer Gewichtszunahme des Uterus messbar ist (Hegele-Hartung et al. 2004). Diese proliferierende Wirkung von Genistein wird insgesamt als schwächer beschrieben als von E2. Genistein scheint demnach ein schwacher Agonist am Uterus zu sein (Diel et al. 2004, Aidoo et al. 2005, Erlandsson et al. 2005, Rimoldi et al. 2007).

Die Expression von Genen, wie beispielsweise dem Wachstumsfaktor IGF-1, kann wichtige Hinweise auf eine proliferierende Wirkung am Uterus liefern. Die Expression von IGF-1 am Uterus wird durch Östrogen gesteigert (Murphy und Ghahary 1990). In einer anderen Untersuchung der Arbeitsgruppe konnte gezeigt werden, dass Genistein bei Mäusen in der Dosierung $1 \mathrm{~g} / \mathrm{kg}$ als Futterzusatz die Genexpression von IGF-1 am Uterus im Vergleich zur ovarektomierten Kontrollgruppe steigert. Die Erhöhung der Genexpression war jedoch im Gegensatz zur Gabe von E2 nicht signifikant, wobei ein Signifikanzniveau von $\mathrm{p}<0,001$ verwendet wurde (Nguyen et al. 2012b). In dieser Arbeit wurde die Genexpression am Uterus nicht weiter untersucht.

Es gibt Studien, die geprüft haben, inwieweit eine Gewichtszunahme des Uterus ein Risiko für eine maligne Transformation darstellt. Hierzu gibt es Untersuchungen an postmenopausalen Ratten, denen Genistein subkutan in verschiedenen Dosierungen appliziert wurde (Salleh et al. 2013). Hier konnten für hohe Genisteindosierungen (50 mg/kg/Tag und $100 \mathrm{mg} / \mathrm{kg} / \mathrm{Tag})$ über einen Zeitraum von 3 Tagen oder bei chronischer Verabreichung von einer niedrigen Genisteindosierung (1,6 mg/kg/Tag) diverse morphologische Veränderungen wie beispielweise eine glanduläre Hyperplasie und erhöhte Expression von proliferating-cellnuclear-antigen (PCNA) am Uterus nachgewiesen werden, die bekanntermaßen ein Risiko für die Entwicklung eines Endometriumkarzinoms darstellen. Eine andere Arbeitsgruppe beschreibt allerdings eine geringe Inzidenz von Dysplasien am Uterus von ovarektomierten Ratten nach Langzeitverabreichung von Genistein und Behandlung mit dem stark krebserregendem 7,12-Dimethylbenz[a]anthracen (DMBA) verglichen mit E2 (Aidoo et al. 2005). Des Weiteren konnten in einer klinischen Studie mit täglicher Einnahme von $150 \mathrm{mg}$ Isoflavonen inklusive 60-67 mg Genistein pro Tag über fünf Jahre zwar hyperplastische, jedoch keine dysplastischen Veränderungen nachgewiesen werden (Unfer et al. 2004). 
Schlussfolgernd konnte in der vorliegenden Arbeit in Bezug auf das relative Uterusgewicht gezeigt werden, dass Genistein in hohen Dosierungen eine signifikante Erhöhung des Uterusgewichts bewirkte. Diese Zunahme war dosisabhängig; die kritische Dosis lag zwischen 1 und 3 g/kg Genistein im Futter. Das Auftreten von uterotrophen Nebenwirkungen und das hiermit verbundene Risiko für ein Endometriumkarzinom sind bei Genisteineinnahme wahrscheinlich geringer als bei E2. Möglicherweise ist zur Therapie postmenopausaler Beschwerden und Hormonmangel-assoziierter Erkrankungen wie Osteoporose und kardiovaskulären Erkrankungen eine niedrige Genisteindosierung ausreichend. Es sollte eine Dosis gefunden werden, bei der die erwünschte Wirkung bereits erreicht wird, die proliferative Wirkung am Uterus aber noch nicht eintritt. Hierfür werden weitere Untersuchungen ausschlaggebend sein.

\subsubsection{Herz}

In diesem Teil wird die Wirkung von Genistein auf das relative Gewicht des linken Ventrikels sowie die Genexpression von IGF-1, ER $\alpha$ und Myocardin im linken Ventrikel der verschiedenen Tiergruppen erörtert. Es wird zunächst die Wirkung von E2 beschrieben und dann das Ergebnis nach Genistein-Gabe dazu in Bezug gesetzt.

Wie im Ergebnisteil unter 3.3 aufgezeigt war das relative Gewicht des linken Ventrikels der Gruppen Intakt und E2 signifikant höher als das der ovarektomierten Kontrollgruppe. Somit bestätigte sich auch für das Herz, dass ein Östrogenmangel zu einer Abnahme des relativen Organgewichts führte, welcher durch Gabe von E2 verhindert werden konnte. Hiermit wird der bedeutende Einfluss von Östrogen zum Schutz vor postmenopausal bedingten kardiovaskulären Erkrankungen deutlich (Nguyen et al. 2012b). In großen klinischen Studien konnte bisher allerdings keine protektive Wirkung durch eine HET beweisen werden (Nelson et al. 2002). In dieser Arbeit soll die Gruppe E2 auch als Positivkontrolle der vergleichenden Wirkung mit Genistein dienen.

Neben dem Organgewicht wurde auch die Genexpression von verschiedenen östrogensensitiven Genen am linken Ventrikel untersucht (siehe Abschnitt 3.4). Durch Gabe von E2 in einer für Mäuse physiologischen Dosis konnte die Expression von IGF-1 und Myocardin, verglichen mit der Kontrolle, signifikant gesteigert werden. Dies Ergebnis entspricht der oben beschriebenen direkten Wirkung von Östrogen am Herzen. 
Im Rahmen dieser Arbeit wurde zudem die Genexpression von ER $\alpha$ im linken Ventrikel untersucht, weil angenommen wird, dass die Wirkung von Östrogen und Genistein vornehmlich über ER $\alpha$ vermittelt wird (Geraldes et al. 2003, Nguyen et al. 2012b). Für die Expression von ER $\alpha$ konnte jedoch keine veränderte Expression nach E2-Gabe gemessen werden. Eine Östrogenbehandlung verändert somit die Expression von ausgewählten von östrogen-regulierten Genen wie IGF-1 oder Myocardin am linken Ventrikel, nicht aber von $\mathrm{ER} \alpha$ selbst. Nachfolgend konnte in der Arbeitsgruppe auch an ovarektomierten Knock-outMäusen gezeigt werden, dass Östrogen seine Wirkung am Herzen über ER $\alpha$ entfaltet und die Expression von östrogensensitiven Genen wie IGF-1 und Myocardin steigert. (Kararigas et al. 2014).

Für die Gabe von Genistein konnte in der vorliegenden Arbeit erstmals am Modell der langzeitovarektomierten gesunden und stressfreien Maus für hohe Genisteindosen eine signifikante Erhöhung des relativen Gewichts des linken Ventrikels, verglichen mit der Kontrollgruppe, nachgewiesen werden. Für das relative Herzgewicht besteht somit eine Dosisabhängigkeit. Die kritische Dosis für einen Anstieg des relativen Gewichts des linken Ventrikels liegt zwischen 1 und 3 g/kg als Futterzusatz. In der Dosierung 3 g Genistein pro kg Futter erreichte das relative Herzgewicht das Niveau der Gruppen Intakt und E2. Der Erhalt von Herzgröße und Struktur sind wichtige Voraussetzungen für eine normale Herzfunktion (Nguyen et al. 2012a). Daraus lässt sich ableiten, dass Genistein als Nahrungsergänzungsmittel besonders bei postmenopausalen Frauen möglicherweise vorteilhaft für die Herzfunktion sein kann (Nguyen et al. 2012a). Hierfür werden weitere Studien, insbesondere mit Funktionstests am Herzen, notwendig sein.

Die Genexpression von IGF-1 im linken Ventrikel ließ sich durch Genistein in der Dosierung $1 \mathrm{~g}, 3 \mathrm{~g}$ und $10 \mathrm{~g}$ im Vergleich zur ovarektomierten Kontrolle steigern, jedoch nur bei $3 \mathrm{~g}$ mit Signifikanz. Bei der Gruppe Gen $10 \mathrm{~g}$ sind große Schwankungen bei der Analyse der Genexpression aufgetreten, so dass für diese Gruppe eine signifikante Erhöhung weder sicher ausgeschlossen noch bestätigt werden kann. Insgesamt lässt sich auf eine dosisabhängige Steigerung der Genexpression von IGF-1 am Herzen schließen.

IGF-1 ist über den Akt-Signalweg maßgeblich am Schutz von Kardiomyozyten beteiligt (Fujio et al. 2000; Li et al. 1997). In dieser Arbeit wurde durch Gabe von Genistein die Genexpression von IGF-1 signifikant erhöht. Genistein ist also möglicherweise in der Lage, in der Menopause die protektive Wirkung von IGF-1 zu steigern. Andere Studien an Mäusen mit 
hypertropher Kardiomyopathie konnten zeigen, dass eine sojareiche Ernährung für die weiblichen Tiere durch gesteigerte IGF-1-Expression vorteilhaft für die Erkrankung war (Luczak et al. 2011, Nguyen et al. 2012a).

Für die Genexpression von ER $\alpha$ im linken Ventrikel konnte keine signifikante Änderung, verglichen mit der Kontrolle, gemessen werden. Obwohl, wie oben beschrieben, die Wirkung am Herzen über ER $\alpha$ vermittelt wird, scheint ähnlich wie bei Östrogen kein Einfluss auf die Expression des Rezeptors zu bestehen.

Die Genexpression von Myocardin im linken Ventrikel konnte durch Genisteinaufnahme ab $1 \mathrm{~g} / \mathrm{kg}$ als Futterzusatz, verglichen mit der ovarektomierten Kontrollgruppe, signifikant gesteigert werden. Für die Genexpression von Myocardin besteht somit auch eine Dosisabhängigkeit. Dieses Ergebnis zeigt, dass Genistein ebenso wie Estradiol in der Lage ist, die Genexpression von Myocardin zu modulieren. Da Myocardin die Expression von Genen in glatten Muskelzellen reguliert, scheint es für ein gesundes Herz eine wichtige Funktion einzunehmen (Wang et al. 2003).

Zusammengefasst ist in der vorliegenden Arbeit die Wirkung für E2 am linken Ventrikel bestätigt worden und für Genistein eine dosisabhängige Wirkung am Herzen nachgewiesen worden. Die kritische Dosis für eine Veränderung des relativen Gewichts des linken Ventrikels lag für Genistein als Futterzusatz zwischen 1 und 3 g/kg als Futterzusatz. Genistein ist somit ebenso wie Estradiol in der Lage, am Herzen einen durch Ovarektomie bedingten Verlust von Herzgewicht zu verhindern. Die kritische Dosis für eine Veränderung der Genexpression von IGF-1 und Myocardin lag bei einer Dosis von $1 \mathrm{~g} / \mathrm{kg}$ Genistein im Futter. Zu berücksichtigen ist hier allerdings, dass für die Gruppe Gen $1 \mathrm{~g}$ die gesteigerte Expression von IGF-1 nicht signifikant war.

Die Unterschiede in der kritischen Dosis und die Möglichkeit für eine Modulierung der Genexpression, ohne das Gewicht des linken Ventrikels stark zu verändern, könnten ein therapeutischer Vorteil sein. Eine sichere, aber dennoch wirksame Dosis von Genistein am Herzen lag für diesen Effekt bei ovarektomierten Mäusen in dieser Arbeit bei einer Dosis von 1 g/kg Genistein im Futter.

\subsection{Knochenparameter}

Im folgenden Abschnitt wird die dosisabhängige Wirkung von Genistein auf verschiedene Knochenparameter am osteoporotischen Knochen im Mausmodell diskutiert. Ein 
Östrogenmangel in der Menopause ist die häufigste Ursache für eine Osteoporose, die wegen des erhöhten Frakturrisikos häufig Schmerzen und Immobilisation zur Folge hat. Aufgrund der unerwünschten Nebenwirkungen einer klassischen Hormonersatztherapie soll in dieser Arbeit auch die dosisabhänge Wirksamkeit von Genistein als Phytoöstrogen im Hinblick auf eine knochenerhaltende Wirkung geprüft werden.

Zunächst werden in diesem Abschnitt das Tiermodell und das verwendete Messverfahren besprochen. Anschließend werden die Auswirkungen der verwendeten Testsubstanzen auf die Dichte der Spongiosa, das polare Widerstandsmoment und den prozentualen Anteil der Spongiosa an der Trabekelquerschnittsfläche diskutiert.

Es konnte in der Vergangenheit vielfach demonstriert werden, dass eine Ovarektomie bei Kleintieren, aber auch beim Menschen, einen Verlust der Knochendichte bewirkt, der eine Osteoporose induziert (Jee und Yao 2001). Zur Erforschung von Therapien zur Behandlung einer postmenopausalen Osteoporose konnte gezeigt werden, dass das Modell der ovarektomierten Ratte, verglichen mit dem Modell der ovarektomierten Maus, diesem in gewissen Punkten überlegen ist. Die ovarektomierte Ratte ahmt die Entwicklung eines bei Frauen in der Menopause beobachteten postmenopausalen Knochendichteverlusts mit kontinuierlichen Verlust der Spongiosa und hohem Knochenumsatz exakter und beständiger nach als das Modell der ovarektomierten Maus (Iwaniec et al. 2006, Sehmisch et al. 2010). Dennoch wurde in der vorliegenden Arbeit das Mausmodell verwendet, da es in Hinblick auf nachfolgende Untersuchungen mit Knockout-Tieren eine bessere Vergleichbarkeit und ein wesentlich breiteres Spektrum an Möglichkeiten bietet. So ist die ovarektomierte Maus das bevorzugte Modell zur Erkennung von spezifischen Genen, die im Fall der postmenopausalen Osteoporose und deren Therapie zu einer Veränderung der Knochendichte und zum Knochenumbau beitragen (Sehmisch et al. 2010). Ein weiterer Vorteil ist die schnelle Reproduzierbarkeit. Aufgrund von vom Mäusestamm abhängigen Veränderungen der Knochendichte nach einer Ovarektomie wurden für die vorliegende Studie Mäuse des Stammes C57BL/6J ausgewählt, der sich für diese Anwendung bereits bewährt hat (Sehmisch et al. 2010).

Die Messungen der Knochenparameter mittels pQCT wurden nach Ende des dreimonatigen Versuchs an der proximalen Metaphyse der Tibia durchgeführt, da dieser Bereich wegen seines hohen Spongiosaanteils sehr sensitiv auf Stoffwechselveränderungen, wie beispielsweise einen Östrogenmangel, reagiert (Jee und Yao 2001, Stürmer et al. 2006). 
Eine ovarektomie-induzierte Osteoporose lässt sich anfangs insbesondere an der großen spongiösen Oberfläche durch massive Dichteverluste detektieren (Prevrhal und Genant 1999). Da bei der pQCT-Messung die volumetrische Knochendichte (in $\mathrm{mg} / \mathrm{cm}^{3}$ Kalziumhydroxylapatit) für trabekuläre und kortikale Knochenanteile separat ermittelt werden kann, eignet sich dieses Verfahren hervorragend zur Diagnostik einer Osteoporose in der Menopause.

\subsubsection{Dichte der Spongiosa}

Ein durch Östrogenmangel bedingter gesteigerter Knochenumbau betrifft anfangs überwiegend die spongiösen Knochenanteile, da vor allem die Spongiosa mit dem Trabekelnetzwerk sehr sensitiv auf Veränderungen im Hormonhaushalt reagiert (Prevrhal und Genant 1999, Dirisamer und Grampp 2002). Um den Schweregrad einer Osteoporose einzustufen, gehört die Dichte der Spongiosa daher zu den ausschlaggebenden Messwerten (Stürmer et al. 2006).

In der vorliegenden Studie führte die Gabe von E2 bei ovarektomierten Tieren wie erwartet zu einer signifikanten Steigerung der spongiösen Knochendichte, verglichen mit der ovarektomierten Kontrolle (siehe Abschnitt 3.5.1). Somit ist erneut der knochenerhaltende Effekt von Estradiol in einer für Mäuse physiologischen Dosis bestätigt worden. Aufgrund der bereits in Kapitel 1.6 aufgeführten Nebenwirkungen ist eine Hormonersatztherapie mit E2 allerdings derzeit in Deutschland nicht als Medikament der ersten Wahl zur Prävention oder Therapie einer Osteoporose empfohlen. Die Ergebnisse der Gruppe E2 können aber als Positivkontrolle dienen und ein hilfreicher Vergleich zur Wirkung von Genistein sein.

Im Fall von Genistein konnte bei allen Gruppen eine Erhöhung der Spongiosadichte, verglichen mit der ovarektomierten Kontrollgruppe, gemessen werden. Dabei bestand eine deutliche Dosisabhängigkeit. Die kritische Dosis für einen signifikanten Dichteanstieg der Spongiosa lag zwischen 0,3 und $1 \mathrm{~g} / \mathrm{kg}$ Genistein als Futterzusatz. Für die Tiergruppen Gen $1 \mathrm{~g}, 3 \mathrm{~g}$ und $10 \mathrm{~g}$ war die Erhöhung der Spongiosadichte im Vergleich zur Kontrolle signifikant. Verglichen mit der Gruppe E2 war die Spongiosadichte bei den drei höchsten Genisteindosierungen sogar signifikant höher als bei einer für Mäuse physiologischen E2Dosis. Um einen moderaten Dichteanstieg der Spongiosa zu erzielen, könnte somit schon eine niedrigere Dosierung zwischen 0,3 g/kg und $1 \mathrm{~g} / \mathrm{kg}$ im Futter ausreichend sein. Eine solche Dosis wäre auch im Hinblick auf uterotrophe Nebenwirkungen, wie in Abschnitt 4.2.1 aufgeführt, sicherer. 
Auch in einer weiteren Untersuchung konnte im Modell der langzeitovarektomierten Maus bei einem Futterzusatz von $1 \mathrm{~g} / \mathrm{kg}$ Genistein im Futter eine signifikante Verbesserung der Spongiosadichte, verglichen mit der ovarektomierten Kontrollgruppe, erzielt werden (Sehmisch et al. 2010). Eine andere Studie konnte eine Erhöhung der trabekulären Dichte von ovarektomierten Mäusen nach vierwöchiger täglicher subkutaner Applikation von 0,7 mg Genistein ohne Nachweis einer hypertrophen Wirkung am Uterus messen (Ishimi et al. 2000). Ein wichtiger Aspekt in der Osteoporosetherapie ist neben der Ernährung vor allem auch körperliche Aktivität. Eine Interventionsstudie mit ovarektomierten Mäusen konnte zeigen, dass schon eine subkutane Dosis von 0,4 mg Genistein in Kombination mit Bewegung über einen Zeitraum von 4 Wochen vor einem Knochendichteverlust schützt (Wu et al. 2001).

\subsubsection{Prozentualer Anteil der Trabekel an der Spongiosaquerschnittsfläche}

Da neben der Dichte auch die trabekuläre Mikrostruktur der Spongiosa für die Festigkeit des Knochens eine Rolle spielt, wurde in dieser Arbeit auch der prozentuale Anteil der Trabekel an der Spongiosaquerschnittsfläche bestimmt (Prevrhal und Genant 1999). Untersuchungen haben ergeben, dass sich ein Östrogenmangel bei Frauen an der Spongiosa vor allem durch eine Demineralisation mit Verschmälerung der Trabekel und Abnahme der Trabekelanzahl bemerkbar macht (Seeman 2003). Nach derzeitigen Erkenntnissen scheint vor allem die Anzahl der Trabekel für die Knochenfestigkeit von Bedeutung zu sein (Silva und Gibson 1997, Guo und Kim 2002).

In der vorliegenden Arbeit wurde der prozentuale Anteil der Trabekel an der Spongiosaquerschnittsfläche rechnerisch anhand der mit dem qCT ermittelten Dichtewerte für Kortikalis und Spongiosa ermittelt (siehe Abschnitt 3.5.2). Leider ist es mit dieser Methode nicht möglich zwischen einer Ausdünnung der Trabekel oder einer Verringerung der Trabekelanzahl zu unterscheiden. Hierfür wären histomorphologische Methoden notwendig. Wie zuvor angenommen konnte eine Abnahme des prozentualen Anteils der Trabekel an der Spongiosaquerschnittsfläche durch Gabe von E2, verglichen mit der ovarektomierten Kontrollgruppe, signifikant gemildert werden. Diese Erhöhung des Trabekelanteils durch E2 erreichte jedoch nicht das Niveau der nicht ovarektomierten Tiergruppe.

Mit Genistein als Futterzusatz ließ sich bei allen ausgewählten Dosierungen eine Steigerung des prozentualen Trabekelanteils an der Spongiosa messen, der, verglichen mit der ovarektomierten Kontrolle, bei den Gruppen Gen $1 \mathrm{~g}$, $3 \mathrm{~g}$ und $10 \mathrm{~g}$ signifikant war. Für die Gruppen Gen $1 \mathrm{~g}$ und $10 \mathrm{~g}$ war der prozentuale Trabekelanteil sogar signifikant höher als bei 
der Gruppe E2. Der prozentuale Trabekelanteil der Gruppe Gen $3 g$ lag ebenfalls über dem der Gruppe E2, die Messwerte dieser Gruppe streuen jedoch so stark, dass sich keine signifikante Erhöhung daraus ableiten lässt.

Die kritische Dosis von Genistein für eine signifikante Erhöhung der Trabekelanzahl, verglichen mit der Kontrollgruppe, lag genau wie für die Dichte der Spongiosa bei einer Dosierung zwischen 0,3 und 1 g/kg Genistein im Futter. Diese Ergebnisse erscheinen bündig, da die Dichte der Spongiosa in die Berechnung des prozentualen Anteils der Trabekel an der Spongiosaquerschnittsfläche mit einfließt.

\subsubsection{Polares Widerstandmoment}

Das polare Widerstandmoment dient als Maßstab, um die Festigkeit des Knochens gegenüber einer Torsion bewerten zu können (Cindik et al. 2000). Es kann anhand der mit dem QCT ermittelten Daten aus Knochendichte und Knochengeometrie ermittelt werden. Das polare Widerstandsmoment erlaubt erste Einschätzungen der Biegefestigkeit eines Knochens (Gasser 1995). Vergleichende Messungen mit biomechanischen Torsionstests haben eine hohe Übereinstimmung der Messergebnisse zeigen können (Cindik et al. 2000, Ferretti et al. 2001).

In der vorliegenden Studie konnten für alle Genistein-Tiergruppen sowie für die Gruppe E2 höhere absolute Werte für das polare Widerstandmoment gemessen werden als für die ovarektomierte Kontrollgruppe (siehe Abschnitt 3.5). Im Fall von Genistein war das polare Widerstandsmoment bei den Gruppen Gen $1 \mathrm{~g}$ und Gen $3 \mathrm{~g}$ signifikant gegenüber der Kontrolle erhöht. In der Dosierung $3 \mathrm{~g} / \mathrm{kg}$ Genistein im Futter erreichte das polare Widerstandsmoment in absoluten Zahlen ein ähnlich hohes Niveau wie das von Tieren der Gruppen E2 oder Intakt. Die kritische Dosis für eine signifikante Erhöhung des polaren Widerstandmoments lag somit für Genistein zwischen 0,3 und $1 \mathrm{~g} / \mathrm{kg}$ im Futter. Durch Einnahme von Genistein lässt sich also dosisabhängig eine verbesserte Knochenbruchfestigkeit gegenüber einer einwirkenden Torsion erzielen. Auch biomechanische Biege- und Bruchtests an ovarektomierten Mäusen haben nach dreimonatiger Applikation von $1 \mathrm{~g} / \mathrm{kg}$ Genistein im Futter zu ähnlichen Ergebnissen wie bei einer E2Gruppe geführt und die Bruchfestigkeiten dieser Gruppen waren der der ovarektomierten Kontrollgruppe signifikant überlegen (Sehmisch et al. 2010).

Die Gruppe Gen $10 \mathrm{~g}$ mit der höchsten verabreichten Genisteindosis zeigte dagegen nur eine moderate Erhöhung des polaren Widerstandmoments. Ein möglicher Grund hierfür könnte 
das geringe Gewicht dieser Tiergruppe sein. Es ist bekannt, dass ein geringes Körpergewicht ein Risikofaktor für Osteoporose und Frakturen ist. Da Knochen und umliegende Weichteile einer biomechanischen Koppelung unterliegen, könnte ein höheres Körpergewicht auch zu einer stärkeren mechanischen Stimulation des Knochens führen, wodurch eine knochenerhaltende Wirkung gefördert wird (Ferretti et al. 2003, Gilsanz et al. 2009). Auch sind in der Literatur Angaben zu einem zweiphasigen Effekt von Genistein beschrieben. Die Einnahme von geringen oder mittleren Dosen von Genistein hatte bei ovarektomierten Ratten einen schützenden Effekt am Knochen, während sich für die hohe Dosis kein Schutz vor Osteoporose nachweisen ließ (Anderson et al. 1998). In der vorliegenden Arbeit konnte jedoch für die Spongiosadichte und den prozentualen Anteil der Trabekel an der Spongiosaquerschnittsfläche kein Wirkungsverlust bei hohen Genisteindosierungen nachgewiesen werden, wodurch eher die Theorie des geringen Körpergewichts der Gruppe Gen $10 \mathrm{~g}$ als Ursache für das geringe polare Widerstandmoment bestätigt wird.

Die oben beschriebenen Resultate bestätigen die schützende Wirkung von Östrogen auf die untersuchten Knochenparameter und stützen die Annahme aus vorherigen Untersuchungen, dass Genistein einen protektiven Einfluss auf den postmenopausalen Knochen hat. Die durchgeführten Untersuchungen haben gezeigt, dass durch einen Futterzusatz von E2 oder Genistein bei ovarektomierten Mäusen ein Verlust der Spongiosadichte verhindert werden kann, der prozentuale Anteil der Trabekel an der Spongiosaquerschnittsfläche, verglichen zur Kontrolle, gesteigert werden kann und das der Knochen einer einwirkenden Torsion gegenüber einen höheren Widerstand entgegen bringen kann. Darüber hinaus konnte bewiesen werden, dass für Genistein als Futterzusatz im Modell der langzeitovarektomierten Maus für die untersuchten Knochenparameter eine Dosisabhängigkeit besteht. Die kritische Dosis für eine signifikante Veränderung der Messwerte am Knochen lag jeweils zwischen $0,3 \mathrm{~g} / \mathrm{kg}$ und $1 \mathrm{~g} / \mathrm{kg}$ Genistein als Futterzusatz. Ein Einsatz von Genistein zur Osteoporoseprophylaxe oder -therapie der postmenopausalen Frau muss gegenüber einer potentiellen proliferativen Wirkung am Uterus (siehe Kapitel 4.2.1) und an der Brust (siehe Kapitel 1.9) abgewogen werden. Die Ergebnisse dieser Arbeit zeigen, dass es durchaus einen Dosisbereich geben könnte, in dem Genistein sinnvoll angewendet werden kann. Unklar ist, inwieweit sich diese Ergebnisse auch auf die postmenopausale Frau übertragen lassen. Für einen sicheren Einsatz von Genistein und die Bewertung möglicher Risiken und Nebenwirkungen sind weiterführende Untersuchungen notwendig 


\subsection{Fazit}

In der vorliegenden Arbeit wurde die dosisabhängige Wirkung von Genistein an ausgewählten Organen am Modell der langzeitovarektomierten Maus untersucht.

Das Modell der ovarektomierten Maus im Langzeitversuch über drei Monate hat sich dabei auch in dieser Arbeit zur Simulation der postmenopausalen Frau bewährt.

In der Studie gab es verschiedene Kontrollgruppen, die der vergleichenden Beurteilung der Wirksamkeit von Genistein dienten. Die Gruppe E2 war die Positivkontrolle, eine Gruppe aus ovarektomierten Mäusen, denen Östrogen in einer für Mäuse physiologischen Dosis im Futter verabreicht wurde. Für diese Gruppe bestätigte sich die vielfach beschriebene und erwartete Wirkung von Östrogen an den untersuchten Organen. Die Negativkontrolle bestand aus ovarektomierten Tieren, die östrogen- und sojafreies Futter erhielten. Eine weitere Kontrollgruppe bildeten die intakten Tiere, die nicht ovarektomiert waren und sojafreies Futter erhielten.

Für Genistein konnte für alle untersuchten Parameter eine dosisabhängige Wirkung gemessen werden. Die kritische Dosis für eine signifikante Veränderung, verglichen mit der ovarektomierten Kontrolle, variierte je nach Organ oder untersuchten Parametern.

Untersucht wurden das Körpergewicht der Tiere, das bei Östrogenmangel oft erhöht ist und durch Östrogen reguliert werden kann sowie der Knochen, der bei Östrogenmangel demineralisiert. Weiter wurde das Herz untersucht, da die Inzidenz für kardiovaskuläre Erkrankungen in der Menopause steigt. Die klassische Hormonersatztherapie, die diese Beschwerden und Erkrankungen zum Teil gut abfangen kann, ist aufgrund lebensgefährlicher Nebenwirkungen umstritten (Nelson et al. 2002). Deswegen wurde in dieser Arbeit auch das Uterusgewicht untersucht, wo die Gabe von E2 eine unerwünschte Proliferation hervorrufen kann.

Die Untersuchungen zielten auf die Frage ab, ob es für Genistein eine Dosis gibt, bei der die erwünschten Effekte wie bei einer E2-Gabe auftreten, eine Proliferation am Uterus aber noch nicht.

Die unerwünschte Wirkung einer signifikanten Erhöhung des relativen Uterusgewichts, die ein Risiko für eine maligne Entartung des Uterus darstellt, trat bei $3 \mathrm{~g} / \mathrm{kg}$ Genistein als Futterzusatz auf. Diese Dosis ist daher nicht mehr sicher im Hinblick auf eine uterotrophe 
Nebenwirkung anzusehen. Die Dosis für eine signifikante Verringerung des Körpergewichts, verglichen mit der ovarektomierten Kontrolle, lag ebenfalls bei 3 g/kg Genistein als Zusatz im Pelletfutter. Das bedeutet im Umkehrschluss, dass von einer Erhöhung des Uterusgewichts als unerwünschter Nebenwirkung auszugehen ist, wenn man eine Gewichtsreduzierung durch Genistein bewirken möchte.

Eine signifikante Erhöhung des relativen Gewichts des linken Herzventrikels, verglichen mit der Kontrolle, trat bei einer Dosis von $3 \mathrm{~g} / \mathrm{kg}$ Genistein im Futterzusatz auf. Das heißt wiederum, dass auch die gewünschte Wirkung am Herzen, dem durch Östrogenmangel bedingten Verlust des relativen Gewichts des linken Ventrikels entgegenzuwirken, nur unter Inkaufnahme einer Proliferationsinduktion am Uterus möglich ist. Eine Steigerung der Genexpression von IGF-1 und Myocardin am linken Ventrikel wurde schon ab einer Dosierung von $1 \mathrm{~g} / \mathrm{kg}$ Genistein als Futterzusatz gemessen, jedoch nur für Myocardin in dieser Dosierung mit Signifikanz. Folglich ist davon auszugehen ist, dass eine Wirkung am Herzen auch schon bei einer geringeren Dosis auftritt, sich aber im Experiment nicht in einer Veränderung der relativen Gewichts des linken Ventrikels niederschlug.

Für die ermittelten Knochenparameter lag die Dosis für eine signifikante Veränderung für alle drei gemessenen Parameter bei $1 \mathrm{~g} / \mathrm{kg}$ Genistein als Futterzusatz. Demnach konnte die gewünschte osteoprotektive Wirkung bei ovarektomierten Mäusen schon mit einer Genisteindosierung erreicht werden, bei der in dieser Arbeit noch kein Nachweis einer unerwünschten Wirkung am Uterus vorlag. Diese Ergebnisse wecken Zuversicht in Hinblick auf eine Therapiealternative der postmenopausalen Osteoporose.

In der vorliegenden Arbeit wurde die Genexpression am Uterus nicht bestimmt, so dass unklar bleibt, ob eine Veränderung der Genexpression auch schon unterhalb der Dosis von 3 g/kg Genistein im Futter vorlag, ab der eine Erhöhung des Uterusgewichts aufgetreten ist. In einer anderen Studie der Arbeitsgruppe wurde bei einer Dosierung von 1 g/kg Genistein als Futterzusatz bei ovarektomierten Mäusen nach dreimonatigem Versuchszeitraum keine Veränderung des relativen Uterusgewichts gemessen, aber eine Erhöhung der Expression von IGF-1, die jedoch weniger stark als bei E2-Gabe war (Nguyen et al. 2012b). Da die gesteigerte Produktion des Wachstumsfaktors IGF-1 molekularbiologisch ein Korrelat für das Wachstum der Gebärmutter darstellt, sollte dieser Faktor nicht unterschätzt werden (Klotz et al. 2002). 
Anhand der Ergebnisse der vorliegenden Arbeit kann man schlussfolgern, dass eine Genisteindosierung von $1 \mathrm{~g} / \mathrm{kg}$ im Futter bei Mäusen als relativ sichere Dosis in Hinblick auf uterotrophe Nebenwirkungen angesehen werden kann. Bei dieser Dosis war das relative Uterusgewicht noch nicht erhöht, aber eine Wirksamkeit am Knochen lag schon vor. Eine signifikante Reduzierung des Körpergewichts sowie Erhöhung des Herzgewichts waren bei dieser Dosierung nicht zu erzielen, wohl aber ein Einfluss auf die Genexpression am Herzen. Da aus den Erkenntnissen anderer Experimente von einer gesteigerten Genexpression am Uterus bei einer Genisteindosierung von $1 \mathrm{~g} / \mathrm{kg}$ Futter ausgegangen werden muss, ist der langfristige Einsatz von Genistein dennoch kritisch zu bewerten. Hier sind weiterführende Untersuchungen bezüglich einer exakten Nutzen-Risiko-Evaluation hilfreich. Wichtig wäre auch zu wissen, wie sich die untersuchten Parameter bei einer feineren Dosisabstufung von Genistein besonders in dem Bereich zwischen 0,75 und $3 \mathrm{~g} / \mathrm{kg}$ Futterzusatz verhalten. Inwieweit sich die in dieser Arbeit erhobenen Ergebnisse der Wirkung von Genistein im Hinblick auf eine sichere und effiziente Therapiealternative zur klassischen Hormonersatztherapie auf die menopausale Frau übertragen lassen muss noch genauer untersucht werden.

Eine im Rahmen dieser Arbeit nicht untersuchte unerwünschte Wirkung von Genistein ist die potentiell proliferative Wirkung von Genistein an der Brustdrüse. Nach derzeitigen Erkenntnissen scheinen auch an der Brust die Dosis, die Dauer und der Zeitpunkt der Exposition auschlaggebend zu sein (Bouker und Hilakivi-Clarke 2000). In der asiatischen Bevölkerung bietet ein lebenslanger Konsum von Genistein möglicherweise einen Schutz vor Brustkrebs (Bouker und Hilakivi-Clarke 2000, Warri et al. 2008). Bei einer Langzeittherapie von Genistein mit Beginn in der Menopause muss nach aktuellem Stand der Forschung eine proliferative Wirkung an der Brust, die einen Risikofaktor für Brustkrebs darstellt, berücksichtigt werden (Rimoldi et al. 2007).

Zusammenfassend kann gesagt werden, dass eine dosisabgängige Wirkung von Genistein auf Körpergewicht, Uterus und verschiedene Knochenparameter besteht. Darüber hinaus wurde gezeigt, dass nicht nur Estradiol, sondern auch Genistein in der Lage ist, das relative Herzgewicht und die Genexpression am Herzen zu beeinflussen. Auch hier lag jeweils eine Dosisabhängigkeit von Genistein vor.

Trotz der zu großen Teilen positiven, hoffungsvollen Wirkung von Genistein ist aktuell aufgrund der oben genannten potentiellen Risiken von einer medikamentösen Genistein- 
einnahme bei menopausalen Frau, wie vielfach beworben, abzuraten. Eine Herausforderung für die weitere Forschung an Genistein besteht darin, eine sichere Dosis zu finden, bei Gabe die positive Wirkung von Genistein entfaltet wird, sich jedoch keine unerwünschten Nebenwirkungen an Uterus und Brust zeigen. Diese Arbeit hat gezeigt, dass dies zumindest im Fall der Wirkung von Genistein am Knochen möglich sein könnte. 


\section{Zusammenfassung}

Die Inzidenz von Herzerkrankungen und Osteoporose steigt bei Frauen nach der Menopause, bedingt durch den Östrogenmangel, stark an. Darüber hinaus leiden Frauen im Klimakterium, bedingt durch die Hormonumstellung, häufig unter so genannten Wechseljahrsbeschwerden. Mit einer klassischen Hormonersatztherapie lassen sich viele dieser Beschwerden lindern. In großen, klinisch randomisierten Langzeitstudien konnte jedoch gezeigt werden, dass die Risiken dieser Hormonersatztherapie für Brustkrebs und thrombembolische Ergebnisse zu groß sind, um einen breiten Einsatz in der Therapie von klimakterischen Beschwerden zu rechtfertigen. In den vergangenen Jahren sind deshalb Phytohormone als potentielle Alternative zunehmend in den Fokus der Wissenschaft gerückt.

In der vorliegenden Arbeit wurde die dosisabhängige Wirkung des Phytoöstrogens Genistein an ausgewählten östrogenselektiven Organen näher untersucht. Aus anderen Studien ist bereits bekannt, dass Genistein als Futterzusatz bei ovarektomierten Tieren die kardiale Genexpression beeinflusst und die Knochenqualität verbessert. Unklar war bislang, wo der genaue Dosisbereich liegt, bei dem eine Wirkung von Genistein auftritt und ob für Genistein eine dosisabhängige Beziehung besteht. Für einen Einsatz von Genistein in der Therapie von klimakterischen Beschwerden ist es wichtig zu prüfen, bei welcher Dosis potentiell erwünschte und unerwünschte Wirkungen von Genistein auftreten und wie sicher Genistein im Hinblick auf Risiken ist, die von einer klassischen HET ausgehen.

Für diese Arbeit wurde das Modell der langzeitovarektomierten Maus gewählt, das in Hinblick auf nachfolgende Untersuchungen an Knock-out-Mäusen eine bessere Vergleichbarkeit als das Rattenmodell gewährleistet. Es wurden 70 ovarektomierte Tiere in sieben Gruppen mit je zehn Tieren aufgeteilt und untersucht. Fünf der sieben Gruppen erhielten genisteinhaltiges Futter in verschiedenen Konzentrationen (0,1 g, 0,3 g, 1 g, 3 g, und 10 g Genistein/ kg Futterzusatz), wobei der Dosisbereich anhand des Vorgängerexperiments gewählt und in beide Richtungen erweitert wurde. Die anderen beiden Gruppen erhielten Estradiol (4,32 mg 17ß-Estradiol-benzoat pro kg sojafreies Futter) als Zusatz oder sojafreie Diät und dienten jeweils als Positiv- und Negativkontrollgruppe. Weitere zehn nicht ovarektomierte Tiere bildeten die intakte Kontrollgruppe, die ebenfalls sojafreies Futter erhielt. Während des dreimonatigen Versuchszeitraums wurden regelmäßig Gewicht und Futterverbrauch der Tiere gemessen. Nach Ende des Versuchs wurden die Feuchtgewichte von Uterus und Herz bestimmt sowie die Genexpression am linken Ventrikel von IGF-1, ER $\alpha$ 
und Myocardin mittels PCR analysiert. Darüber hinaus wurde am Tibia-Knochen per pQCT die Messung der Spongiosadichte, des polaren Widerstandsmoments und des prozentualen Anteils der Trabekel an der Spongiosaquerschnittsfläche durchgeführt.

Eine signifikante Verringerung des Körpergewichts, verglichen mit der sojafreien Kontrolle, konnte für E2 und für Genistein in der Dosierung $3 \mathrm{~g} / \mathrm{kg}$ als Futterzusatz gemessen werden. Auch die unerwünschte Wirkung einer Erhöhung des relativen Uterusgewichts trat, verglichen mit der ovarektomierten Kontrolle, bei einer Dosierung von 3 g/kg Genistein als Futterzusatz auf. In dieser Dosierung war die Erhöhung des relativen Uterusgewichts jedoch signifikant schwächer als mit E2. Das relative Organgewicht des linken Herzventrikels war, verglichen mit der ovarektomierten Kontrolle, für E2 und ab einer Dosierung von $3 \mathrm{~g} / \mathrm{kg}$ im Futterzusatz für Genistein signifikant erhöht. Die Genexpression am linken Ventrikel war ab einer Genisteindosierung von $1 \mathrm{~g} / \mathrm{kg}$ für Myocardin und IGF-1, verglichen mit der ovarektomierten Kontrolle, erhöht, jedoch nur für Myocardin in dieser Dosierung mit Signifikanz. Auch durch E2-Gabe ließ sich die Genexpression von Myocardin und IGF-1 signifikant steigern. Die Genexpression von ER $\alpha$ war, verglichen mit der ovarektomierten Kontrolle, in keiner Gruppe deutlich verändert. Die untersuchten Knochenparameter ergaben, verglichen mit der ovarektomierten Kontrolle, eine signifikante Erhöhung der Spongiosadichte, des polaren Widerstandsmoments und des prozentualen Anteils der Trabekel an der Spongiosa-querschnittsfläche ab einer Genisteindosierung von $1 \mathrm{~g} / \mathrm{kg}$ als Futterzusatz.

Anhand dieser Ergebnisse lässt sich schlussfolgern, dass für alle untersuchten Parameter eine dosisabhängige Wirkung von Genistein vorlag. Die kritische Dosis für eine signifikante Veränderung variierte je nach Organ oder zu untersuchendem Parameter. Darüber hinaus bestätigen die Ergebnisse, dass das Modell der langzeitovarektomierten Maus auch geeignet ist, eine dosisabhängige Wirkung von östrogenartigen Stoffen an verschiedenen Organen zu charakterisieren. Die Dosierung von $1 \mathrm{~g} / \mathrm{kg}$ Genistein im Futter ergab eine osteoprotektive Wirkung, ohne jedoch eine signifikante Zunahme des relativen Gewichts des Uterus zu induzieren. In dieser Dosierung blieb auch das relative Herzgewicht, verglichen mit der Kontrolle, unverändert. Die kardiale Genexpression von Myocardin und IGF-1, von denen letzterem auch eine herzprotektive Wirkung zugeschrieben wird, war bereits erhöht. Da anhand von anderen Untersuchungen eine gesteigerte Genexpression am Uterus bei $1 \mathrm{~g} / \mathrm{kg}$ Genistein im Futter nicht ausgeschlossen werden kann, ist der Einsatz dennoch kritisch zu bewerten. Auch eine in dieser Arbeit nicht untersuchte proliferationsfördernde Wirkung an 
der Brust muss in der Nutzen-Risiko-Bewertung für einen Einsatz von Genistein berücksichtigt werden.

In dieser Arbeit konnte gezeigt werden, dass Genistein direkt am Herz wirkt, indem es das relative Herzgewicht und die Genexpression am Herz erhöht. Genistein beeinflusst auch das Körpergewicht und das relative Gewicht des Uterus und die untersuchten Knochenparameter dosisabhängig. Genistein kann in höherer Dosierung am Uterus proliferierend wirken, jedoch nach derzeitigem Kenntnisstand weniger stark als der klassische HormonersatztherapieWirkstoff E2. Genistein kann zukünftig nur dann eine Therapiealternative zur klassischen Hormonersatztherapie darstellen, wenn es gelingt, eine Dosis zu finden, bei der Genistein die gewünschten Wirkungen entfaltet, gleichzeitig aber die unerwünschte proliferierende Wirkung an Brust und Uterus sicher ausgeschlossen werden kann. Im Modell der ovarektomierten Maus scheint eine Dosis von $1 \mathrm{~g} / \mathrm{kg}$ Genistein im Futter ein vielversprechender Ansatzpunkt für weitere Untersuchungen zu sein. 


\section{Literaturverzeichnis}

Adlercreutz H (1998): Epidemiology of phytoestrogens. Baillieres Clin Endocrinol Metab $\underline{12}$, 605-623.

Adlercreutz H, Mazur W (1997): Phyto-oestrogens and Western diseases. Ann Med 29, 95120.

Adlercreutz H, Bannwart C, Wähälä K, Mäkelä T, Brunow G, Hase T, Arosemena P, Kellis JJ, Vickery L (1993): Inhibition of human aromatase by mammalian lignans and isoflavonoid phytoestrogens. J Steroid Biochem Mol Biol 44, 147-153.

Aidoo A, Bishop M, Shelton S, Lyn-Cook L, Chen T, Manjanatha M (2005): Effects of daidzein, genistein, and 17 $\beta$-estradiol on 7,12-dimethylbenz[a]anthracene-induced mutagenicity and uterine dysplasia in ovariectomized rats. Nutr Cancer $\underline{53}$, 82-90.

Akiyama T, Ishida J, Nakagawa S, Ogawara H, Watanabe S, Itoh N, Shibuya M, Fukami Y (1987): Genistein, a specific inhibitor of tyrosine-specific protein kinases. J Biol Chem 262, 5592-5595.

Alekel DL, Loan MD Van, Koehler KJ, Hanson LN, Stewart JW, Hanson KB, Kurzer MS, Peterson CT (2010): The Soy Isoflavones for Reducing Bone Loss ( SIRBL ) Study : a 3-y randomized controlled trial in postmenopausal women Am J Clin Nutr 91, 218-230.

Anderson J, Garner S (1998): Phytoestrogens and bone. Baillieres Clin Endocrinol Metab 12, 543-557.

Anderson J, Ambrose W, Garner S (1998): Biphasic effects of genistein on bone tissue in the ovariectomized, lactating rat model. Proc Soc Exp Biol Med 217, 345-350.

Arias-Loza P, Jazbutyte V, Pelzer T (2008): Genetic and pharmacologic strategies to determine the function of estrogen receptor alpha and estrogen receptor beta in cardiovascular system. Gend Med $\underline{5}$, 34-45.

Asarian L, Geary N (2006): Modulation of appetite by gonadal steroid hormones. Philos Trans R Soc Lond B Biol Sci $\underline{361}$ 1251-1263.

Bagchi D, Tosak A, Bagchi M, Kothari S (2001): Benefits of resveratrol in women's health. Drugs Exp Clin Res 27, 233-248.

Barnes S (1995): Effect of Genistein on In Vitro and In Vivo Models of Cancer. J Nutr $\underline{125}$ 777S-783S.

Beral V, Collaborators MWS (2003): Breast cancer and hormone-replacement therapy in the Million Women Study. Lancet 362, 419-427.

Beral V, Bull D, Green J, Reeves G (2007): Ovarian cancer and hormone replacement therapy in the Million Women Study. Lancet 369, 1703-1710. 
Bian Z, Nilsson S, Gustafsson JA (2001): Selective Estrogen Receptor Modulators and Coronary Heart Disease. Trends Cardiovasc Med 11, 196-202.

Bord S, Horner A, Beavan S, Compston J (2001): Estrogen receptors alpha and beta are differentially expressed in developing human bone. J Clin Endocrinol Metab 6, 2309-2314.

Bouker KB, Hilakivi-Clarke L (2000): Genistein: Does It Prevent or Promote Breast Cancer? Estrogenic Effects of Possible Antiestrogenic Effects of Genistein. Environ Health Perspect 108, 701-708.

Büchler P, Gukovskaya AS, Mouria M, Büchler MC, Büchler MW, Friess H, Pandol SJ, Reber H, Hines OJ (2003): Prevention of metastatic pancreatic cancer growth in vivo by induction of apoptosis with genistein, a naturally occurring isoflavonoid. Pancreas $\underline{26}$, 264273.

Butera PC (2010): Estradiol and the control of food intake. Physiol Behav $\underline{99}$, 175-180.

Cabanes A, Wang M, Olivo S, De Assis S, Gustafsson JA, Khan G, Hilakivi-Clarke L (2004): Prepubertal estradiol and genistein exposures up-regulate BRCA1 mRNA and reduce mammary tumorigenesis. Carcinogenesis $\underline{25}$, 741-748.

Carlson S, Peng N, Prasain JK, Wyss JM (2008): The effects of botanical dietary supplements on cardiovascular, cognitive and metabolic function in males and females. Gend Med $\underline{5}$, S76S90.

Cassidy A, Bingham S, Setchell KD (1994): Biological effects of a diet of soy protein rich in isoflavones on the menstrual cycle of premenopausal women. Am Soc Clin Nutr $\underline{60}$, 333-340.

Chao W, Matsui T, Novikov MS, Tao J, Li L, Liu H, Ahn Y, Rosenzweig A (2003): Strategic advantages of insulin-like growth factor-I expression for cardioprotection. J Gen Med $\underline{5}$, 277286.

Chiechi L (1999): Dietary phytoestrogens in the prevention of long-term postmenopausal diseases. Int J Gynaecol Obstet $\underline{67}$, 39-40.

Chiechi L, Lobascio A, Grillo A, Valerio T (1999): Phytoestrogen-containing food and prevention of postmenopausal osteoporosis and cardiovascular diseases. Minerva Ginecol $\underline{51}$, 343-348.

Chien KR, Karsenty G (2005): Longevity and lineages: toward the integrative biology of degenerative diseases in heart, muscle, and bone. Cell $\underline{120}$, 533-544.

Chlebowski RT, Wactawski-Wende J, Ritenbaugh C, Allan Hubbell, Ascensao J, Rodabough RJ, Rosenberg CA, Taylor VM, Harris R, Chen C, Adams-Campbell LL, White E (2004): Estrogen plus progestin and colorectal cancer in postmenopausal women. N Engl J Med $\underline{350}$, 2417-2419.

Cindik E, Willnecker J, Wolf E, Eckstein F (2000): Analyse femoraler Knocheneigenschaften im MT-bGH-trans-genen Mausmodell mit der hochauflösenden pQCT. Osteologie $\underline{9}$, 85-92. 
Clarkson TB (2002): Soy Phytoestrogens and Cardiovascular Disease. J Nutr 132, 566S569S.

Colditz GA, Willett WC, Stampfer MJ, Rosner B, Speizer FE, Hennekens CH. (1987):

Menopause and the Risk of Coronary Heart Disease in Women. N Engl J Med 316, 11051110.

Cullinan-Bove K, Koos D (1993): Vascular endothelial growth factor/vascular permeability factor expression in the rat uterus: rapid stimulation by estrogen correlates with estrogeninduced increases in uterine capillary permeability and growth. Endocrinology 133, 829-837.

Cutler GB Jr (1997): The role of estrogen in bone growth and maturation during childhood and adolescence. J Steroid Biochem Mol Biol 61, 141-144.

D’Eon TM, Souza SC, Aronovitz M, Obin MS, Fried SK, Greenberg AS (2005): Estrogen regulation of adiposity and fuel partitioning. Evidence of genomic and non-genomic regulation of lipogenic and oxidative pathways. J Biol Chem 280, 35983-35991.

Dahlman-Wright K, Cavailles V, Fuqua SA, Jordan VC, Katzenellenbogen JA, Korach KS, Maggi A, Muramatsu M, Parker MG, Gustafsson JA (2006): International Union of Pharmacology LXIV Estrogen Receptors. Pharmacol Rev 무, 773-781.

Davis S, Dalais F, Simpson E, Murkies A (1999): Phytoestrogens in health and disease. Recent Prog Horm Res 노, 185-210.

Delmas PD (2002): Treatment of postmenopausal osteoporosis. Lancet $\underline{359}$, 2018-26.

Deutsche Gesellschaft für Gynäkologie und Geburtshilfe: Leitlinie „Hormontherapie in der Peri- und Postmenopause (HT)“. hrsg. v. Deutsche Gesellschaft für Gynäkologie und Geburtshilfe (DGGG), Autorisiert für elektronische Publikation: AWMF online, Düsseldorf; http://www.awmf.org/leitlinien/detail/ll/015-062.html, Abrufdatum: 23.05.2013.

DeVere White RW, Tsodikov A, Stapp EC, Soares SE, Fujii H, Hackman RM (2010): Effects of a High Dose, Aglycone-Rich Soy Extract on Prostate- Specific Antigen and Serum Isoflavone Concentrations in Men With Localized Prostate Cancer. Nutr Cancer 62, 10361043.

Diel P, Geis R, Caldarelli A, Schmidt S, Leschowsky U, Voss A, Vollmer G (2004): The differential ability of the phytoestrogen genistein and of estradiol to induce uterine weight and proliferation in the rat is associated with a substance specific modulation of uterine gene expression. Mol Cell Endocrinol 221, 21-32.

Dirisamer A, Grampp S (2002): Radiologische Diagnostik der Osteoporose. J für Miner $\underline{9}$, 715.

Douglas PS, Katz SE, Weinberg EO, Chen MH, Bishop SP, Lorell BH (1998): Hypertrophic remodeling: gender differences in the early response to left ventricular pressure overload. $\mathrm{J}$ Am Coll Cardiol 32, 1118-1125. 
Dutertre M, Smith CL (2000): Molecular mechanisms of selective estrogen receptor modulator (SERM) action. J Pharmacol Exp Ther 295, 431-437.

Edwards BJ, Li J (2013): Endocrinology of menopause. Periodontol 2000 61, 177-194.

Eickels M Van, Grohé C, Cleutjens JP, Janssen BJ, Wellens HJ, Doevendans PA (2001): 17beta-Estradiol Attenuates the Development of Pressure-Overload Hypertrophy. Circulation 104, 1419-1423.

Erlandsson MC, Islander U, Moverare S, Ohlsson C, Carlsten H (2005): Estrogenic agonism and antagonism of the soy isoflavone genistein in uterus, bone and lymphopoiesis in mice. APMIS $\underline{113}$, 317-323.

Ernst M, Heath JK, Rodan GA (1989): Estradiol Effects on Proliferation, Messenger Ribonucleic Acid for Collagen and Insulin-like Growth Factor-I, and Parathyroid HormoneStimulated Adenylate Cyclase Activity in Osteoblastic Cells from Calvariae and Long Bones. Endocrinology 125, 825-833.

Evans B, Griffiths K, Morton M (1995): Inhibition of 5 alpha-reductase in genital skin fibroblasts and prostate tissue by dietary lignans and isoflavonoids. J Endocrinol 147, 295302.

Fanti P, Geng Z, Schmidt J, Morris PE, Cohen D, Malluche HH (1998): The Phytoestrogen Genistein Reduces Bone Loss in Short-Term Ovariectomized Rats. Osteoporos Int $\underline{8}, 274$ 281.

Ferretti J, Cointry G, Capozza R, Frost H (2003): Bone mass, bone strength, muscle-bone interactions, osteopenias and osteoporoses. Mech Ageing Dev 124, 269-279.

Ferretti JL, Cointry GR, Capozza RF, Capiglioni R, Chiappe M a (2001): Analysis of biomechanical effects on bone and on the muscle-bone interactions in small animal models. $\mathrm{J}$ Musculoskelet Neuronal Interact $\underline{1}$, 263-274.

Finking G, Hussein Gohar M, Lenz C, Hanke H (2000): Die Wirkungen von Östrogen im kardiovaskulären System. Z Kardiol 89, 442-453.

Fotsis T, Pepper MS, Montesano R, Aktas E, Breit S, Schweigerer L, Rasku S, Wähälä K, Adlercreutz H (1998): Phytoestrogens and inhibition of angiogenesis. Baillieres Clin Endocrinol Metab 12, 649-666.

Fujio Y, Nguyen T, Wencker D, Kitsis RN, Walsh K (2000): Akt Promotes Survival of Cardiomyocytes In Vitro and Protects Against Ischemia-Reperfusion Injury in Mouse Heart. Circulation 101, 660-667.

Fungfuang W, Terada M, Komatsu N, Moon C, Saito TR (2013): Effects of estrogen on food intake, serum leptin levels and leptin mRNA expression in adipose tissue of female rats. Lab Anim Res 29, 168-173. 
Gadducci A, Biglia N, Sismondi P, Genazzani AR (2005): Breast cancer and sex steroids: critical review of epidemiological, experimental and clinical investigations on etiopathogenesis, chemoprevention and endocrine treatment of breast cancer. Gynecol Endocrinol 20, 343-360.

Gallagher PE, Li P, Lenhart JR, Chappell MC, Brosnihan KB (1999): Estrogen Regulation of Angiotensin-Converting Enzyme mRNA. Hypertension 33, 323-328.

Gao Q, Horvath TL (2008): Cross-talk between estrogen and leptin signaling in the hypothalamus. Am J Physiol Endocrinol Metab 294, 817-826.

Gao Z, Lau C, Wong T, Li G (2004): Protein tyrosine kinase-dependent modulation of voltage-dependent potassium channels by genistein in rat cardiac ventricular myocytes. Cell Signal 16, 333-341.

Gasser J. A. (1995): Assessing bone quantity by pQCT. Bone 17, 145-154.

van der Geer P, Hunter T, Diego S, Lindberg RA, Ction I (1994): Receptor protein-tyronise kinases and their signal transduction pathways. Annu Rev Cell Biol 10, 251-337.

Gencel VB, Benjamin MM, Bahou SN, Khalil RA (2013): Vascular Effects of Phytoestrogens and Alternative Menopausal Hormone Therapy in Cardiovascular Disease. Mini Rev Med Chem 12, 149-174.

Geraldes P, Sirois MG, Tanguay JF (2003): Specific contribution of estrogen receptors on

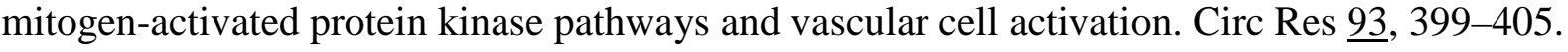

Gercel-Taylor C, Feitelson AK, Taylor DD (2004): Inhibitory effect of genistein and daidzein on ovarian cancer cell growth. Anticancer Res 24, 795-800.

Gilsanz V, Chalfant J, Mo AO, Lee DC, Dorey FJ, Mittelman SD (2009): Reciprocal relations of subcutaneous and visceral fat to bone structure and strength. J Clin Endocrinol Metab $\underline{94}$, 3387-3393.

Goldwyn S, Lazinsky A, Wei H (2000): Promotion of health by soy isoflavones: efficacy, benefit and safety concerns. Drug Metabol Drug Interact 17, 261-289.

Goodman-Gruen D, Kritz-Silverstein D (2003): Usual dietary isoflavone intake and body composition in postmenopausal women. Menopause $\underline{10}$, 427-432.

Green S, Walter P, Kumar V, Krust A, Bornert J, Argos P, Chambon P (1986): Human oestrogen receptor cDNA: sequence, expression and homology to v-erb-A. Nature $\underline{320}, 134$ 139.

Greendale G, Reboussin B, Hogan P, Barnabei V, Shumaker S, Johnson S, Barrett-Connor E (1998): Symptom relief and side effects of postmenopausal hormones: results from the Postmenopausal Estrogen/Progestin Interventions Trial. Obstet Gynecol 92, 982-988.

Grodstein F, Stampfer M (1995): The epidemiology of coronary heart disease and estrogen replacement in postmenopausal women. Prog Cardiovasc Dis $\underline{38}, 199-210$. 
Grodstein F, Colditz G, Stampfer M (1994): Postmenopausal hormone use and cholecystectomy in a large prospective study. Obstet Gynecol 83, 5-11.

Grohé C, Kahlert S, Löbbert K, Stimpel M, Karas RH, Vetter H, Neyses L (1997): Cardiac myocytes and fibroblasts contain functional estrogen receptors. FEBS Lett $\underline{416}$, 107-112.

Gruber CJ, Tschugguel W, Schneeberger C, Huber JC (2002): Production and actions of estrogens. N Engl J Med 346, 340-352.

Guo X, Kim C (2002): Mechanical consequence of trabecular bone loss and its treatment: a three-dimensional model simulation. Bone $\underline{30}$, 404-411.

He Z, Zhang SS, Meng Q, Li S, Zhu HH, Raquil MA, Alderson N, Zhang H, Wu J, Rui L, Cai D, Feng G-S (2012): Shp2 controls female body weight and energy balance by integrating leptin and estrogen signals. Mol Cell Biol 32, 1867-1878.

Hegele-Hartung C, Siebel P, Peters O, Kosemund D, Müller G, Hillisch A, Walter A, Kraetzschmar J, Fritzemeier KH (2004): Impact of isotype-selective estrogen receptor agonists on ovarian function. Proc Natl Acad Sci U S A 101, 5129-5134.

Heim M, Frank O, Kampmann G, Sochocky N, Pennimpede T, Fuchs P, Hunziker W, Weber P, Martin I, Bendik I (2004): The phytoestrogen genistein enhances osteogenesis and represses adipogenic differentiation of human primary bone marrow stromal cells. Endocrinology 145, 848-859.

Helterbrand JD, Higgs RE, Iversen PW, Tysarczyk-Niemeyer G, Sato M (1997): Application of automatic image segmentation to tibiae and vertebrae from ovariectomized rats. Bone $\underline{21}$, 401-409.

Herold G u.a.: Innere Medizin. Auflage 2010; Hrsg. v. Gerd Herold, Köln 2009, 685-765.

Hertrampf T, Degen GH, Kaid AA, Laudenbach-Leschowsky U, Seibel J, Di Virgilio AL, Diel P (2006): Combined effects of physical activity, dietary isoflavones and 17beta-estradiol on movement drive, body weight and bone mineral density in ovariectomized female rats. Planta Med 72, 484-487.

Hillard TC, Stevenson JC (1991): Role of oestrogen in the development of osteoporosis. Calcif Tissue Int $\underline{49}$, 55-59.

Hintz KK, Ren J (2004): Phytoestrogenic Isoflavones Daidzein and Genistein Reduce Glucose-Toxicity-Induced Cardiac Contractile Dysfunction in Ventricular Myocytes. Endocr Res 30, 215-223.

Hodge EB (1966): Estrogenic compounds and animal growth promoters. U.S. Patent No. 3,239,345; 8.03.1966.

Hofbauer LC, Khosla S, Dunstan CR, Lacey DL, Boyle WJ, Riggs BL (2000): The roles of osteoprotegerin and osteoprotegerin ligand in the paracrine regulation of bone resorption. $\mathrm{J}$ Bone Miner Res $\underline{15}$, 2-12. 
Hogervorst E, Yaffe K, Richards M, Huppert FA (2009): Hormone replacement therapy to maintain cognitive function in women with dementia. Cochrane Database of Systematic Reviews 1, 1-25.

Hooper L, Ryder JJ, Kurzer MS, Lampe JW, Messina MJ, Phipps WR, Cassidy A (2009): Effects of soy protein and isoflavones on circulating hormone concentrations in pre- and postmenopausal women: a systematic review and meta-analysis. Hum Reprod Update 15, 423 440 .

Horst-Sikorska W, Wawrzyniak A (2011): The role of hormonal therapy in osteoporosis Terapia hormonalna w osteoporozie. Polish J Endocrinol 62, 61-64.

Hulley S, Grady D, Bush T, Furberg C, Herrington D, Riggs B, Vittinghoff E (2013): Randomized Trial of Estrogen Plus Progestin for Secondary Prevention of Coronary Heart Disease in Postmenopausal Women. J Am Med Assoc 280, 605-613:

Huppelsberg J, Walter K: Kurzlehrbuch Physiologie. 2. Auflage; Georg Thieme Verlag, Stuttgart 2005, 225-235

Hwang Y, Kim S, Jee S, Kim Y, Nam C (2009): Soy food consumption and risk of prostate cancer: a meta-analysis of observational studies. Nutr Cancer $\underline{61}$, 598-606.

Ishimi Y, Arai N, Wang X, Wu J, Umegaki K, Miyaura C, Takeda a, Ikegami S (2000): Difference in effective dosage of genistein on bone and uterus in ovariectomized mice. Biochem Biophys Res Commun 274, 697-701.

Isles CG, Hole DJ, Hawthorne VM, Lever AF (1992): Relation between coronary risk and coronary mortality in women of the Renfrew and Paisley survey: comparison with men. Lancet $\underline{339}$, 702-706.

Iwaniec UT, Yuan D, Power RA, Wronski TJ (2006): Strain-Dependent Variations in the Response of Cancellous Bone to Ovariectomy in Mice. 21, 1068-1074.

Jee WS, Yao W (2001): Overview: animal models of osteopenia and osteoporosis. J Musculoskelet Neuronal Interact $\underline{1}$, 193-207.

Johnson BD, Zheng W, Korach KS, Scheuer T, Catterall WA, Rubanyi GM (1997): Increased expression of the cardiac L-type calcium channel in estrogen receptor-deficient mice. J Gen Physiol 110, 135-140.

Jovanović S, Jovanović A, Shen WK, Terzic A (2000): Low concentrations of 17betaestradiol protect single cardiac cells against metabolic stress-induced Ca2+ loading. J Am Coll Cardiol 36, 948-952.

Kamakshi K, Verbalis JG, Zheng W, Zheng W, Clerch LB, Sandberg K (1999): Estrogen Regulates Angiotensin AT1 Receptor Expression via Cytosolic Proteins that Bind to the 5' Leader Sequence of the Receptor mRNA. Endocrinology 140, 5435-5438. 
Kanno J, Onyon L, Peddada S, Ashby J, Jacob E, Owens W (2003): The OECD Program to Validate the Rat Uterotrophic Bioassay. Phase 2: Dose-Response Studies. Environ Health Perspect 111, 1530-1549.

Kapiotis S, Hermann M, Held I, Seelos C, Ehringer H, Gmeiner BM (1997): Genistein, the Dietary-Derived Angiogenesis Inhibitor, Prevents LDL Oxidation and Protects Endothelial Cells From Damage by Atherogenic LDL. Arterioscler Thromb Vasc Biol 17, 2868-2874.

Kararigas G, Becher E, Mahmoodzadeh S, Knosalla C, Hetzer R, Regitz-Zagrosek V (2010): Sex-specific modification of progesterone receptor expression by $17 \beta$-oestradiol in human cardiac tissues. Biol Sex Differ 1:2, 1-9.

Kararigas G, Nguyen B, Jarry H (2014): Estrogen modulates cardiac growth through an estrogen receptor $\alpha$-dependent mechanism in healthy ovariectomized mice. Mol Cell Endocrinol 382, 909-914.

Karck U, Keck C, Karck M, Breckwoldt M (1998): Wirkung von Östrogenen auf das kardiovaskuläre System. Geburtshilfe Frauenheilkd $\underline{58}$, 401-407.

Khan NS, Malhotra S (2003): Effect of hormone replacement therapy on cardiovascular disease: current opinion. Expert Opin Pharmacother 4, 667-674.

Khan S, Chatterton R, Michel N, Bryk M, Lee O, Ivancic D, Heinz R, Zalles C, Helenowski I, Jovanovic B, Franke A, Bosland M, Wang J, Hansen N, Bethke K, Dew A, Coomes M, Bergan R (2013): Soy Isoflavone supplementation for breast cancer risk reduction: a randomized phase II trial. Cancer Prev Res (Phila) $\underline{5}$, 309-319.

Kim HK, Nelson-Dooley C, Della-Fera MA, Yang JY, Zhang W, Duan J, Hartzell DL, Hamrick MW, Baile CA, (2006): Genistein Decreases Food Intake, Body Weight, and Fat Pad Weight and Causes Adipose Tissue Apoptosis in Ovariectomized Female Mice. J Nutr 136, 409-414.

Kim SH, Kim SH, Kim YB, Jeon YT, Lee SC, Song YS (2009): Genistein inhibits cell growth by modulating various mitogen-activated protein kinases and AKT in cervical cancer cells. Ann N Y Acad Sci 1171, 495-500.

Klotz DM, Hewitt SC, Ciana P, Raviscioni M, Lindzey JK, Foley J, Maggi A, DiAugustine RP, Korach KS (2002): Requirement of estrogen receptor-alpha in insulin-like growth factor1 induced uterine responses and in vivo evidence for IGF-1/estrogen receptor cross-talk. J Biol Chem 277, 8531-8537.

Kuhl H (1996): Kardiovaskuläre Protektion durch Östrogen/Gestagen-Substitution. Dtsch Ärzteblatt 93, 1116-1119.

Kuiper GG, Enmark E, Pelto-Huikko M, Nilsson S, Gustafsson JA (1996): Cloning of a novel receptor expressed in rat prostate and ovary. Proc Natl Acad Sci U S A $\underline{93}$, 5925-5930.

Kuiper GG, Carlsson B, Grandien K, Enmark E, Häggblad J, Nilsson S, Gustafsson JA (1997): Comparison of the ligand binding specificity and transcript tissue distribution of estrogen receptors $\alpha$ and $\beta$. Endocrinology $\underline{138}$, 863-870. 
Kuiper GG, Lemmen JG, Carlsson BO, Corton JC, Safe SH, Saag PT van der, Burg B van der, Gustafsson JA (1998): Interaction of Estrogenic Chemicals and Phytoestrogens with Estrogen Receptor $\beta$. Endocrinology 139, 10-16.

Kurzer MS (2002): Hormonal Effects of Soy in Premenopausal Women and Men. J Nutr $\underline{132}$, 570S-573S.

Lakatta EG (2002): Age-associated cardiovascular changes in health: impact on cardiovascular disease in older persons. Heart Fail Rev $\underline{7}$, 29-49.

Lamartiniere CA (2002): Timing of exposure and mammary cancer risk. J Mammary Gland Biol Neoplasia $\underline{7}, 67-76$.

De Lemos M (2001): Effects of soy phytoestrogens genistein and daidzein on breast cancer growth. Ann Pharmacother $\underline{35}$, 1118-1121.

LeRoith D, Roberts CJ (2003): The insulin-like growth factor system and cancer. Cancer Lett 195, 127-137.

Levis S, Strickman-Stein N, Ganjei-Azar P, Xu P, Doerge DR, Krischer J (2013): Soy Isoflavones in the Prevention of Menopausal Bone Loss and Menopausal Symptoms. Am Med Assoc 171, 1363-1369.

Li H, Zhang Y, Tian Z, Qiu X, Gu J, Wu J (2008): Genistein stimulates myocardial contractility in guinea pigs by different subcellular mechanisms. Eur J Pharmacol 597, 70-74.

Li HJ, Haque Z, Lu Q, Li L, Karas R, Mendelsohn M (2007): Steroid receptor coactivator 3 is a coactivator for myocardin, the regulator of smooth muscle transcription and differentiation. Proc Natl Acad Sci U S A 104, 4065-4070.

Li Q, Li B, Wang X, Leri A, Jana KP, Liu Y, Kajstura J, Baserga R, Anversa P (1997): Overexpression of insulin-like growth factor-1 in mice protects from myocyte death after infarction, attenuating ventricular dilation, wall stress, and cardiac hypertrophy. J Clin Invest 100, 1991-1999.

Liew R, Williams JK, Collins P, Macleod KT (2003): Soy-Derived Isoflavones Exert Opposing Actions on Guinea Pig Ventricular Myocytes. J Pharmacol Exp Therap 304, 985993.

Liggins J, Bluck LJ, Runswick S, Atkinson C, Coward WA, Bingham SA (2000): Daidzein and genistein contents of vegetables. Br J Nutr $\underline{84}$, 717-725.

Lindberg MK (2002): Estrogen Receptor (ER)-beta Reduces ERalpha-Regulated Gene Transcription, Supporting a "Ying Yang” Relationship between ERalpha and ERbeta in Mice. Mol Endocrinol 17, 203-208.

Ling S, Komesaroff P, Sudhir K (2006): Cellular mechanisms underlying the cardiovascular actions of oestrogens. Clin Sci (Lond) $\underline{111}$, 107-118. 
Lissin LW, Cooke JP (2000): Phytoestrogens and cardiovascular health. J Am Coll Cardiol 35, 1403-1410.

Losordo DW, Kearney M, Kim EA., Jekanowski J, Isner JM (1994): Variable expression of the estrogen receptor in normal and atherosclerotic coronary arteries of premenopausal women. Circulation 89, 1501-1510.

Luczak ED, Barthel KKB, Stauffer BL, Konhilas JP, Cheung TH, Leinwand LA (2011):

Remodeling the cardiac transcriptional landscape with diet. Physiol Genomics $\underline{43}$, 772-780.

Mäkelä S, Poutanen M, Kostian M, Lehtimäki N, Strauss L, Santti R, Vihko R (1998): Inhibition of 17beta-hydroxysteroid oxidoreductase by flavonoids in breast and prostate cancer cells. Proc Soc Exp Biol Med 217, 310-316.

Manolagas SC (2000): Birth and death of bone cells: basic regulatory mechanisms and implications for the pathogenesis and treatment of osteoporosis. Endocr Rev 21, 115-137.

Marini H, Minutoli L, Polito F, Bitto A, Altavilla D, Atteritano M, Gaudio A, Mazzaferro S, Frisina A, Frisina N, Lubrano C, Bonaiuto M, D’Anna R, Cannata ML, Corrado F, Adamo EB, Wilson S, Squadrito F (2007): Effects of the Phytoestrogen Genistein on Bone Metabolism in Osteopenic Postmenopausal Women. Ann Intern Med 146, 839-848.

Marini H, Polito F, Adamo EB, Bitto A, Squadrito F, Benvenga S (2012): Update on genistein and thyroid: an overall message of safety. Front Endocrinol $\underline{3}, 94$.

Markovits J, Linassier C, Fossé P, Couprie J, Pierre J, Jacquemin-Sablon A, Saucier JM, Le Pecq JB, Larsen AK (1989): Inhibitory Effects of the Tyrosine Kinase Inhibitor Genistein on Mammalian DNA Topoisomerase II. Canc Res 49, 5111-5117.

Masciotra S, Picard S, Deschepper CF (1999): Cosegregation Analysis in Genetic Crosses Suggests a Protective Role for Atrial Natriuretic Factor Against Ventricular Hypertrophy. Circ Res $\underline{84}$, 1453-1458.

Maskarinec G, Aylward AG, Erber E, Takata Y, Kolonel LN (2008): Soy intake is related to a lower body mass index in adult women. Eur J Nutr 47, 138-144.

Matthews J, Gustafsson JA (2003): Estrogen Signaling: A Subtle Balance Between ER $\alpha$ and ERß. Mol Interv $\underline{3}, 281-292$.

Mayes JS, Watson GH (2004): Direct effects of sex steroid hormones on adipose tissues and obesity. Obes Rev $\underline{5}, 197-216$.

Mazur W (1998): Phytoestrogen content in foods. Baillière's Clin Endocrinol Metab $\underline{12, ~ 729-~}$ 742.

McClain MR, Wolz E, Davidovich A, Pfannkuch F, Edwards JA, Bausch J (2006): Acute, subchronic and chronic safety studies with genistein in rats. Food Chem Toxicol 44, 56-80. 
McInerney EM, Weis KE, Sun J, Mosselman S, Katzenellenbogen BS (1998): Transcription activation by the human estrogen receptor subtype beta (ER beta) studied with ER beta and ER alpha receptor chimeras. Endocrinology 139, 4513-4522.

Mendelsohn ME, Karas RH (1999): The Protective Effects of Estrogen on the Cardiovascular System. N Engl J Med 340, 1801-1811.

Messina MJ, Persky V, Setchell K, Barnes S (1994): Soy intake and cancer risk: a review of the in vitro and in vivo data. Nutr Cancer 21, 113-131.

Morabito N, Crisafulli A, Vergara C, Gaudio A, Lasco A, Frisina N, D’Anna R, Corrado F, Pizzoleo MA, Cincotta M, Altavilla D, Ientile R, Squadrito F (2002): Effects of genistein and hormone-replacement therapy on bone loss in early postmenopausal women: a randomized double-blind placebo-controlled study. J Bone Miner Res 17, 1904-1912.

Mousavi Y, Adlercreutz H (1993): Papers Genistein is an effective stimulator of sex hormone-binding globulin production in hepatocarcinoma human fiver cancer cells and suppresses proliferation of these cells in culture. $\underline{58}, 301-304$.

Mueller SO, Simon S, Chae K, Metzler M, Korach KS (2004): Phytoestrogens and their human metabolites show distinct agonistic and antagonistic properties on estrogen receptor alpha (ERalpha) and ERbeta in human cells. Toxicol Sci 무, 14-25.

Murphy LJ, Ghahary A (1990): Uterine insulin-like growth factor-1: regulation of expression and its role in estrogen-induced uterine proliferation. Endocr Rev $\underline{11}$, 443-453.

Naaz A, Yellayi S, Zakroczymski M, Bunick D, Doerge D, Lubahn D, Helferich W, Cooke P (2003): The Soy Isoflavone Genistein Decreases Adipose Deposition in Mice. Endocrinology 144, 3315-3320.

Nakamura T, Imai Y, Matsumoto T, Sato S, Takeuchi K, Igarashi K, Harada Y, Azuma Y, Krust A, Yamamoto Y, Nishina H, Takeda S, Takayanagi H, Metzger D, Kanno J, Takaoka K, Martin TJ, Chambon P, Kato S (2007): Estrogen prevents bone loss via estrogen receptor alpha and induction of Fas ligand in osteoclasts. Cell $\underline{130}$, 811-823.

Nakamura Y, Yogosawa S, Izutani Y, Watanabe H, Otsuji E, Sakai T (2009): A combination of indol-3-carbinol and genistein synergistically induces apoptosis in human colon cancer HT-29 cells by inhibiting Akt phosphorylation and progression of autophagy. Mol Cancer 8:100, 1-15.

Nelson HD, Humphrey LL, Nygren P, Teutsch SM, Allan JD (2002): Postmenopausal Hormone Replacement Therapy. JAMA 288, 872-881.

Nguyen BT, Kararigas G, Jarry H (2012a): Dose-dependent effects of a genistein-enriched diet in the heart of ovariectomized mice. Genes Nutr $\underline{8}, 383-390$.

Nguyen BT, Kararigas G, Wuttke W, Jarry H (2012b): Long-term treatment of ovariectomized mice with estradiol or phytoestrogens as a new model to study the role of estrogenic substances in the heart. Planta Med $\underline{78}, 6-11$. 
Nilsson JA, Gustafsson S (2002): Biological Role of Estrogen and Estrogen. Crit Rev Biochem Mol Biol 37, 1-28.

Nilsson S, Mäkelä S, Treuter E, Tujague M, Thomsen J, Andersson G, Enmark E, Pettersson K, Warner M, Gustafsson J (2001): Mechanisms of Estrogen Action. Physiol Rev $\underline{81}$, 15351565.

Nordmeyer J, Eder S, Mahmoodzadeh S, Martus P, Fielitz J, Bass J, Bethke N, Zurbrügg HR, Pregla R, Hetzer R, Regitz-Zagrosek V (2004): Upregulation of myocardial estrogen receptors in human aortic stenosis. Circulation 110, 3270-3275.

Nuedling S, Kahlert S, Loebbert K, Doevendans P a, Meyer R, Vetter H, Grohé C (1999): 17 Beta-estradiol stimulates expression of endothelial and inducible NO synthase in rat myocardium in-vitro and in-vivo. Cardiovasc Res $\underline{43}$, 666-674.

Owens JW, Ashby J (2002): Critical Review and Evaluation of the Uterotrophic Bioassay for the Identification of Possible Estrogen Agonists and Antagonists : In Support of the Validation of the OECD Uterotrophic Protocols for the Laboratory Rodent. Crit Rev Toxicol 32, 445-520.

Pacifici R (1998): Editorial : Cytokines, Estrogen, and Postmenopausal Osteoporosis - The Second Decade. Endocrinology 139, 2659-2661.

Pereira MA, Barnes LH, Rassman VL, Kelloff GV, Steele VE (1994): Use of azoxymethaneinduced foci of aberrant crypts in rat colon to identify potential cancer chemopreventive agents. Carcinogenesis $\underline{15}, 1049-1054$.

Petersen DN, Tkalcevic GT, Koza-Taylor PH, Turi TG, Brown TA (1998): Identification of estrogen receptor beta2, a functional variant of estrogen receptor beta expressed in normal rat tissues. Endocrinology 139, 1082-1092.

Pfleiderer A, Breckwoldt M, Martius G: Gynäkologie und Geburtshilfe. 3. Auflage; Georg Thieme Verlag, Stuttgart 1999, 75-77.

Pike M, Peters R, Cozen W, Probst-Hensch N, Felix J, Wan P, Mack T (1997): Estrogen-

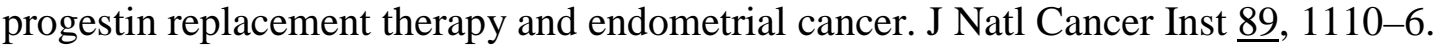

Posadzki P, Lee M, Onakpoya I, Lee HW, Ko BS, Ernst E (2013): Dietary supplements and prostate cancer: a systematic review of double-blind, placebo-controlled randomised clinical trials. Maturitas $\underline{75}, 125-130$.

Prevrhal S, Genant H (1999): Quantitative Computertomographie. Radiologie 39, 194-202.

Raisz LG (2005): Pathogenesis of osteoporosis: concepts, conflicts, and prospects. J Clin Invest $\underline{115}$, 3318-3325.

Ramsey L, Ross B, Fischer R (1999): Phytoestrogens and the management of menopause. Adv Nurse Pract $\underline{7}, 26-30$. 
Rees M, Stevenson J, British Menopause Society Council (2008): Primary prevention of coronary heart disease in women. Menopause Int $\underline{14}, 40-45$.

Renehan A, Zwahlen M, Minder C, O’Dwyer S, Shalet S, Egger M (2004): Insulin-like growth factor (IGF)-I, IGF binding protein-3, and cancer risk: systematic review and metaregression analysis. Lancet $\underline{393}, 1346-1353$.

Rickard DJ, Monroe DG, Ruesink TJ, Khosla S, Riggs BL, Spelsberg TC (2003):

Phytoestrogen genistein acts as an estrogen agonist on human osteoblastic cells through estrogen receptors alpha and beta. J Cell Biochem 모, 633-646.

Rimoldi G, Christoffel J, Seidlova-Wuttke D, Jarry H, Wuttke W (2007): Effects of chronic genistein treatment in mammary gland, uterus, and vagina. Environ Health Perspect 115, 6268.

Rodan GA, Martin TJ (2000): Therapeutic approaches to bone diseases. Science 289, 15081514.

Rossouw JE, Anderson GL, Prentice RL, LaCroix AZ, Kooperberg C, Stefanick ML, Jackson RD, Beresford SA, Howard BV, Johnson KC, Kotchen JM, Ockene J (2002): Risks and Benefits of Estrogen Plus Progestin in Healthy Postmenopausal Women. JAMA 288, 321333.

Sakamoto T, Horiguchi H, Oguma E, Kayama F (2010): Effects of diverse dietary phytoestrogens on cell growth, cell cycle and apoptosis in estrogen-receptor-positive breast cancer cells. J Nutr Biochem 21, 856-864.

Salleh N, Helmy MM, Fadila KN, Yeong SO (2013): Isoflavone genistein induces fluid secretion and morphological changes in the uteri of post-pubertal rats. Int J Med Sci 10, 665675.

Sandhu SK, Hampson G (2011): The pathogenesis, diagnosis, investigation and management of osteoporosis. J Clin Pathol 64, 1042-1050.

Sano M, Jacobs D, Andrews H, Bell K, Graff-Radford N, Lucas J, Rabins P, Bolla K, Tsai WY, Cross P, Andrews K, Costa R, Luo X (2008): A multi-center, randomized, double blind placebo-controlled trial of estrogens to prevent Alzheimer's disease and loss of memory in women: design and baseline characteristics. Clin Trials $\underline{5}$, 523-533.

Santell RC, Chang YC, Nair MG, Helferich WG (1997): Dietary Genistein Exerts Estrogenic Effects upon the Uterus, Mammary Gland and the Hypothalamic / Pituitary Axis in Rats. Biochem Mol Roles Nutr 127, 263-269.

Sargeant P, Farndale RW, Sage SO (1993): The tyrosine kinase inhibitors methyl 2,5dihydroxycinnamate and genistein reduce thrombin-evoked tyrosine phosphorylation and Ca2+ entry in human platelets. FEBS Lett $\underline{315}$, 242-246.

Schairer C, Lubin J, Troisi R, Sturgeon S, Brinton L, Hoover R (2000): Menopausal estrogen and estrogen-progestin replacement therapy and breast cancer risk. JAMA 283, 485-491. 
Seeman E (2003): Physiology of Aging Invited Review: Pathogenesis of osteoporosis. J Appl Physiol 95, 2142-2151.

Sehmisch S, Uffenorde J, Maehlmeyer S, Tezval M, Jarry H, Stuermer KM, Stuermer EK (2010): Evaluation of bone quality and quantity in osteoporotic mice--the effects of genistein and equol. Phytomedicine 17, 424-430.

Seidlová-Wuttke D, Christoffel J, Rimoldi G, Jarry H, Wuttke W (2006): Comparison of effects of estradiol with those of octylmethoxycinnamate and 4-methylbenzylidene camphor on fat tissue, lipids and pituitary hormones. Toxicol Appl Pharmacol 214, 1-7.

Setchell KD (2001): Soy Isoflavones - Benefits and Risks from Nature's Selective Estrogen Receptor Modulators (SERMs). J Am Coll Nutr 20, 354S-362S.

Shevde NK, Bendixen AC, Dienger KM, Pike JW (2000): Estrogens suppress RANK ligandinduced osteoclast differentiation via a stromal cell independent mechanism involving c-Jun repression. Proc Natl Acad Sci U S A 97, 7829-7834.

Shimizu H, Ross RK, Bernstein L, Pike MC, Henderson BE (1990): Serum oestrogen levels in postmenopausal women: comparison of American whites and Japanese in Japan. $\mathrm{Br} \mathrm{J}$ Cancer 62, 451-453.

Silbernagl S, Despopoulos A: Taschenatlas der Physiologie. 4. Auflage; Georg Thieme Verlag, Stuttgart 2001, 266-309.

Silva M, Gibson L (1997): Modeling the mechanical behavior of vertebral trabecular bone: Effects of age-related changes in microstructure. Bone 21, 191-199.

Simons R, Gruppen H, Bovee TF, Vincken, Marian A. Verbruggen JP (2012): Prenylated isoflavonoids from plants as selective estrogen receptor modulators (phytoSERMs). Food Funct $\underline{3}, 810-827$.

Sims NA, Dupont S, Krust A, Clément-Lacroix P, Minet D, Resche-Rigon M, Gaillard-Kelly M, Baron R (2002): Deletion of estrogen receptors reveals a regulatory role for estrogen receptors-beta in bone remodeling in females but not in males. Bone $\underline{30}, 18-25$.

Sims NA, Clément-Lacroix P, Minet D, Fraslon-Vanhulle C, Gaillard-Kelly M, Resche-Rigon M, Baron R (2003): A functional androgen receptor is not sufficient to allow estradiol to protect bone after gonadectomy in estradiol receptor-deficient mice. J Clin Invest $\underline{111}$, 13191327.

Squadrito F, Altavilla D, Crisafulli A, Saitta A, Cucinotta D, Morabito N, D’Anna R, Corrado F, Ruggeri P, Frisina N, Squadrito G (2003): Effect of genistein on endothelial function in postmenopausal women: a randomized, double-blind, controlled study. Am J Med 114, 470476.

Stettner M, Kaulfuss S, Burfeind P, Schweyer S, Strauss A, Ringert RH, Thelen P (2007): The relevance of estrogen receptor-beta expression to the antiproliferative effects observed with histone deacetylase inhibitors and phytoestrogens in prostate cancer treatment. Mol Cancer Ther $\underline{6}$, 2626-2633. 
Strom S, Yamamura Y, Duphorne C, Spitz M, Babaian R, Pillow P, Hursting S (2000): Phytoestrogen intake and prostate cancer: a case-control study using a new database. Nutr Cancer 33, 20-25.

Stürmer EK, Seidlová-Wuttke D, Sehmisch S, Rack T, Wille J, Frosch KH, Wuttke W, Stürmer KM (2006): Standardized bending and breaking test for the normal and osteoporotic metaphyseal tibias of the rat: effect of estradiol, testosterone, and raloxifene. J Bone Miner Res 21, 89-96.

Taku K, Melby M, Kronenberg F, Kurzer M, Messina M (2012): Extracted or synthesized soybean isoflavones reduce menopausal hot flash frequency and severity: systematic review and meta-analysis of randomized controlled trials. Menopause 19, 776-790.

Taylor CK, Levy RM, Elliott JC, Burnett BP (2009): The effect of genistein aglycone on cancer and cancer risk: a review of in vitro, preclinical, and clinical studies. Nutr Rev $\underline{67}$, 398-415.

Tostes RC, Nigro D, Fortes ZB, Carvalho MH (2003): Effects of estrogen on the vascular

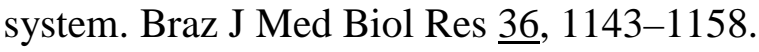

Unfer V, Casini M, Luisa A, Costabile L, Mignosa M, Gerli S, Di Renzo GC (2004): Endometrial effects of long-term treatment with phytoestrogens: a randomized, double-blind, placebo-controlled study. Fertil Steril 82, 145-148.

Vitale DC, Piazza C, Melilli B, Drago F, Salomone S (2012): Isoflavones: estrogenic activity, biological effect and bioavailability. Eur J Drug Metab Pharmacokinet 15-25.

Wade GN (1975): Some effects of ovarian hormones on food intake and body weight in female rats. J Comp Physiol Psychol 8, 183-193.

Wade GN, Heller HW (1993): Tamoxifen mimics the effects of estradiol on food intake, body weight, and body composition in rats. Am J Physiol 264, 1219-1223.

Walker HA, Dean TS, Sanders TA, Jackson G, Ritter JM, Chowienczyk PJ (2001): The phytoestrogen genistein produces acute nitric oxide-dependent dilation of human forearm vasculature with similar potency to 17beta-estradiol. Circulation 103, 258-262.

Walsh B, Schiff I, Rosner B, Greenberg L, Ravnikar V, Sacks F (1991): Effects of postmenopausal estrogen replacement on the concentrations and metabolism of plasma lipoproteins. N Engl J Med 325, 1196-1204.

Wang D, Chang PS, Wang Z, Sutherland L, Richardson JA, Small E, Krieg PA, Olson EN (2001): Activation of cardiac gene expression by myocardin, a transcriptional cofactor for serum response factor. Cell $\underline{105}$, 851-862.

Wang Z, Wang DZ, Pipes GC, Olson EN (2003): Myocardin is a master regulator of smooth muscle gene expression. Proc Natl Acad Sci U S A 100, 7129-7134.

Warri A, Saarinen NM, Makela S, Hilakivi-Clarke L (2008): The role of early life genistein exposures in modifying breast cancer risk. Br J Cancer $\underline{98,1485-1493 . ~}$ 
Wegorzewska IN, Walters K, Weiser MJ, Cruthirds DF, Ewell E, Larco DO, Handa RJ, Wu TJ (2008): Postovariectomy weight gain in female rats is reversed by estrogen receptor $\alpha$ agonist, propylpyrazoletriol. Am J Obstet Gynecol 199, 67.e1-67e.5.

Wei H, Cai Q, Rahn RO (1996): Inhibition of UV light- and Fenton reaction-induced oxidative DNA damage by the soybean isoflavone genistein. Carcinogenesis $\underline{17}, 73-77$.

Weiderpass E, Adami HO, Baron JA, Magnusson C, Bergström R, Lindgren A, Correia N, Persson I (1999): Risk of endometrial cancer following estrogen replacement with and without progestins. J Natl Cancer Inst $\underline{91}$, 1131-1137.

Weihua Z, Saji S, Mäkinen S, Cheng G, Jensen EV, Warner M, Gustafsson JA (2000): Estrogen receptor (ER) beta, a modulator of ERalpha in the uterus. Proc Natl Acad Sci U S A 97, 5936-5941.

White R, Darkow D, Lang J (1995): Estrogen relaxes coronary arteries by opening BKCa channels through a cGMP-dependent mechanism. Circ Res 77, 936-942.

Whitten PL, Patisaul HB (2001): Cross-Species and Interassay Comparisons of Phytoestrogen Action. Environ Health Perspect 109, Suppl 1:5-20.

Wikipedia.org: Genistein. In: Wikipedia, Die freie Enzyklopädie; http://de.wikipedia.org/wiki/Genistein, Abrufdatum: 16.09.2013.

Wilcox N, Blumenthali F (1995): Thrombotic Mechanisms in Atherosclerosis: Potential Impact of Soy Proteins. J Nutr 125, 631S-638S.

Wocławek-Potocka I, Mannelli C, Boruszewska D, Kowalczyk-Zieba I, Waśniewski T, Skarżyński DJ (2013): Diverse effects of phytoestrogens on the reproductive performance: cow as a model. Int J Endocrinol 2013, 650984.

Wong WW, Lewis RD, Steinberg FM, Murray MJ, Cramer MA, Amato P, Young RL, Barnes S, Ellis KJ, Shypailo RJ, Fraley JK, Konzelmann KL, Fischer JG, Smith EOB (2009): Soy isoflavone supplementation and bone mineral density in menopausal women : a 2-y multicenter clinical trial 1 - 4. Am J Clin Nutr 90, 1433-1439.

Wu A, Stanczyk F, Hendrich S, Murphy P, Zhang C, Wan P, Pike M (2000): Effects of soy

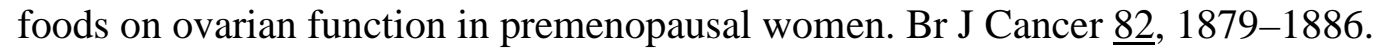

Wu J, Wang XX, Takasaki M, Ohta a, Higuchi M, Ishimi Y (2001): Cooperative effects of exercise training and genistein administration on bone mass in ovariectomized mice. J Bone Miner Res 16, 1829-1836.

Wuttke W, Jarry H, Westphalen S, Christoffel V, Seidlová-Wuttke D (2002): Phytoestrogens for hormone replacement therapy? J Steroid Biochem Mol Biol 83, 133-147.

Xu Y, Nedungadi TP, Zhu L, Sobhani N, Irani BG, Davis KE, Zhang X, Zou F, Gent LM, Hahner LD, Khan S a, Elias CF, Elmquist JK, Clegg DJ (2011): Distinct hypothalamic neurons mediate estrogenic effects on energy homeostasis and reproduction. Cell Metab $\underline{14}$, 453-465. 
Yakar S, Pennisi P, Wu Y, Zhao H, LeRoith D (2005): Clinical relevance of systemic and local IGF-I. Endocr Dev $\underline{9}, 11-16$.

Yamagishi T, Otsuka E, Hagiwara H (2001): Reciprocal control of expression of mRNAs for osteoclast differentiation factor and OPG in osteogenic stromal cells by genistein: evidence for the involvement of topoisomerase II in osteoclastogenesis. Endocrinology 142, 36323637.

Yamori Y (2004): Worldwide epidemic of obesity: hope for Japanese diets. Clin Exp Pharmacol Physiol 31, 2-4.

Yoneda N, Saito S, Kimura M, Yamada M, Iida M, Murakami T, Irahara M, Shima K, Aono $\mathrm{T}$ (1998): The Influence of Ovariectomy on ob Gene Expression in Rats. Horm Metab Res $\underline{30}$, 263-265.

Yusuf S, Reddy S, Ôunpuu S, Anand S (2001): Clinical Cardiology : New Frontiers Global Burden of Cardiovascular Diseases. Circulation 104, 2746-2753.

Zhang Z, Laping J, Glasser S, Day P, Mulholland J (1998): Mediators of estradiol-stimulated mitosis in the rat uterine luminal epithelium. Endocrinology 139, 961-966.

Zhou J, Gugger ET, Tanaka T, Guo Y, Blackburn GL, Clinton SK (1999): Soybean phytochemicals inhibit the growth of transplantable human prostate carcinoma and tumor angiogenesis in mice. J Nutr 129, 1628-1635.

Zweifel JE, O`Brien WH (1997): A meta-analysis of the effect of hormone replacement therapy upon depressed mood. Psychoneuroendocrinology 22, 189-212. 


\section{Danksagung}

Mein besonderer Dank gilt Herrn Prof. Dr. med. H. Jarry, der mir dieses Thema für meine Dissertation überlassen hat und mich allzeit mit schnellen Korrekturen und Anregungen konstruktiv unterstützt hat.

Zudem möchte ich mich bei allen weiteren Mitarbeitern und Mitarbeiterinnen der früheren Abteilung für experimentelle Endokrinologie der Universitätsklinik Göttingen und ihrem Leiter Herrn Prof. Dr. med. W. Wuttke bedanken. Frau Dr. D. Seidlová-Wuttke danke ich für die Unterstützung bei der Anwendung der Kleintier-Computertomographie. Des Weiteren gilt mein Dank den Medizinisch-technischen Assistentinnen der Abteilung für ihre Unterstützung bei der praktischen Arbeit.

Ich bedanke mich bei meiner Kommilitonin Marie für das sorgfältige Gegenlesen der Dissertation. 